\title{
GOING NORTH
}

\section{A REFLECtion ON LINES AT the FIRST CANAdIAN ROAD \\ TO THE ARCTIC COAST}

\author{
by \\ Stephanie Murray \\ A thesis submitted to the Faculty of Graduate and Postdoctoral Affairs in \\ partial fulfillment of the requirements for the degree of
}

Master of Architecture

in

Azrieli School of Architecture \& Urbanism

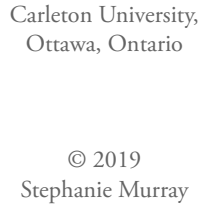




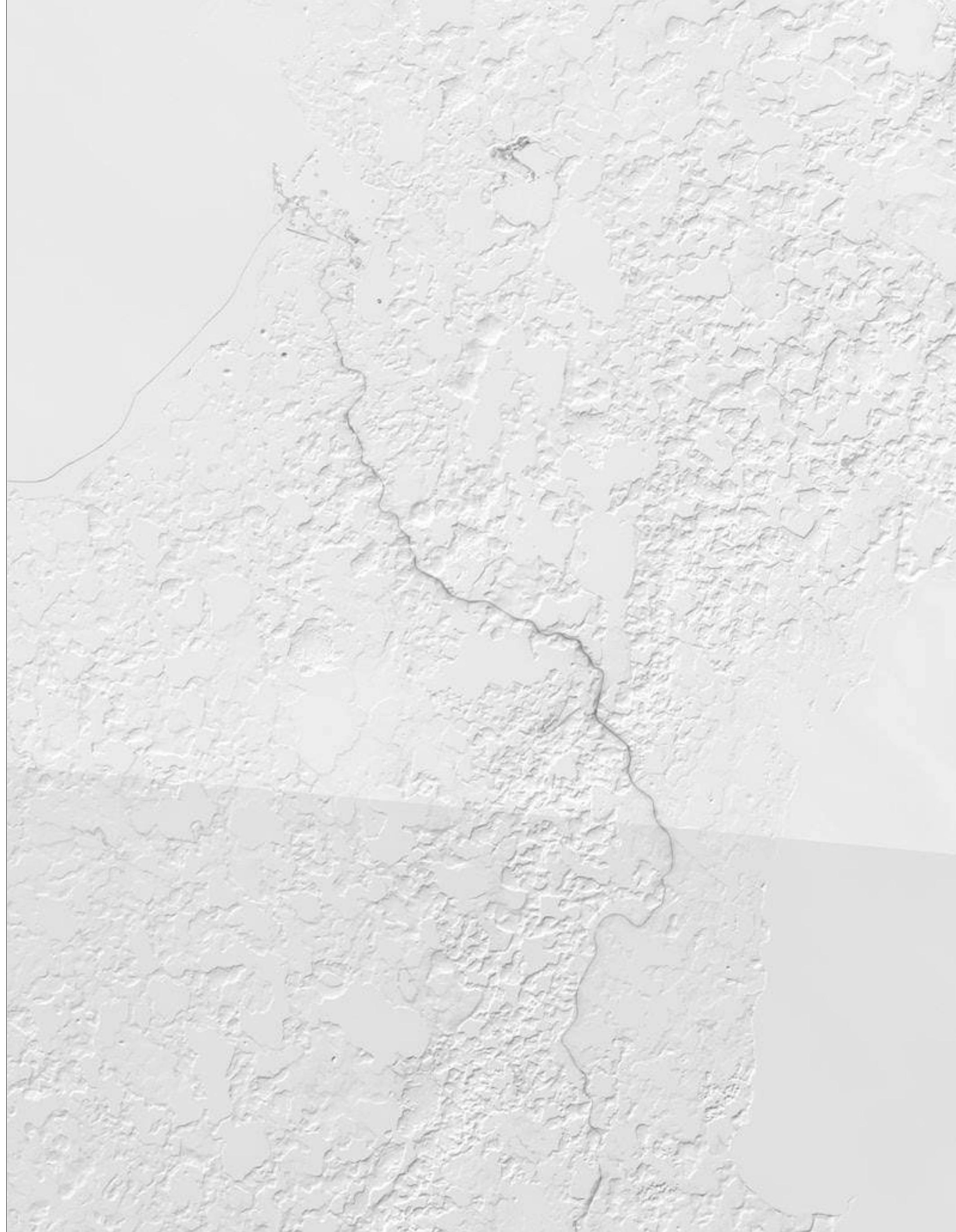


The experience of the first Canadian Road to the Arctic Coast informed the trajectory of this thesis which investigates "the line" as a tool that explores and describes spatial understandings: whether as a physical artifact in space (the road) in making (maps, notations, models and drawings), in storylines (with their material consequences) or physical perspectives (as lines of sight); all of which inform thinking and acting in and toward the site of study.

A line doesn't necessarily manifest as "the dot that went for a walk", but often as an inclination, a thought pattern, a habit of spatial engagement, an assumption, or physical act. The lines we draw and imagine, order our spatial and social practices and write the stories of our understandings. Through a series of reflective exercises this thesis looks for ways in which we might begin destabilizing our patterns of seeing, thinking and making. 


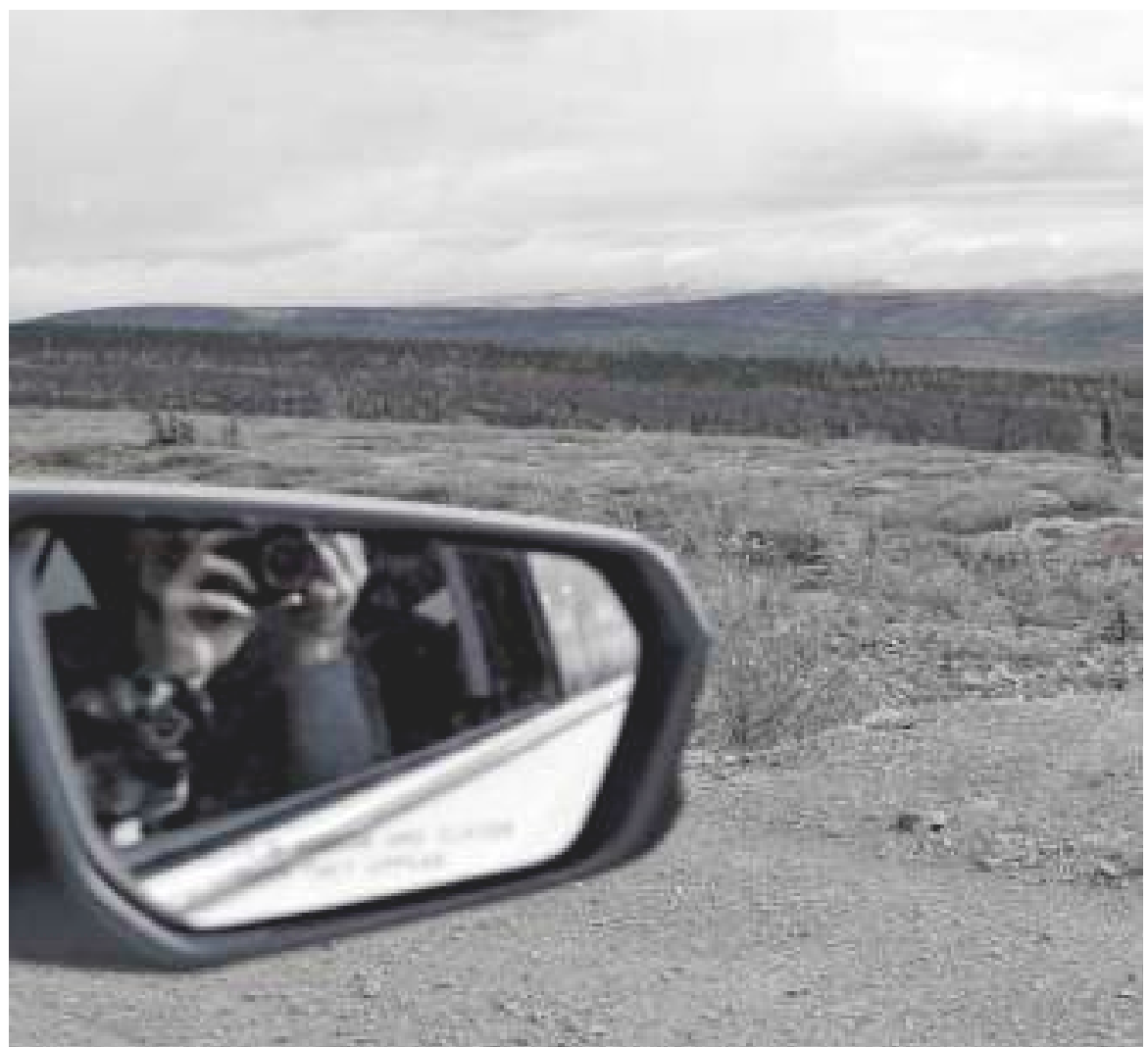

An expression of gratitude is due to my advisor, Ozayr, for the reassurance and challenge offered during the endeavor of this thesis

And many thanks to Josh, for being patient, for asking questions, and for sticking it out through all the unlikely life events.

To the careful doctors and caring roommates, who facilitated a physical stability of one form or another at different points along this path: for the breath and function that allows me to move through and engage space.

To Kaia my research companion, for welcoming me into your early home on those sunny summer nights, for endless excitability, for sinking into mossy heaves or racing over winter waters, and for reminding me to think toward the ground plane. And of course, for transitioning to hardscaped urbanity for the pursuit of this work.

To my parents, who offered me a childhood that kept my hands in the dirt and (I hope) my feet on the ground, which, in so many ways helped nurture an appreciation for the complexities of dust and mud wherever 1 find myself.

To the communities between the edge of the Boreal and the polar sea, which showed me the multiplicitness of site and story.

To the brilliant, striking simplicities of winter, which seems like such a distant friend these days, for the quiet clarities you offer.

And lastly, for the echoing reminder that you never know when you will give, recieve or happen upon something precious. 
To those who stay curious and wonder

through their work.

To all the questions that we don't yet know how to ask. 


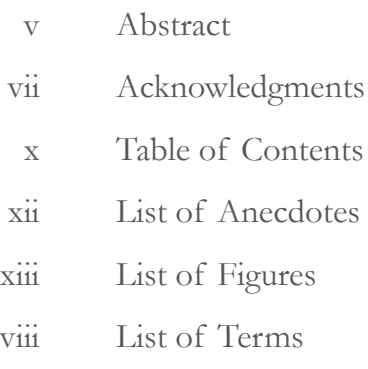

Part One INITIAL INQUIRIES

$$
\begin{array}{ll}
3 & \text { Foreword } \\
9 & \text { Site Visit }
\end{array}
$$$$
21 \text { Site Information }
$$

Part Two JURISDICTIONS

33 Physical Jurisdiction

38 Personal Jurisdictions

Part Three CULTIVATING CHRONICLES
43 Storyscapes
Authorship
Storying a National Identity
A Material Ordering Practice
The Bridge Between Earth \& Animal

79 Tracks of Abstraction

83 Line Drawings

Part Five

107

111

Part Six

EXTENDING STRATAS:SENSORY SATELLITES

131 The View from Nowhere

147 Speculative Futures

143 Blind Drawings

CONCLUSION

$157 \quad$ Forward Inquiries 


$\begin{array}{lll}A .01 & 7 & \text { Freshwater Oceanfront } \\ A .02 & 21 & \text { I Questioned My Confidence } \\ A .03 & 107 & 1: 1 \\ A .04 & 111 & \text { The Scale With Which We Reference It } \\ A .05 & 137 & \text { Speculative Futures }\end{array}$

$x \quad$ vi $\quad$ Si(gh)t(e) Research: Companions. Photo by Josh Wallace.

Part Ore

$\begin{array}{llll}1.1 & 6 & \text { Arctic Coast Sign. } \\ 1.2 & 8 & \text { Site visit contact sheet \#1. } \\ 1.3 & 10 & \text { Site visit contact sheet \#2. } \\ 1.4 & 11 & \text { Site visit contact sheet \#3. } \\ 1.5 & 12 & \text { Site visit contact sheet \#4. } \\ 1.6 & 13 & \text { Site visit contact sheet \#5. } \\ 1.7 & 14 & \text { Site visit images-constructed coast line and mountain valley. } \\ 1.8 & 15 & \text { Site visit images- frost at mountain lookout and taiga cordillera. } \\ 1.9 & 16 & \text { Constructed coast line and driftwood. } \\ 1.10 & 17 & \text { DEW Line. } \\ 1.11 & 18 & \text { Into the Arctic. } \\ 1.12 & 20 & \text { Map of Canada road network and planned access corridors. } \\ 1.13 & 23 & \text { Corporal Dempster and the searchteam, leaving to find "The Lost Patrol,", } \\ & & \text { Dawson City, } 1911 . \\ 1.14 & 23 & \text { Construction of the Inuvik to Tuktoyaktuk Highway. } \\ 1.15 & 23 & \text { Moment during construction when the Inuvik to Tuktoyaktuk Highway } \\ & & \text { connected to the Dempster Highway. } \\ 1.16 & 25 & \text { Satellite view of road construction during winter. }\end{array}$


3.154 Certificates from the Northern frontie.

3.256 Certificate details

$3.364 \quad$ Plant Story \#1: Richardsoni

Various story tracings.

3.569 Dedication page in Flora Boreali-American

3.670 Activating Plant Stories \#1, stills.

3.7 70 Activating Plant Stories \#2, stills.

3.8 - 71 Plants from site.

3.971 Activating Plant Stories \#3, stills.

$3.1072 \quad$ Plant Story \#4: Off record.

Diagram showing road, straightened.

Activating Collected Lines drawing, hanging, layered.

Collected Lines Legend.

A collection of lines along a straightened road.

Panoramas from site which were used for the following drawings,

Blind contour drawings \#1-2

Blind contour drawings \#3-4

Blind contour drawings \#5-6

Blind contour drawings \#7-8

Blind contour drawings \#9-10

Blind contour drawings \#11-12

Blind contour drawings \#13-14

Blind contour drawings \#15-16
5.1

5.2 How Official Representation \#1: Government of Canada map showing region of Tuktovaktuk.

5.3 112 Official Representation \#2: Government of Canada map showing destination region of the Lost Patrol

$5.4 \quad 113$ Ice on a map, process image.

5.5114 Detail of marks made by ice on map, \#1.

5.6115 Detail of marks made by ice on map, \#2-3.

5.7 116 A series of material tests exploring drawing and modeling techniques that collaborate with scaled phenomena present on site.

$58 \quad 118$ Material Tests \#1:

5.9119 Material Tests \#2

5.10120 Material Tests \#3:

5.11 Material Tests \#

5.12122 Material Tests Detail \#1:

$.13 \quad 123$ Material Tests Detail \#2:

$5.14 \quad 124$ Material Tests Detail \#3:

$515 \quad 125$ Material Tests Detail Ha

EXTENDING STRATAS: SENSORY SATELLITES
6.1130 Droning along the road
6.2134 Section of the Strata.
6.3136 A Partial Assemblage of a Region.
6.4137 Layers of the Assemblage of a Region.
6.5138 Seeing the map through layers of material, lines blur.
6.6139 Hanging mechanisms.
6.7139 Layers as assembled.
6.8140 Contours of the Cold.
6.9142 Reference satellite images.
6.10145 Roll of blind satellite drawings 


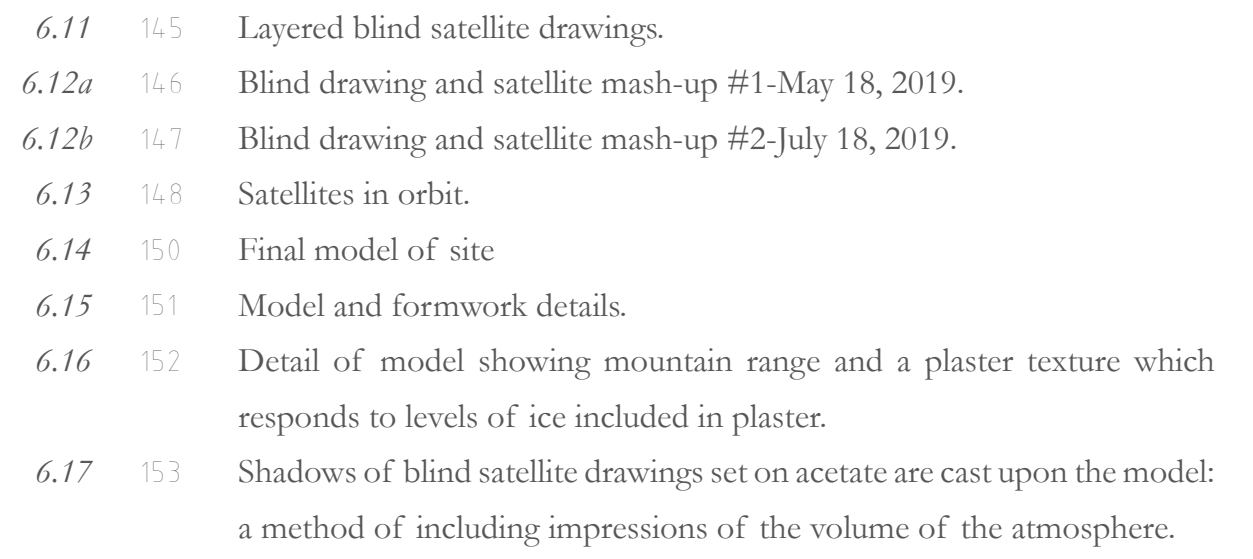

CONCLUSION

C.1 156 Final defense installation in the Morgue, view \#1.

C.2 159 Final defense installation in the Morgue, views \#2, \#3. 
Architecture

a personal definition) human and non-human interaction with and creation of space

Sensorium

The multitude of sensory capacity.

Entropy

To fall out of category To become disordered or unpredictable.

Tecbnolog

Both tangible and intangible methods or practices with specific, sometimes specialized

tool sets. A capability given by the practical application of knowledge.

Jurisdiction

The authority to have authority over a particular territory both tangible and intangible.

Landscape

An aggregation of perceivable features, landforms, and terrains of an outdoor space. A canvas that registers the synthesis of human and geologic layers and is often integrated as part of the defining characteristics of identities within a region. Fo the purposes of this thesis, landscape is considered to be either designed, storied or projected and differs fir

Literal

A competency or knowledge in a specified area; a person's knowledge of a particula subject or field; or, the ability to interpret, articulate and communicate indicators signs, or symbols within a specific system or ecological context.
Represent

To be entitled or appointed to act or speak for (someone)-especially in an official capacity; to serve by delegated authority; or, to form an image in the mind.

Stories are accounts of incidents or events, people or places and regardless of evidentiary references they are feats of human creativity: tools used in the social technologies which communicate perceptual understanding. A story can formally be visual, textual, oral or it can take the shape of any other creative act and be authored and sustained at different scales from cultural producers, political actors, technica visualists, designers, intellectuals or individuals. Note: interchanged with narrative. 


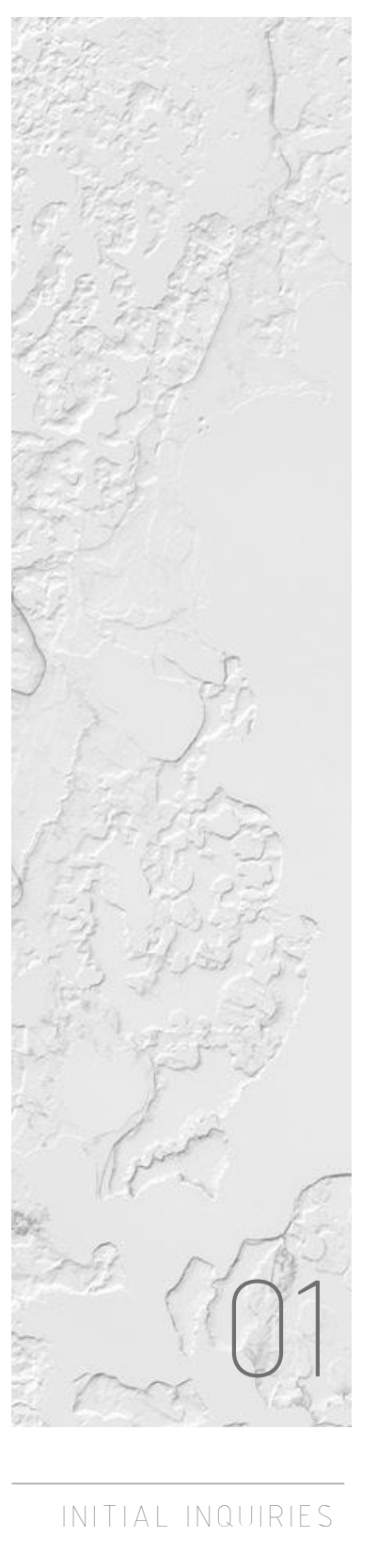


First with a quote in a reading on ethnographic fieldwork in the hamlet of Igloolik, in Northern Canada. The quote referenced a linguistic indication of spatial perception and understanding stating that navigation, as a concept is absent in the Inuktitut language. ${ }^{1}$ According to Claudio Aporta, an Inuit understanding of their own bodies moving in space, even across vast and subtle landscapes, is part of the broader tas of dwelling, of intimate relations to the land and sociospatial events. This is a stark contrast to the empirical navigation systems of global projections, mathematica locators and geometric calculations. Initially, the first Canadian highway to the Arctic coast (a region of assumed perceptual differences) seemed like a rich backdrop on which to position an architectural proposal.

The second origin of this thesis comes from the simultaneous enticemen warmth, groundedness and dislocation I seem to always feel when I am in the North. This is a region where spaces are less constructed, but deeply engaged and inhabited in ways that I have always experienced to be wholesome, though frequently unfamiliar. Whether it's three years in the Yukon, three days in Igloolik, or excursion into the Northwest Territories, I feel a clear confrontation of my own otherness and distress in the pairing of this with the assumed authority bestowed upon designers students and researchers. These are the individuals with the privilege to gather perpetuate and condone knowledge; acting toward pursuits that are sometimes motivated by the urgencies of future imaginaries and academic performance. This bumps up against the difficult notions of ethics and integrity-conversations of which, in my experience, are difficult for their lack of familiarity and practice. This is an ambiguous intangible territory, laced with assumed authorities and jurisdiction and resulting in real, material consequences.

From its intention, the road is more about destination and origin than it is about the space it passes through, yet simultaneously it is always also about the space in which it is. I began this project with the intention of investigating the end point of the road but found myself very much upon the road, curious about my 
presence on it and the histories that lead to me getting there. The destination of the road is an important factor in its contemporary acclaim and I had the intention to study it and the Inuvialuit of the area (feeling awkward, however, about the pan-Inuit assumption that the ethnographic research of the Igloolik Inuit would be applicable to the Inuvialuit). But as I found myself upon the road and not exclusively at the end or beginning, I concluded that the space between those two points matters just as much and highlights the western phenomena of privileging origins and destinations and willfully neglecting the in-between. ${ }^{2}$

From the outset I had known that the road passes through the traditional territories and settlement regions of many Indigenous groups ${ }^{3}$ as well as a diversity of eco and climatic regions. This is partially what made a study of the end point so tempting-it offered a clear and appealing subject. It was appealing also for the romantic notions associated with the extreme nature of the Arctic: the most exotic of the North, which, in the representations of our imagined architectural narratives tends to produce a lightly textured spectacle of blue and white and (seemingly) good intentions. ${ }^{4}$ Less romantic and less clear in my own preconceptions was the study of what moved me through those spaces.

The third place of origin for this thesis, in its current form, was the necessary re-hearing of some very simple words. They fell into my awareness again as I rewatched the film "Crazywater" by Inuvialuit filmmaker Dennis Allen. I had known him briefly during my time in Whitehorse and it is because of this that his words resonated so deeply. In the film he states:

\section{For too long, we haven't been the ones telling our own story.}

As the thesis progressed, I began to wonder about the ethics of producing maginaries in this place, including supposed "documents" or maps. I began to see the ethical tensions of infrastructure, its history as a tool of settlement and the road's connection to violent appropriation - after which a part of it is named and constructed. ${ }^{6}$ And in this curiosity I saw also the problematic agency of designers and our tools. With this, the aim of the thesis became the pursuit of trying to better understand the abstractions that have been taken for granted in one of the most essential contemporary thought and design tools: the line.

In many ways, the work became more introspective than extrospective and fraught with the precariousness and delicacy of pursuing the act of adding lines to a claimed and distant territory. And so accommodating multiple pivots, and redefinition of intent, the trajectory of this thesis became the study of the stories for which I can claim ownership and responsibility---a study, in part, of the ways we go North. ${ }^{8}$ 


$$
\text { E }
$$



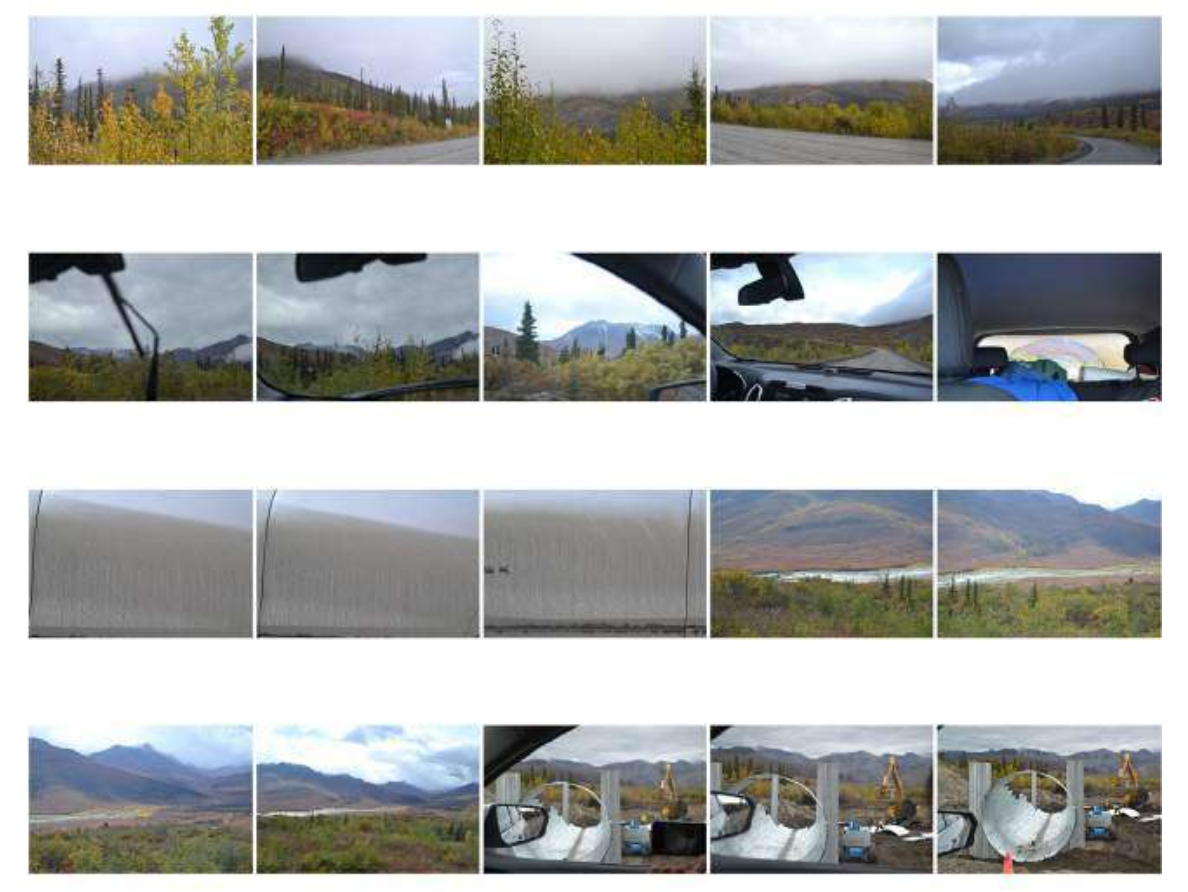

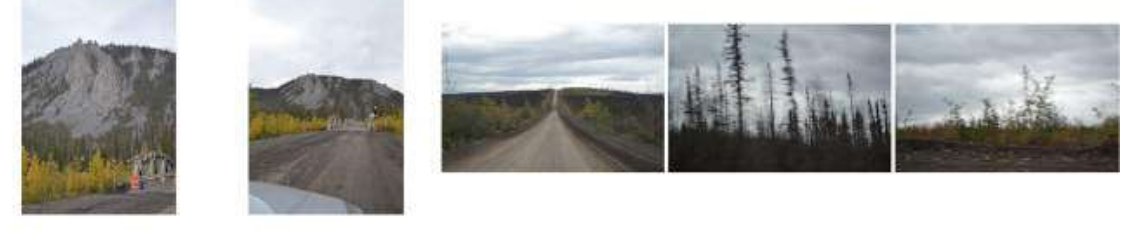

DAn
In early autumn of 2018 a site visit was conducted, from where the Dempster Highway meets the wider road network and then toward Tuktoyaktuk at the Arctic coast. 

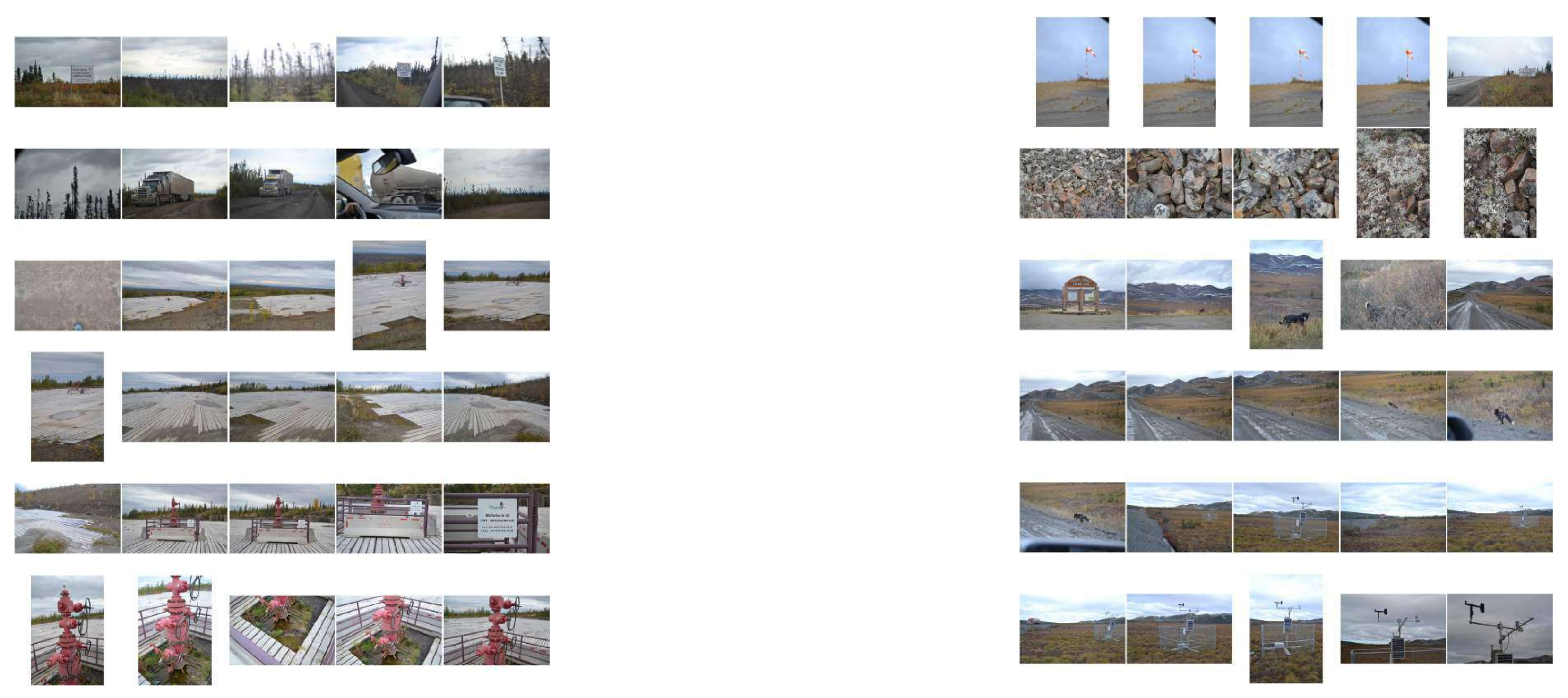

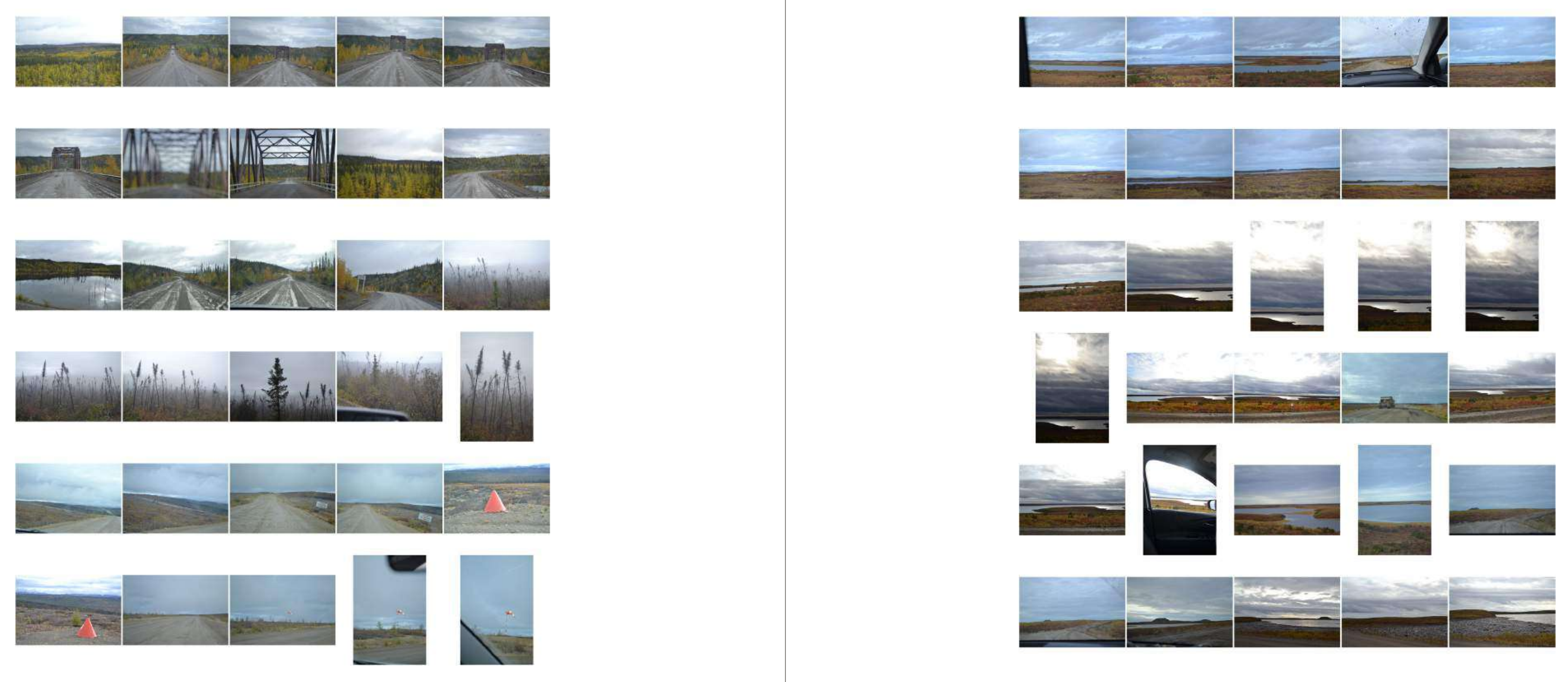

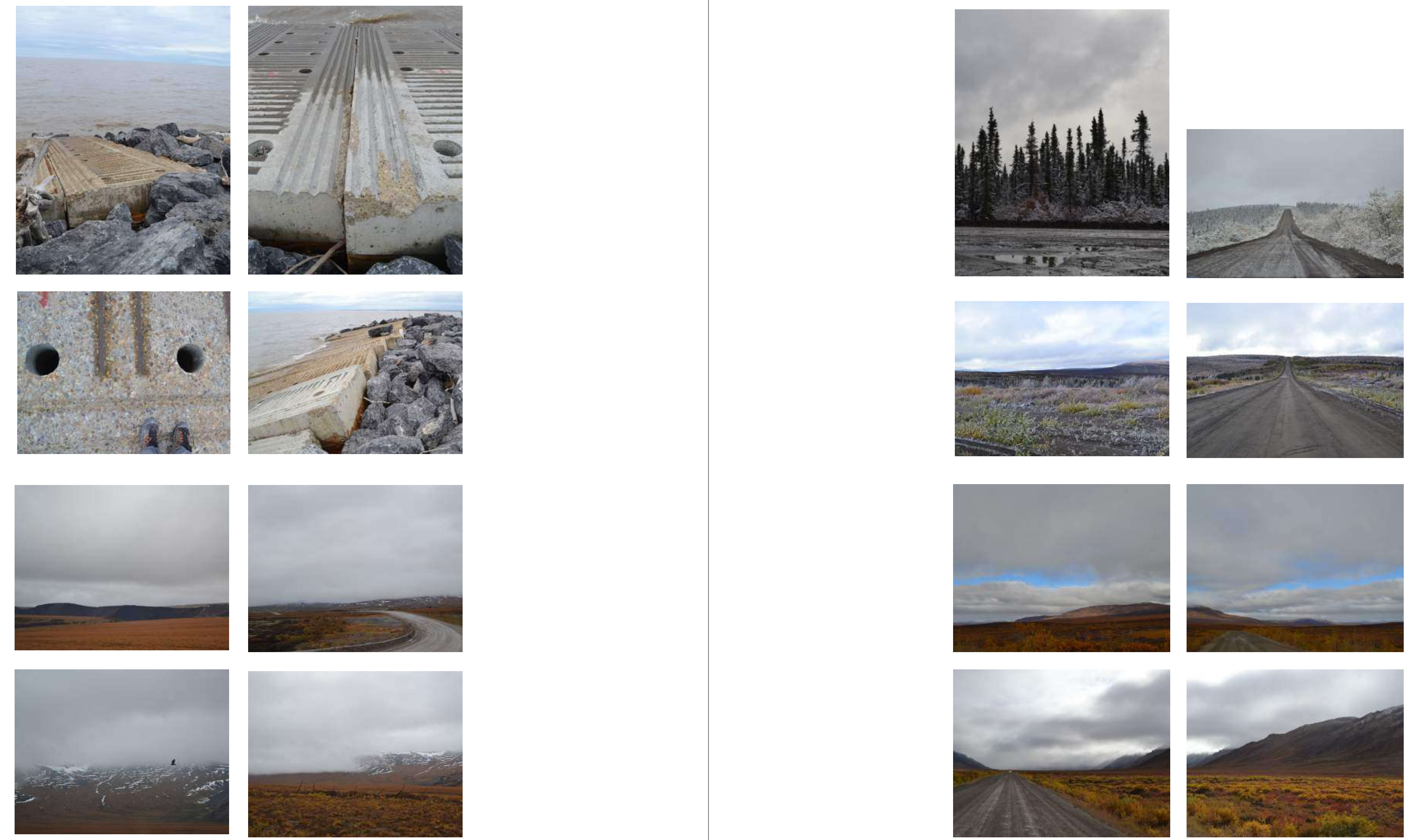

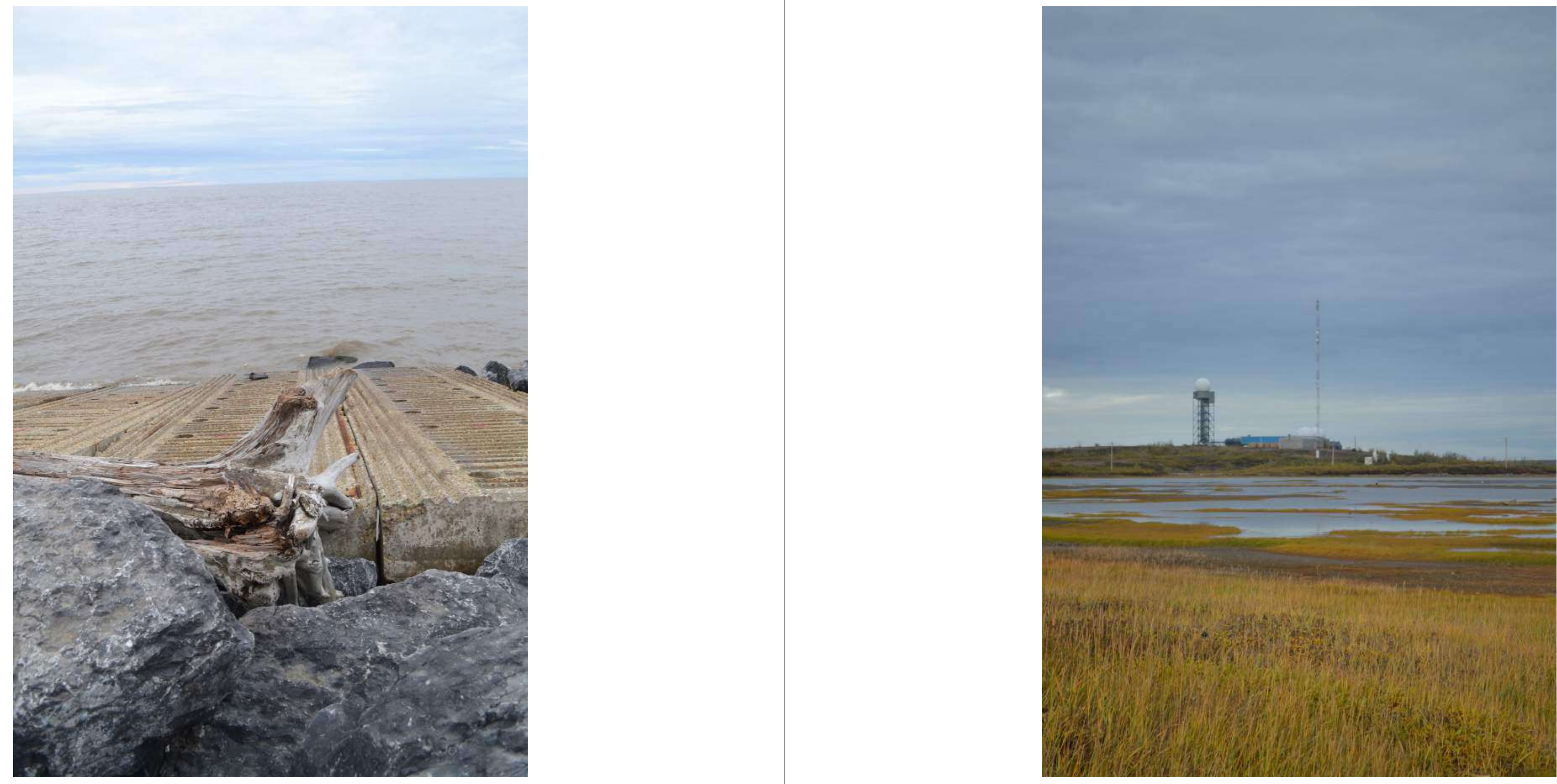

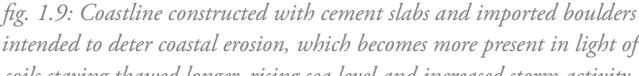

Note the 'Arifif wood' tree trunk. 


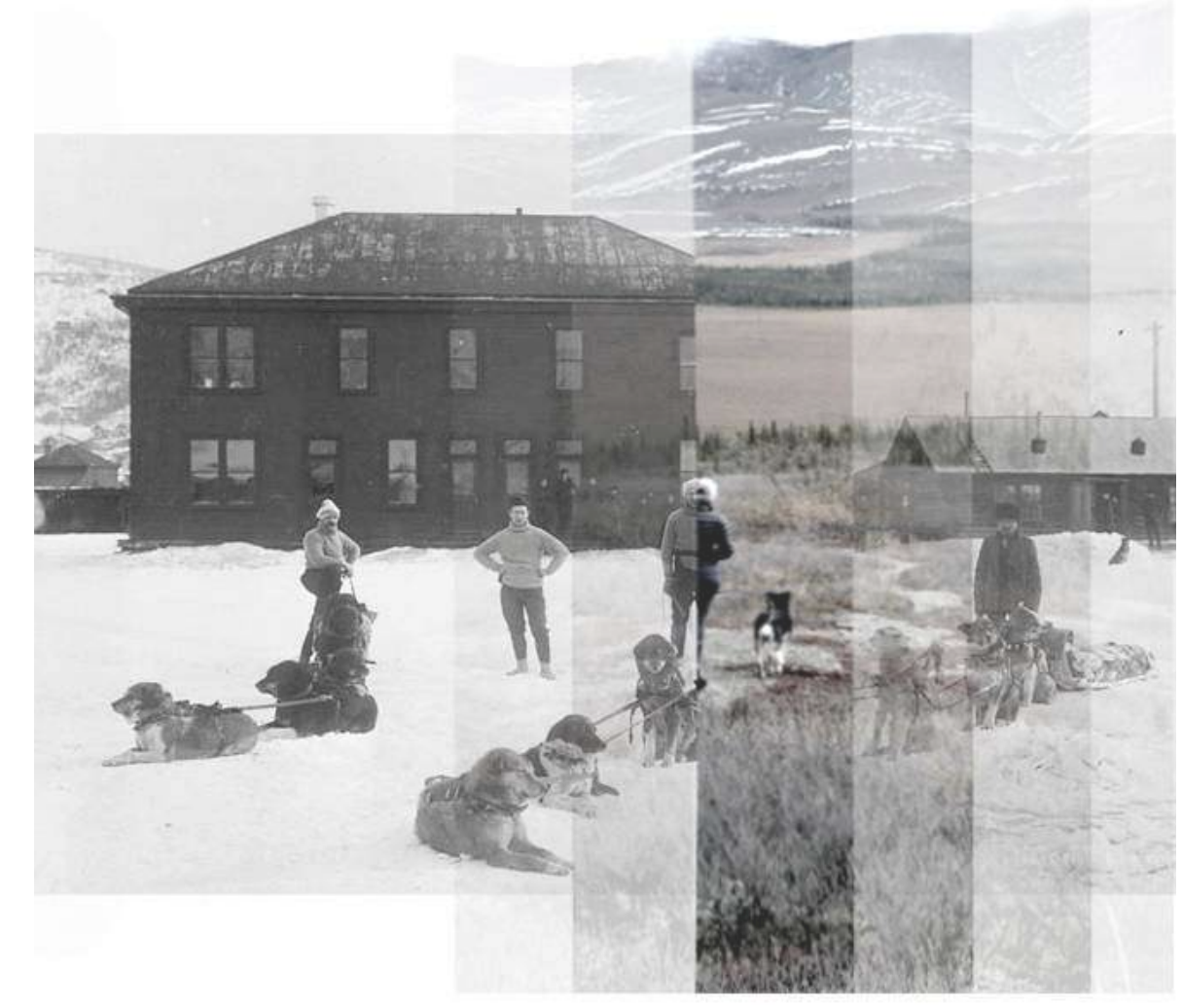

I remember my father's uncle saying that the dogs were dangerous, that sometimes in lanful pursuit they needed to die.

They let them breed with wolles, be said.

Officers died at theirjaws, he said.

That was nortbern Manitoba.

And I am Canadian.

"I came to the conclusion that no one should live there," another said, recalling a January in Inuvik. "You don't mean that." I was shocked.

"Ob, I do," he said.

The frostbite was the worst he'd seen in any of the emergency rooms.

People fell asleep outside, be said.

In the moment I couldn't find the words to say that the location was not the issue.

The North is not Ottawa.

And in this moment I wonder if we are both Canadian.

We arrived in -42. We stayed overnight

Musbers came in, covered in frost and snow. Dogs wiped their snouts on the ground to rid their whiskers of ice. They yelped and pulled at anchored sleds while I checked for survival gear.

Axe. Fuel. Food. Dog boots. "Your time in is 3-28."

Dog sledding as sport.

This is Canadian.

My mother's brother told me that he admired the ice road on the river and the puz zize of lakes in the Delta. He said that his friends who took bim fisbing and muskeratting could navigate a landscape of intricacy with unrelatable ease. And his students were easily excused for days of being out on the land, that this was good and that running at midnight in daylight was a community event

He learned to run marattons.

"My uncle taught school there," I said to a group at the gas pump near Dausson.

Through small talke about destinations and origins I found that one of mine was their home.

"What was his name?"

They were younger than me. "I think he was before your time," I said... but not that far before their time. He believes in a Cbristian God, but that's not what I meant.

I questioned my confidence.

Being Canadian is a complicated thing. 
The Dempster Highway begins at an intersection with the Klondike Highway just south of Dawson City, Yukon stretching north to the town of Inuvik in the Northwest Territories. From there, the newly constructed Inuvik-Tuktoyaktuk Highway (ITH) completes the first Canadian all season road access to the Arctic Coas.

Both roads have become icons of the regions they inhabit and iconic to the Canadian national road network. "The Dempster" as the southern highway is called was the first Canadian road to cross the Arctic Circle and for nearly forty years was the northernmost highway in the country. The Inuvik-Tuktoyaktuk Highway (ITH) is the first road to connect the Arctic Coast to a southern transportation network and is considered an extension of "The Dempster." At 138 kilometers long, the ITH starts in the region of the second largest river delta on the continent, and into the neighboring lake lands, requiring 8 bridges and 359 culverts along its lenoth.

The construction of these highways is specialized to the particulat variations of permafrost and saturated soils upon which they sit. The thickness of the road changes in response to permafrost depth and stability, with layers of piled soil (up to $1.6 \mathrm{~m}$ thick) insulating the frozen ground against possible heat transfer from solar radiation and the vehicles that move across it. For this, as wel as pragmatic construction and maintenance reasons, all 878 kilometers are unpaved, leaving conditions of the road surface subject to frequent change by frost heaves, now melt and rain. The road remains a constant project as the compacted soils of it slip outside of its intended edges.

Throughout the process of building the road, protecting the permafrost was tantamount. Construction was done exclusively in the winter to minimize permafrost damage. Low temperatures also made for easier transportation of heav loads of gravel and soil, all of which had to come from nearby quarries. Permafrost is also the reason that the road is literally built by piling large amounts of sorted earth materials, never cutting into the frozen ground at the location of the road. The recent construction of the Inuvik-Tuktoyaktuk Highway displaced 5 million cubic metres of earth material.9 and was clearly visible on satellite imagery as a thin black line extending across a subtly variegated ground.

Initial motivations for both the Dempster and the Inuvik-Tuktoyaktuk 
Highway was oil extraction. Exploration began in Eagle Plains, central Yukon, in 1954, which sparked interest in goods transported overland in and out of the area In 1957, a new federal government lead by Diefenbaker, had run with a "Roads to Resources" electoral platform that later formed the highway project. Construction began in 1959, but was put on hold in 1962, during which time the "Yukon Order of Pioneers" petitioned for the highway to be named after Corporal William Dempster of the RNWMP. ${ }^{10}$

Dempster has been credited for the successful discovery of his missing colleagues (dubbed the "Lost Patrol") after they perished in the winter of 1911, enroute between what is now Dawson City, Yukon, and Fort McPherson, Northwest Territories. The success of Demspter's endeavor is perhaps more accurately attributed to the accompanying Indigenous guide, known by the English name of Charlie Steward." The demise of the "Lost Patrol" has been attributed to their lack of an experienced guide given the region between the two administrative settlements is over 450 kilometers of challenging terrain and seasonally harsh conditions. Following the loss of the four RNWMP, new policies developed by Corporal Dempster required that any winter traveling party be lead by "a native guide and hunter."”

Despite the assurance of successful traversing actuating from Indigenous guides and their knowledge, a tool of the settler colonial state (a RNWMP officer, Dempster) receives credit for the skill in an appropriated technology (dog sledding) and its application in moving through and surviving in a specific territory. This method of moving across expansive landscapes would also become a tool through which the Canadian Nation would assert sovereignty in its request for Dempster to "find" and establish "new" trails throughout the territory without crossing into Alaska. Despite the area having been successfully traversed for hundreds of years prior and for the already acknowledged necessity of Indigenous knowledge to do so, Dempster remains heralded as "the best trailman in the Yukon."

Decades later, similar sentiments would reawaken the use of transport technologies as a tool to express national claims. Discovery of oil in Sagavanirktok (Prudhoe Bay, Alaska) in $1968^{14}$ reinvigorated Canadian desires for a northern road as a statement of sovereignty in a region of extraction potential. Two years later, road construction of the Dempster Highway restarted and throughout the 70's the Department of National Defense was involved to build bridges over some of the more challenging sections of the route. Inuvik, the destination of the highway, was conceived as an administrative center of the Mackenzie Delta and was initially known as "new Aklavik" at the site of an oil well drill site "Aklavik E-3.,15 The Dempster
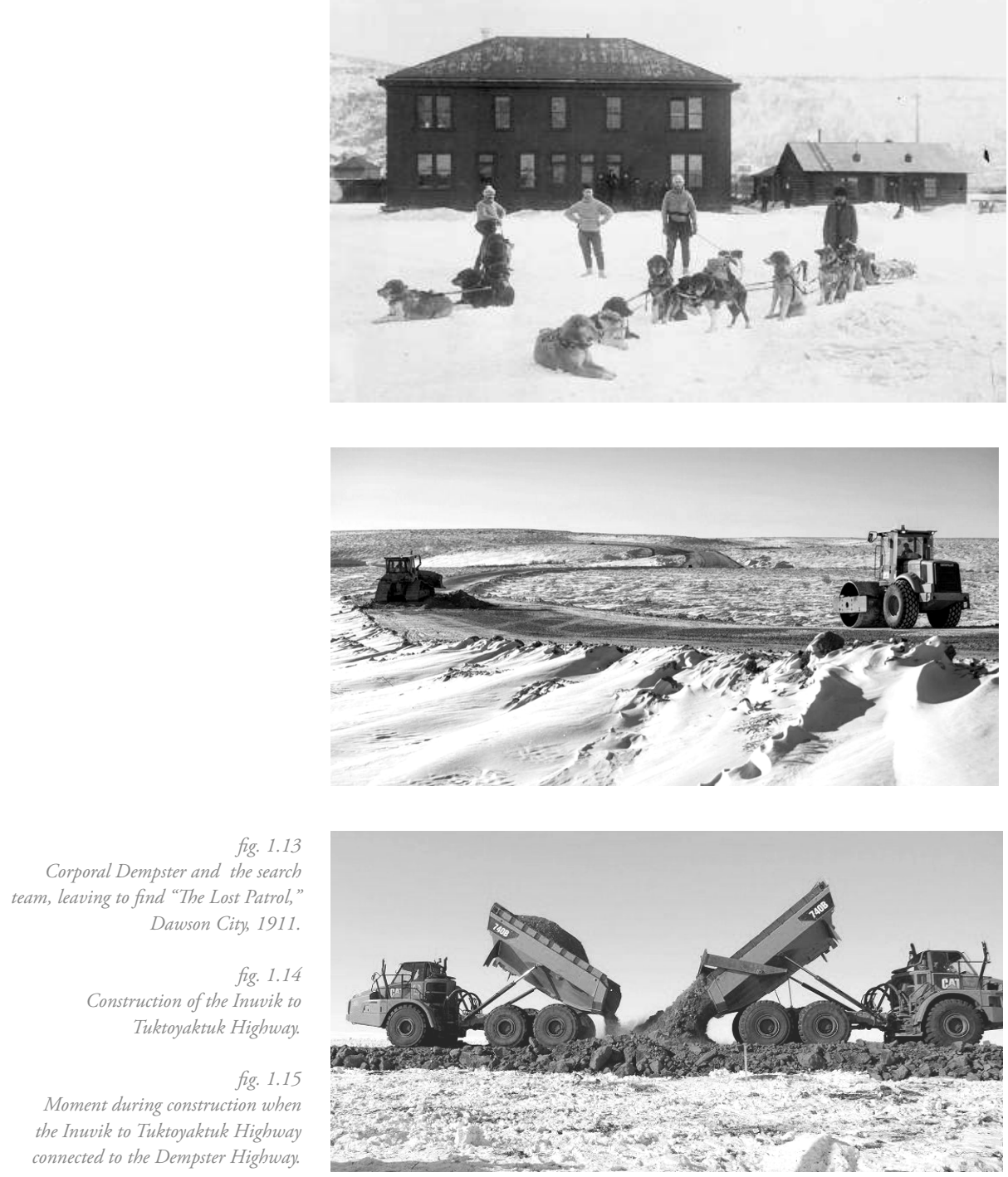
Highway was officially opened August 18, 1979.

During the oil boom of the 70 's, exploration continued north into the Mackenzie Delta region of the Northwest Territories, toward Tuktoyaktuk and further offshore. This catalyzed interest in a continuation of the northern highway to reach extraction sites at the coast but with the oil crash of the 80 's, the road remained unrealized. In the years that followed, community interest in the road grew. It would provide access to Inuvik, a connection to more affordable food, resources, employment and healthcare.

The long period of time from inception to construction gave the Inuvialuit communities of Tuktoyaktuk and Inuvik more agency as they had opportunity to clearly and thoroughly develop their own plans and intentions for the road. In 2014 the Harper government approved the road, offering $\$ 200$ million of the necessary $\$ 300$ million in costs. ${ }^{16}$ Perhaps this was the effective work of the town which had "lobbied anybody who would listen" 17 in favor of revitalizing the project. Perhaps it was a concerted effort to connect a community to resources in an era of undependable ice roads. Perhaps it was politically motivated by an interest in sovereignty and economic potential. It has publicly been touted as a combination of all aforementioned catalysts.

Today the national intention of the road remains uncertain. During a time of pipeline approvals, the current moratorium on offshore drilling seem tentative and the recent public tour through the Northwest Passage to celebrate the sesquicentennial ${ }^{19}$ maintains a grand statement of investments toward sovereignty and bringing presence to the northern coast as a national interest. The new highway does, however, fit into a larger schematic of expansion corridors throughout the Northwest Territories which will give overland vehicle access to active mines an eventually into Nunavut to reach the Arctic Coast for the second time.

For many residents of Tuktoyaktuk, the new highway is a different road to resources. The road, as a vector of resource exchange between endpoints satisfies certain national conomic desires as well as links toward political sovereignty but a has an undeniable value to residents of the remote communities it connects. I am in no way intending to gloss over or deny the urgent need that it fills for people in this way. The road alleviates, to some extent, issues of food scarcity, and contributes to an increase in medical access, social, educational and career opportunities. Beforte the all season highway, an annual ice road was maintained from Inuvik, to Aklavik, to Tuktoyaktuk. But, with warming temperatures the season of stable ice is growing shorter and less consistent, leaving residents increasingly uncertain about ther

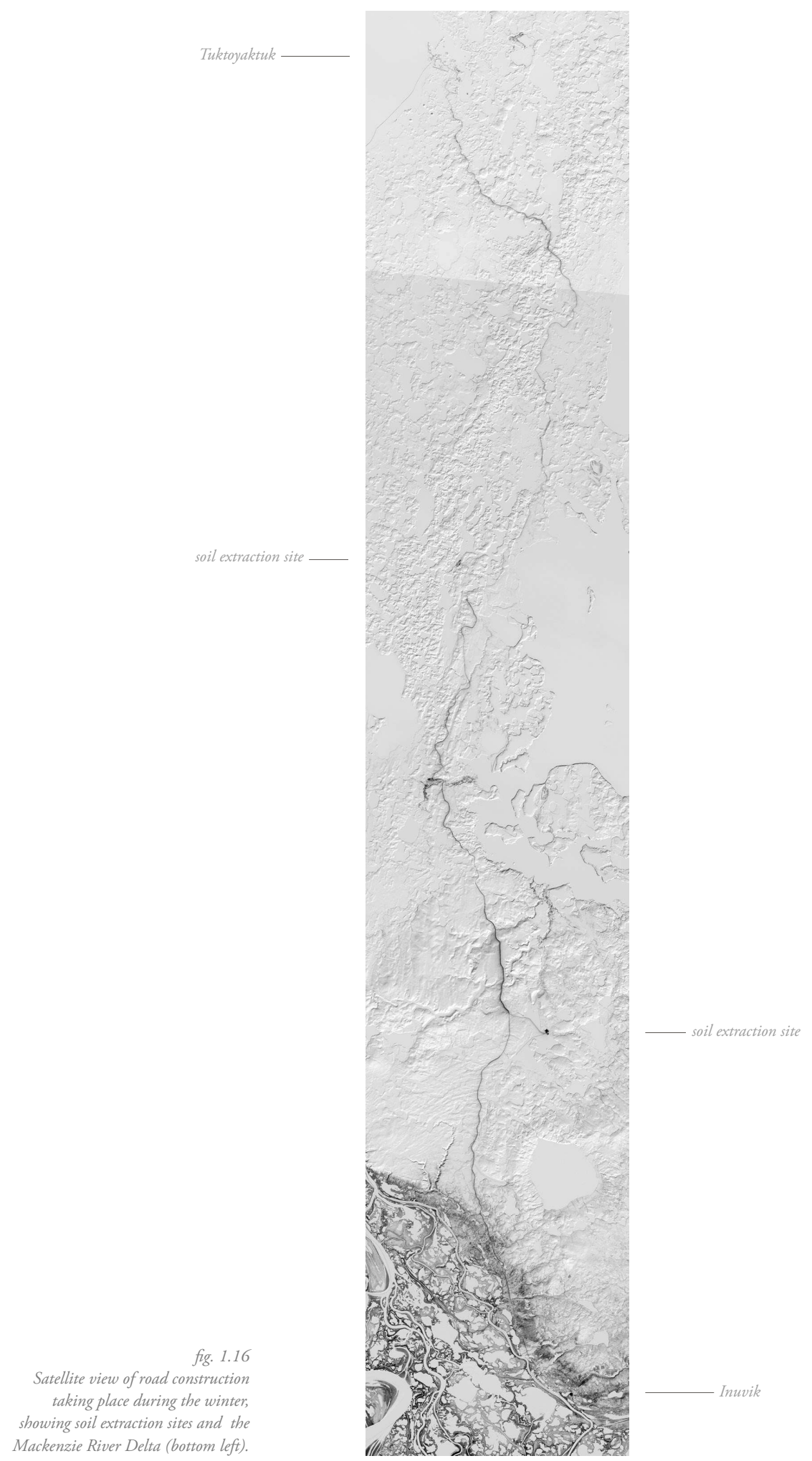


connection to food and services. The new highway is expected to reduce the cost of living by approximately $\$ 1500$ a year per person. ${ }^{20}$ The construction alone created 150 jobs in the community and 51 long term careers. ${ }^{21}$ A medical bus runs almost daily between ${ }^{\circ}$ Tuk and Inuvik.
ENDNOTES

PART 1: INITIAL INQUIRIES

pg $1-26$ 1. Aporta, Claudio. “Inuit Orienting: Traveling Along Familiar Horizons." Sensory Studies, http:// www
sensorystudies.org /inuit-orienting-travelingalong-familiar-horizons/\#_fttn1. Accessed March, 2018. 2. See the section titled "Purity and Danger" which discusses the threat of categorical ambiguity, the

3. Inuvialuit, Vuntut Gwitch'in, Tetlit Gwitch'n, Na-Cho Nyäk Dun, and Trơndèk Hwëch’in.

4. A cultural fault that T've participated in.

5. Dennis Allen, director. Crazywater. National Film Board of Canada, 2013, https://wwwnnflca/fllm/

6. The Dempster Highway follows a historic dog sled route used by the RNWMP. Dog sledding is a known transportation method of many Indigenous peoples (not exclusive to Inuit) and the history of the
relationship between the RNIVMP and Indigenous peoples is of course. fraught This is due in part to the exploitation of this Indigenous knowledge, technique and technology as can be seen in the adoption of dog sledding as transportation by RNWMP, and then the subsequent elimination of dogs, at the hands of government officials,s severing access to ustenance for entire Indigenous communities. The appropriation are a topic within the anecdote "I questioned my confidence." It is worth noting that my experiences
in Dawson City (where Corporal Dempster was stationed, and near the southern end of the Dempster Highway) were peppered with deterring comments that warn of unmarked graves in the area surrounding the town, further describing a violence toward Indigenous peoples at the hands of government police

7. Further into the thesis, the work and investigation became more concerned with the non-line, or the uncertain and unclear line.

8. Admittedly, there is an unresolved issue of identity politics in the use of the word "we."-perhaps some

9. Peter Kuiawinski, "The Road to the Top of the World," The New York Times. February 11, 2016 https:// www.nytimes.com/2016/02/14/travel//canada-tuk-northwest-territory.html?_t=0. Accessed.

10. Michael Gates, "Building the Dempster Highway: an engineering challenge," Yukon News. March 4, 2015. https://wwwyukon-news.com/life/building-the-dempster-highway-an-engineering-challenge/ Accessed: November, 2018

11. "The Lost Patrol," Virtual Museum of Canada. Last modified 2006. http://www.virtualmuseum ca/sgc-cms/expositions-ext

12 . Ibic.

13.https://arctic.journalhosting.ucalgary.ca/arctic/index.php/arctic/article/view/2073/2050

14. James H. Marsh and Liza Piper, “Mackenzie River," The Canadian Encyclopedia. February 7, 2006 
https://www:thecanadianencyclopedia.ca/en/article/mackenzie-river. Accessed November 2018.

15. Michael Gates, "Building the Dempster Highway: an engineering challenge," Yukon News. March 4, 2015. https://www.yukon-news.com/life/building-the-dempster-highway-an-engineering-challenge

16. Peter Foster, "Does Stephen Harper’s $\$ 300 \mathrm{M}$ northern highway to Tuktoyaktuk make economic sense?" Financial Post. January 10, 2014,

https:// business.financialpost.com/opinion/peter-foster-does-stephen-harpers-300m-northernhighway-to-tuktoyaktuk-make-economic-sense.

17. Jim Coyle, Inuvik to Tuktovaktuk road finally eosnects Canada from sea to sect (c)

18. "Stephen Harper hails start of Inuvik's' 'Road to resources', Canadian Brondcesting Corporation thenada/north/stephen-harper-hails-start-of-inuvik-s-roadto-resources-1.2488439. Accessed November, 2018.

19. "An Epic Journey to Celebrate Canada and Connect Canadianss, Canada C3. https://canadac3.ca/en/

20. Jim Coyle, "Inuvik to Tuktoyaktuk road finally connects Canada from sea to sea to sea," The Stat. November 18, 2017, https://www.thestar.com/news/insight/2017/11/18/inuvik-to-tultoyaktuk-road-

21. Foster, “Does Stephen Harpers \$300M northern highway to Tuktoyaktuk make economic sense?” 


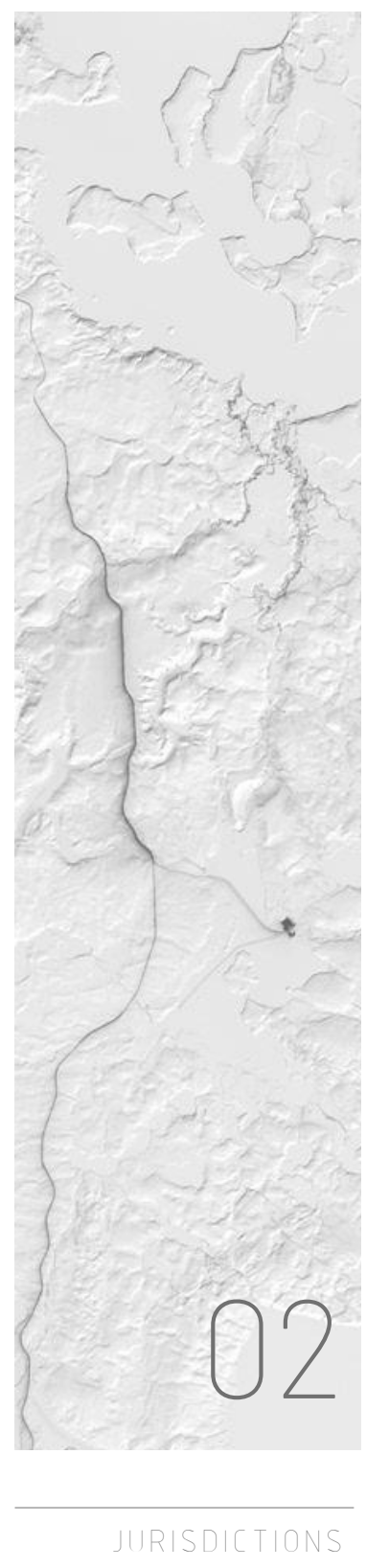




\author{
Jurisdiction is the authority to bave autbority over a particular territory. \\ But jurrisdiction is actualized tbrough material infrastructure. \\ -Deborab Cowen, "The Juriscliction of Infrastructur \\ Circulation and Canadian Settler Colonialism"
}

In the wake of Canada 150 celebrations and the accompanying anti-colonial concerns and critiques, the discourses around settler colonialism seem more curren in the cultural consciousness as a number of Canadians are asking some difficult and necessary questions about their "home and native land." Criticized for ignoring the previous work and intentions of the Truth and Reconciliation Commission, the activities surrounding the sesquicentennial celebrated the successes of colonial enterprise and ignored the foundation of tragedy on which it sits. ${ }^{1}$ Fast forward on more year, to 2017 and the nation completes the dream of former Prime Minister John Diefenbaker of connecting the country "from coast, to coast, to coast." This follows the contentious history of Canadian infrastructural development and is seen by some in an exclusively positive light. In the recommendation for Federal funding of northern corridor expansion projects, the Canadian Senate shared a quote from Transport Canada:

One could consider the large-scale projects that strengthen linkages between Canada's North and our continental trans.portation networkes as transformationad in nature, similar to the ways in which historic projects, like the transcontinental railway the Trans-Canada Highway and the St. Lawrence Seaway, positively impacted national prossperity and quality of life for all Canadians.

While other infrastructural expansion pursuits have operated with force and political division, and in which the pursuit of extraction transformed traditional life sustaining and into carceral landscapes ${ }^{3}$ this new iconic road is forred within an environment of mixed sentiment and altogether different (but still fraught) governance.

The construction of the Inuvik-Tuk highway was made possible by

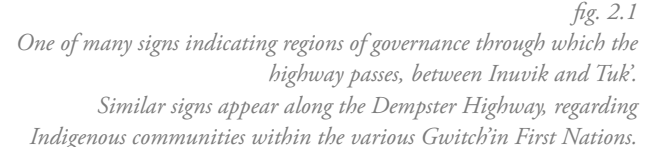


the cooperation between the Government of the Northwest Territories and the Inuvialuit Regional Corporation. The process of this project indicates a fundamentally different dynamic of power and governance than was seen with previous infrastructural projects of national importance. A case could be made for the first road to the Canadian Arctic Coast as the first (or maybe highest profile) multinational infrastructural project, being a joint venture between the Canadian and Inuvialuit nations. A case could also be made for the road as an act of entrenching colonial institutions and power frameworks and ultimately serving national interests under the veil of benevolence. 


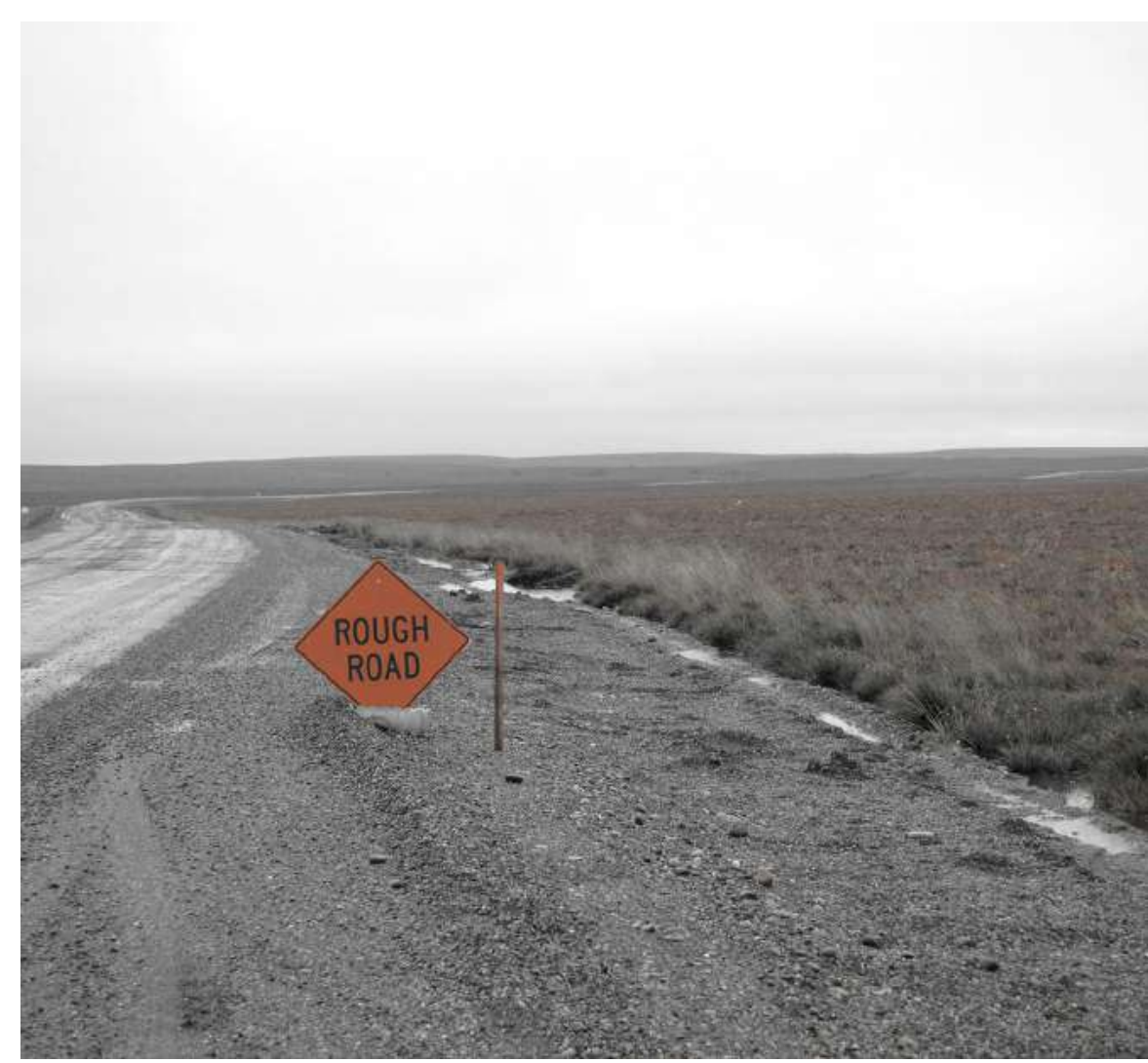

"Imagine Interpreting for us your own people's thinking... instead of interpreting for us our thinking, our lives, our stories"

-Jeanette Armstrong as quoted by Paulette Regan

Paulette Regan's accounts from her time working as the Director of Research fo the Truth and Reconciliation Commission of Canada offer acute reframings and wisdoms on settler identities and agencies. She speaks to the notion that colonial acts are particularly contemporary and active (not exclusively historical), from the scale of institutions to the intimate scale of personal awareness. Frequently, within topics of settler Indigenous relations (including design related site research), there is a tendency for settlers to study the 'Indian problem' or, the 'other', revealing a subtle indication that our own acts and doings are either not worth studying or are already coherently understood. This is hardly the case. Instead of assuming the authority an jurisdiction over the intangible territories of knowledge on the other, or assuming that the non-self is the source of any identified problem, Regan advocates that we pursue a more honest self reflection, acknowledgment, awareness and growth. She

We avoid looking too closely at ourselwes and the collective responsibility we bear for the colonial status qu. The significant challenge that lies before us is to turn the mirror back upon ourselves and to answer the provocative question... How do we solve the settler problem?

Regan also suggests that guilt and empathy can be "barriers to transformative sociopolitical change" given that such responses can easily instigate a "mentality of benevolent paternalism," and often fall outside the acceptable purview of intellectual and academic inquiry. Despite this, guilt and empathy can be necessary milestones and catalysts for the initial settler transitions of re-seeing self and re-learning histories and I advocate for such experiences to be recognized as part of the overduc emotional labour demanded by the vulnerability of pursuits of unsettling.

Further, Regan advocates for a 'Pedagogy of Discomfort,' in which sh 
challenges the notion that research can or should be neutral. ${ }^{7}$ In this she speculates the potential for progressive outcomes which rely on both cognitive and emotional labor, citing both Indigenous and non-Indigenous scholars who concur that learning is not merely rational, but experiential and holistic. ${ }^{8}$ With this, I attempt to pursue an understanding of my own personal jurisdictions. This includes a re-understanding of myself as a learner and maker, especially as an operative in a field that is focused on human interactions with space. What is important for this thesis is not a full solution to the settler problem-such a task is outside the bounds of a single thesis and will entail the work and questions of more than a single author-but the objective, rather, is to instigate a critical recognition of and initial response to it. That is what this thesis hopes to do.
ENDNOTES

PART 2: JURISDICTIONS

pg $31-38$

1. Deborah Cowen, "The Jurisdiction of Infrastructure: Circulation and Canadian Settler Colonialism,"

2. as quoted in the Canadian Senate's recommendation of Federal Funding for the study of Northern

3. Forced displacement, regional boundaries.

4. Paulette Regan, Unsertting the Settler Within: Indian Residential Schools, Truth Telling, and Reconciliation in Curde Vancouver: University of British Columbia Press, 2010

5. Ibid, 11 .

6. The crux of this is to maintain a traiectory removed of moral licensure and acts of self regart

- linking "historical consciousness and collective struggle to elements of critique and hope in ways that are potentially uncomfortable" (Regan, Unsettling the Settler Within, 21).

8. Further "Métis Elder Elmer Ghostkeeper explains that 'we observe and analyze everything holistically using our mind, spirit, emotion, and body. Our wisdom views experiential interactions as the primary 

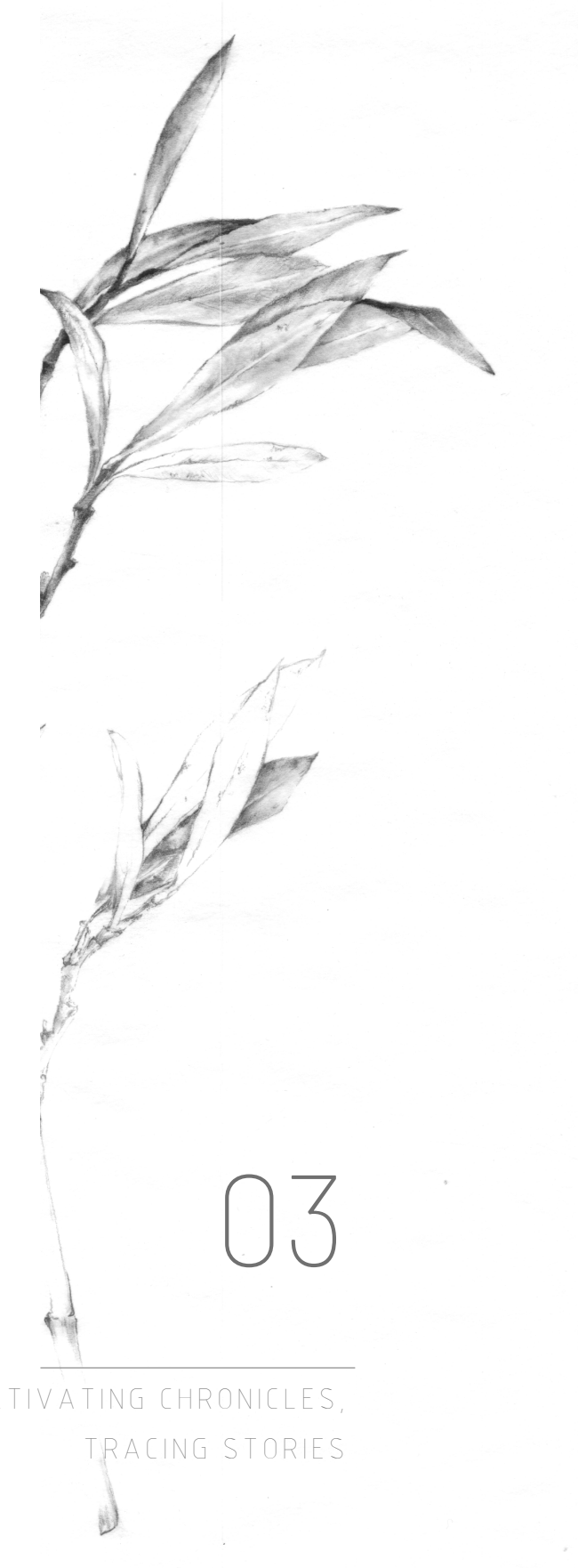
The colonizing eye constitutes landsape out of what it takes to be a terra nullius -Dilip da Cubna

While the label of "discovery" toward settler acts and acquisitions ${ }^{1}$ has been reduced to political incorrectness, the legal fiction of the terra nullius, which underpinned the development of the Canadian nation, is still at large in the collective consciousness and manifests in litigious matters regarding land ownership and jurisdiction. This can be seen specifically in regard to the concept of "crown lands," a title which carrie forward the authority of a not so distant imperial source and the spatial jurisdiction it assumed.

A terra nullius (meaning "no-man's land") is a Latin term used to legally define a space as uninhabited, unclaimed territory available for acquisition. The categorization of a space as such is enabled, perhaps, by the confusion of huma occupation and engagement of space, with the physical human density and material construction within space. For example, a space can be sparsely populated but intimately engaged: a small office with a single person is as inhabited as a large dance studio with a single ballerina. There is no prequalifying factor of density for a space to be deemed inhabited, yet, it is easy to categorize vast expanses of sparsely populated land as a terra nullius if there are few known indicators of human presence simply because of a misunderstanding of the multiplicity of human engagements of and habits within space. This was precisely the case, when, centuries ago, thirsty European eyes gazed upon the unsubmerged terrains of a new-to-them continent, which in turn became a canvas for their colonial vision. A definable landscape of exploits and riches was simultaneously born and claimed.

Most important to note here is that a terra nullius, or any other type of landscape, is a storied thing, which in this case was authored by the colonizing eve. A terra nullius is not an inherent quality of a space, but a definition born of a certain perception that is founded on (in this case) established European literacies. ${ }^{3}$ This is by no means an exclusively historical phenomena but a contemporaty practice in which the northern reaches of the same continent are seen as largely "uninhabited" space, 
open to and thawing for resource extraction, necessarily supported by infrastructural expansion. ${ }^{4}$

Stories are the tools used in the social technologies that help us construct meaning and interpret information and environments. They are the accounts of incidents or events, people or places and regardless of evidentiary references they are feats of human creativity. Furthermore, they are formally flexible, taking shape as visuals, texts, oral iterations or the shape of any other creative act, and are authored and sustained at different scales from cultural producers, political actors, technical visualists, designers, intellectuals or individuals. Often, stories claim of assume a jurisdiction whether physical or intangible and which, when told, shared, found and retold, can be consequential at potentially multiple scales. The jurisdiction of authorship is of particular interest for this thesis due to the conventions behind assumed jurisdictions and the ability and acceptability of imagining, producing and creating with agency as a designer or student about a distant or foreign territory.

Author and designer Dilip da Cunha works with concepts of the storying practices of imaged landscapes specifically as they appear in maps (which will be further discussed in Part 5), however what is important to note here is that the way a landscape is storied informs the spatial acts upon it. Borrowing from Donald Meinig, da Cunha notes that how a landscape is seen is an important factor in how it is regarded, stating that it is "composed not only of what lies before our eyes but what lies within our heads." Landscapes are often characterized as the unfamiliar, seductive and haunting images of expansive outdoor spaces into which we insert our imaginations and ourselves. Further, landscapes contribute to the definition of a regional self-image. In Canada's past, a colonial vision and a budding nation inserted an imaginary of national identity.

Stories are especially powerful when they conform to or fit within a broader, dominant narrative, making them difficult to contest - particularly at the scale of a nation and its associated Western history. I borrow here from Timothy Morton and position stories as 'factoids', which look and feel as if they were a truth, and that they have not been designed. ${ }^{6}$ This is less a conspiracy theory and more an acknowledgement of the degree of human decision making, which is not necessarily always intentional, but is always influenced and influential. Stories that last in a cultural milieu can easily slip into the realm of fact and reframing them as "factoids" may serve to destabilize their agency and open potential alternates. Imagination is not the issue. Stories themselves are not the issue. The issue is the prevalence and consistency of one type of story and the remaking and retelling of stories in ways that edify a dominant, exploitative way of seeing and relating to space and its inhabitants. In the following sections of this document, I attempt to understand the social technology of storying, within the context of relations between the Canadian "North" and "South" which underlie the socio-spatial practices that in turn nurture the fraught uncertainties between "geographic opposites".

Further borrowing ideas from Morton on ecological thinking, the final chapter of this section reflects on a drawing meditation that distupted an assumed need of assembling a taxonomy of plants collected during site research. In later chapters I pursue similar meditations, all of which hope to destabilize the colonizing eye, which is inherently non-ecological. What I appreciate about Morton is that he provides a level of theory in which to ground forward-moving acts, as opposed to simply calling out inherited faults. To be aware of these inherited faults and our own perpetuation of them is a remarkable step forward, to fill the space that their void leaves behind is a more difficult undertaking, if for nothing other than the sheer uncertainty and weight of it. The goal then, is to see and shake the heavy hand of judgement and work instead with (sometimes careful) hands of curiosity, discomfor and uncertainty, toward those hopeful alternative possibilities. 
Despite what factoids would have us believe, no fact just plops out of the skev. Ther is a whole environment in which the fact can appear - otbervise you can't see it at

all... We need all kinds of assumptions about what reality is, about what counts as real, what counts as existing, what counts as correct and incorreet

-Timothy Morton, The Ecological Thought

People become encultured by the images they see and by the stories they consume whether actively or passively. This process in turn develops a spatial cognitive bias toward geographic regions given that narratives and images shape visibility and obscure less established discourses. ${ }^{7}$ When reflecting on storying a foreign territory and my own inherited body of and relationship to stories about the Canadian North, it is useful to borrow concepts from Edward Said's work on Orientalism which is concerned primarily with the concept of imagined geographies that in turn influence social thought models, and more particularly concepts of space and territory. ${ }^{8}$ Both the Canadian North and the Orient were visualized as largely open, disorganized, viroin spaces ${ }^{9}$ and subject to a power asymmetry which favored the Eurocentric authors of hegemonic narratives that characterize people and land as subordinate and as potential resources. Building and contributing to this is the work of cultura producers; that is, anyone imaging and narrating "the North": politicians, journalists, anthropologists, artists, designers, students.

While his discussions of Europe (mostly Britain and France) and the image produced of the Orient is useful in unpacking the relationship between the Canadian "North" and "South" it does have some very particular differences that are necessary to disclose. In Orientalism, the Orient is "Europe's greatest and richest and oldest colony, the source of its civilizations and languages, its cultural contestant, and one of its deepest and most recurring images of the Other."10 While the Canadian Nation has defined some important and ingrained elements of its identity through claim on the North, there are no locations of theological origin nor the same intensity and history of economic exploitation. Canadian resource extraction, economic exploitation and political control of the North have taken place for fewer centuries The storying of the North has also been less prolific than that of the Orient. 
The stories of both these regions share the commonalities of being imaged as hovel, exotic and romantic. The North, however, differs from the Orient in that it is not storied as luxurious and indulgent but adventurous and tough, and supports settler stories of overcoming hardship: conquering harsh, wild environments and perpetuating romantic frontier heroism. Despite these distinctions, a thread can be woven between the similarities of what Said describes as Orientalist fantasies from the perspective of colonial powers, and Northern fantasies, as legible in the imaginative works and tendencies of contemporary Canadians and founding colonial explorers

Orientalism, in specific, describes a cultural understanding and style of thought based on a distinction made between East (the Orient) and West (Occident or Europe, specifically Britain and France). In this, a dominant European political ideology created "social descriptions, and political accounts concerning the Orient, its people [and] customs," which in turn became an origin for theories and narratives as well.11 In this cultural production, which assumed narrative jurisdiction of a distant territory, the West could control and authorize views of the East. For Said, this "nexus of knowledge and power" enabled the West to generalize and misrepresent North Africa, the Middle East and Asia, ${ }^{12}$ describing a multi-century relationship of dominance. To be able to produce a curated image of a region and its people, which then becomes hegemonic, is both a denial of that region's autonomy and an exertion of author's own power. My focus here will be on the power dynamics that Said describes between colonial states and the regions and people which they subjugate. While the dominance of this narration is disintegrating in Canada, as a wider diversity of voices are defining the North and the regions within it, it is still active and remains a foundational element of a cultural consciousness.

More broadly, and relevant to the discussion of the "Canadian North", Said posits that cultural production on and about a non-local subject and the cultural consciousness that it produces are catalysts in the initiation and maintenance of durable exploitative social, political and economic power structures, whether or not such consequences are intended. This is more specifically the case when this type of non-local authorship is more accessible than authorship on the subject by the subject. As Said notes, cultural production of this type is created in relative sovereignty of consciousness, that is, without discussion, feedback or collaboration of the studied subject and from a social position of "un-challenged centrality."13 Such power structures are further amplified when non local authorship is prolific while being posited as and trusted to be factual: enter 'factoid'.
Said asserts that this type of cultural production creates a condition in which the region and culture of description "was not (and is not) a free subject of thought or action." ${ }^{14}$ Nor is such cultural production just a set of myths and lies, which, "were the truth about them to be told, would simply blow away,"15 further stating that "any system of ideas that can remain unchanged as teachable wisdom... must be something more formidable than a mere collection of lies" ${ }^{16}$ Established structures of imagining, representing and projecting a place and its people is more aptly interpreted as a sign of the aforementioned power asymmetries than it is a body of facts. This additionally enables durable political and socio-economic institutions to operate subversively through a dominant social consent, through a "tacit, unwritten agreement often passed off as conventional wisdom or common sense."

Describing how difficult it is to counter narrate or dislodge the conventional wisdoms of a hegemonic narrative, Said states that "facts do not at all speak for themselves, but require a socially acceptable narrative to absorb, sustain and circulate them."18 In other words, the phenomena of storying is so significant that facts cannot operate without a socially functioning narrative to support them. This implies the possibility of a false sense of objectivity. Furthermore once a definition or image has been accepted, it allows other definitions and images to be built off of it, condoning the original image and edifying its power and agency. With this, it is difficult for non-hegemonic perspectives to be narrated outside of the existing and accepted narrative19 and allow existing narratives to remain durable within social consciousness over long periods of time.

Of particular interest is the etymology of the word Orient, which implies a non-autonomous spatial reference. Taking similar derivations as the word 'origin', 'orient' comes from early adjectives (c.1300) indicating the act of facing east, or finding east (via noting the direction of sunrise); but it wasn't until the mid 19th century that the word was found to take the additional meaning of finding one's positioning or bearings in space..$^{20}$ In the case of Orientalism, "The Orient" as a projected title is derived from an initial European geographic position (ie. the Orien is east of Europe), it is the reference from which the authors at hand might find their bearings. The title itself carries the understanding of the act of orienting distant author, here, the subject is not defined independently, but as a utilitarian device through which to define the author. A culture can reinforce its own identity by positioning itself in relation to the created image of another, a dynamic that describes the colonial relationship between Europe and the Orient. In this instance, a single word that is both an act and a title is describing the connection between 
identity and a geospatial phenomena of body positioning, together which manifest some of the socio-spatial consequences that Said highlights.

Taking this notion into the context of the Canadian "North" as defined by authors from the "South," may instigate a reflection on the extent to which the storied region becomes a point of definition for the author, both socially and physically. This can be seen in simple statements such as the Vancouver 2010 Olympics using an Inukshuk to portray a national identity; or that in 2015 a government issued "Northern Strategy" stated that "Canada's North is a fundamental part of Canada it is part of our heritage, our future and our identity as a country."21 To what exten has narration as identity construction contributed to my own relationship with the Northern regions and the site of this thesis? The first Canadian road to the Arctic coast is lauded as a landmark in a national timeline and is an icon in Canada's identity and history. What role will it play in extending these narratives? 
Oh the areful hush that seemed to cursh me dow on every hand,

As I blundered blind with a trail to find throught that blants and bilter land; Hhalf dayed, half craned in the winter wild, with its grim heartbreaking woes, And the nuthless strife for a grip on life that only the sourdough knowes!'

North by the compass, North I pressed; siver and peats and plain

Passed like a dream I slept to lose and I waked to dream again...

North, ayge North, through a land accurst, shumned by the scousing bueles, And all I heard was my owe harsh woud and the whine of the malamutes.

\section{The imagery and textual discourse of past centuries}

still shape the imagined North.

-Victoria Hermann Lavered L andscapes, L avered Identitites

The "idea of North" is both central to nationalist imaginations in Canada

and based on radically limited experience. North is, indeed, an idea for most Qablunaat, ${ }^{22}$ an idea constituted by the stories we tell.

-Emilie Cameron, Far Off Metal River

Canada has a history that is rich with a material culture that has enabled and embraced the "North as a central aspect of the national psyche."233 Surveys indicate that the average Canadian citizen sees the North as an integral part of their heritage and of national identity, further illustrated in the newly minted fifty-dollar bill which features an Arctic icebreaker ${ }^{24}$ - or the tag-line for the Toronto Raptor's "We the North." In her research on northern narratives authored by settler perspectives, Emilie Cameron states that "the story of the North [is] a site of national becoming" which, she continues, "functions with the ability to "underwrite geopolitical claims to northern lands and resources."ㄹ. Despite this, there are indications of a more than geographic distance between the North and the majority of Canadians who have limited firsthand experience of and engagement with it. According to Statistics Canada, of the 328,454,000 domestic trips made by Canadians in 2017, only 0.03 per cent, or 106,000 people, traveled to or within the three territories. ${ }^{26} \mathrm{Ken}$ Coates, a Canada Research Chair and a focus in northern history, northern development and Indigenous rights remarks at the prevailing phenomena that Canadians at large maintain a bonding dislike for winter ${ }^{27}$ a curious inconsistency to the national claim of Northern-ness and its associated frigidity; a paradoxical condition corroborating the idea that the North as part of a national identity is as a claimed and storied entity and not an embodied knowledge. 


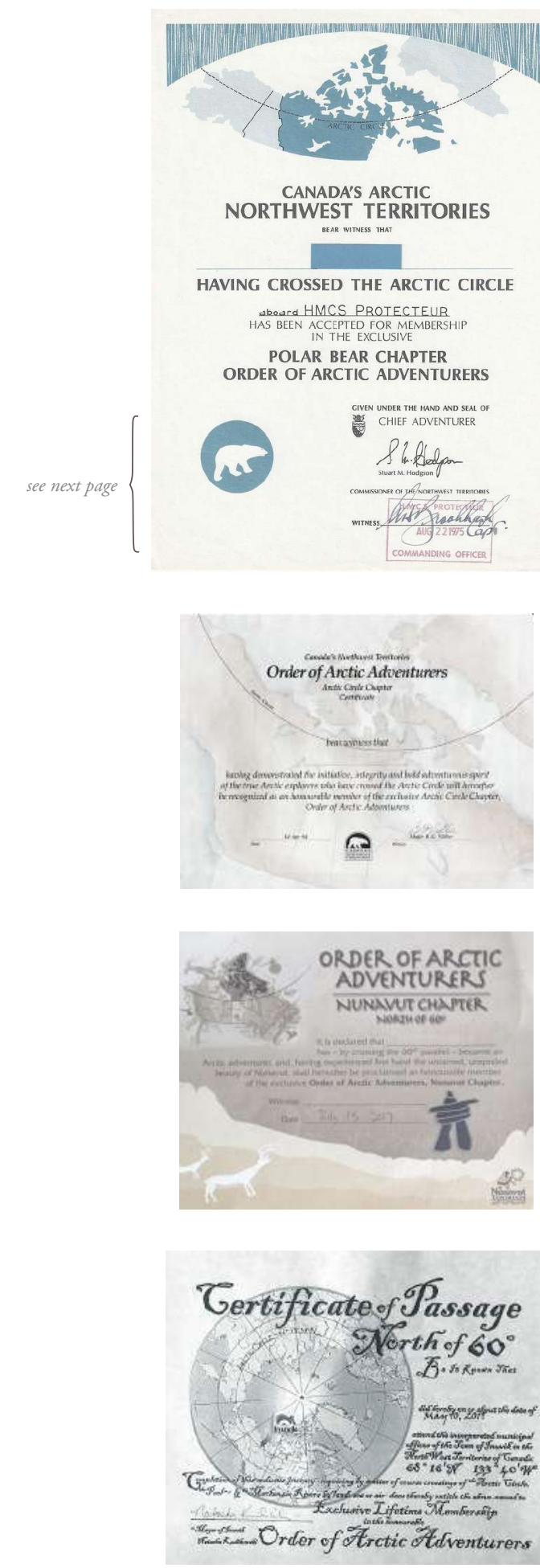

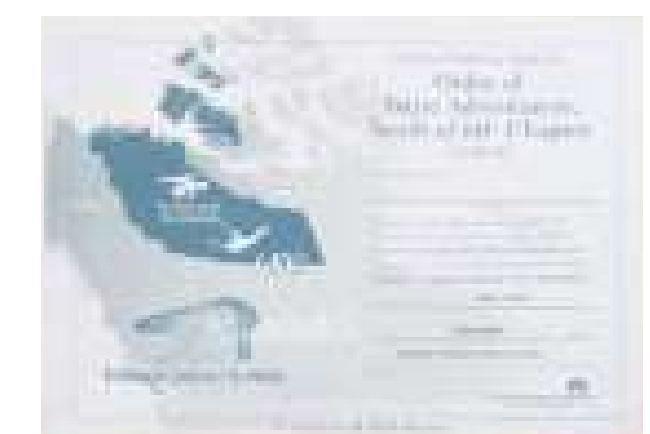
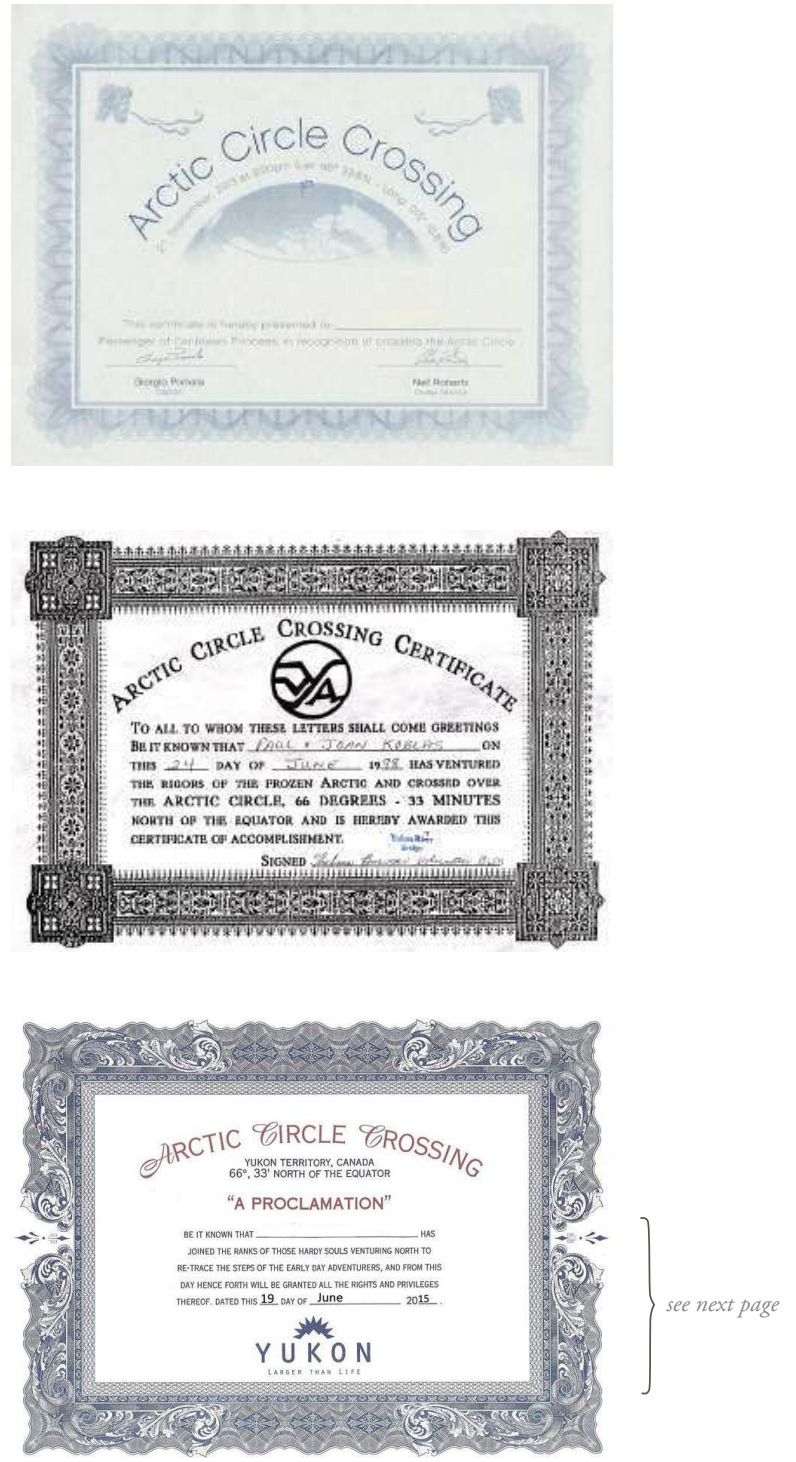

We need look no further than to poet Robert Service (see opposite page), or a fiction that imagined a massacre in service of forging the career of Samue Hearne with the Hudson's Bay Company. This is a history told in frontier narrative, and tracks the colonial presence established by the Company of Adventurers of England Trading into Hudson's Bay (the oldest company on the continent). Hearne' account of events during his employ became historic fact and places and plants alike have been named for this story (Bloody Falls and senecio lugenss). Similarly John Richardson, who accompanied Franklin on an early expedition, largely defined the British polar region exhibiting a so-called expertise that effectively nullified existing knowledge and ecological understandings of the plants and animals involved in his taxonomies. His work abetted in a convincing claim to a territory that is now deemed an important part of Canadian heritage. In art, the Group of Seven and other painters successfully depicted a majestic terra nullius that also sits at the core of national identity. These and more examples were influential in producing a set of standards and perceptions of both the North as an artificially homogenized entity ${ }^{29}$ as well as describing and leading a vision of a settler engagement of and relationship to the region and its inhabitants.

As stories of the North form a strong part of national identity, the region receives projected notions that help define what it means to be "Canadian." Just as Said described the utility of authorship in Orientalism, which served Britain and France, the narratives projected on the geographic region of the Canadian North orioinally served Britain and France and more recently the young nation of Canada. In the essay titled "Layered Landscapes, Layered Identities: Historic Narratives, Arctic Aesthetics, and Indigenous Agency in Canada's Anthropocene," Victoria Hermann describes these deeply seated narratives:

Through exploration and expeditions, the North served as a tabula rasa to perform feats of national heroism and project identity ideas of stately power, bravery, and international importance. In a place so geographically remote from the identities it was meant to extol, images and supportive textual discourse whether in the form of maps, photography, documentaries, or multimedia platforms, became a medium for legitimizing an imperial nation's character. Each selective compositional or contextual element determined the realm of visibilits and invisibility, enacting a particularly politicized disposition of the country's identity. . $^{30}$ 


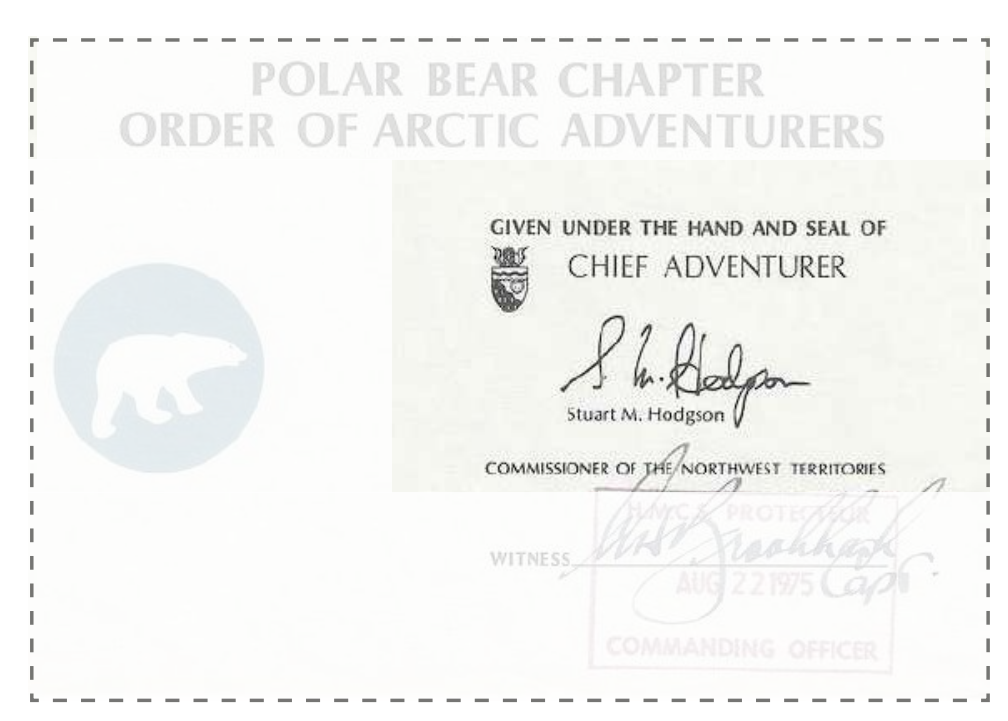
dominance over such a region inherently implies a necessary level of strength on the part of the dominion. This facet of identity became markedly renewed in recent cultural awareness when, in 2014, the location of the lost Franklin Expedition ship Erebus was located (after years of being categorized as an "undiscovered national historic site"). ${ }^{31}$ At the public announcement of the discovery a statement was made clearly indicating that not only had the ship of the wreck "laid the foundations of Canada's Arctic sovereignty" but also that national interest was vested in rediscovering and contemporizing narratives of heroic northern conquests.

Of particular importance is that the unveiling of the discovery was bolstered by images which recreated a visual narrative of geographic claim positioning contemporary photographs of the rediscovery alongside historic images and illustrations depicting moments of Franklin expeditions. In this even connecting past and present visual narratives ensures a contemporary definition of 'northern-ness' as part of the current national identity and sufficed in "painting an unbroken, sweeping national Arctic narrative over the past 200 years" ${ }^{32}$ The fact that such images were broadly distributed across national media alonoside laudatory praise indicates the continued appetite for revalorizing northern frontier narratives as part of national identity.3.3.

Similar to accounts of explorers, the work of poet Robert Service was JONED THE POUNS OF THOSE HAROY SOULS VENTURTS NOSH TO RE-TRACE THE STEPS OF THE EARLY DAY ADVENTURERS, ANO FROM THIS DAY HENCE FORTH WILL BE GRANTED ALL THE RIGHTS AND PRIVILEGES TIS DAY OF JUTC 2015

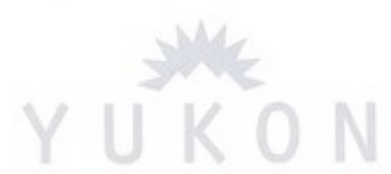
perspective. Service was (and is) involved in disseminating an accessible image of the North through narratives of exploration and frontierism, and the romantic desperation associated with struggling through conditions of unfamiliar and comparatively challenging environments. The early political contestation of the gold rush region in combination with the valour of conquest over the Northern terra nulliw rendered the region of the north-west a place of sublime, exciting, exotic fantasy, to be consumed by historic adventurers seeking riches and fame. This has extended to contemporary adventure tourists pursuing badges of exotic knowledge through their uninvested and brief interludes in the region..$^{34}$ This takes what Hermann describe as "a familiar, historically framed aesthetic motif and reframes it for contemporary nationalism" and adventure tourism. ${ }^{35}$ The motif here is that of the adventurer/ explorer. The certificates of passage (reference fig\#) into the far reaches of the North and the sensational moments shared by Robert Service,allow individuals to fulfill a desire for strength, perseverance, triumph and "Canadian-ness." 
Cultural consciousness of these narrative motifs are evident along the road to the Arctic Coast, where at the Eagle Plains Lodge, visitors can obtain a certificate of fortitude confirming their ventures to the Arctic Circle (despite being farther south than the claimed destination). Similar certificates are available in various locations in Nunavut and the Northwest Territories. In Tuktovaktuk, a similar certificate is available attesting to an individual's contact with the Arctic Ocean, re-contemporizing the narrative of adventure tourism and the non-reciprocal consumption of the exotic during brief spatial proximities. 
Cameron reminds us that "cultural production is intimately related to imperias domination"36 further noting that "stories are not innocent... Colonial texts an the imaginative geographies they help constitute [are] materially consequential." Cameron highlights the practice of storying and the life of stories, framing this socia phenomena as both a relational and material ordering practice: an intangible socia technology. This definition aids in understanding stories as dynamic participants in creating social order, spatial understandings, and informing and catalyzing sociospatial acts (such as claims and occupation). Cameron further notes that the practio of stories is important, not just that they are created, nor that they hold power, but that they are active, shared and built on and becoming operative (sometimes frec) agents. She states:

Stories are not simply about people or places. They are themselves composed of nethorres of relations between people, places, and things, and spre of staries matter. Staries are primaribly atproached as texts not as embodied material practices shaped by the social, cultural, environmental, and political contexts witbin which they are told. It is the imaginative, representational

importance of colonial discourses that is of most acute interest. ${ }^{38}$

Therefore, it is not just the story itself which holds agency, but the practices of seeing, producing, telling, retelling and reproducing g $^{39}$-the conditions necessary for the existence of factoids. This is specifically true for stories that find endurance within a culture (as noted by Said) these stories must then be understood as "relational networks of humans and non humans, not as representations that somehow sit apart from the materials they represent."30 Cameron makes a case for understanding stories as elements that are inextricably tied to the places and people they represent Through understanding the social phenomena of story, it becomes "possible to consider that there is more than one place...and more than one story through which [a] place is made meaningful. ${ }^{31}$ There are more ways of imagining and informing spatial practices, engagements and perceptions. 
Cameron also writes that Indigenous, in particular Inuit, stories are concerned with much more than mere linear consecution. They are a social infrastructural technology of cultural practices and knowledge.42 I would argue that stories maintain similar functions for the non-Indigenous, though we often fail to recognize them as doing so and instead, we approach them more as self-serving, low consequential narratives, without recognition that they function outside of our initial and focused intentions. We are unpracticed in assuming a broader life and function of stories outside a preconceived utility. Just as with storied discourses, in the practice of design, it is mportant to remember that form only follows intended functions, and that every act of design produces functions that are outside of the designer's intentions.

As a caucasian-Canadian of European descent, born within the southern portion of national borders, I've inherited stories of the North. I carry them. I've perpetuated them and in some cases. I've lived them or been confronted by a counter to them. The latter accounts, which present a different narrative, beg a shifted perspective and are experiences that contribute to a frustrated and confused future eception of those original, hegemonic stories. Practices of making might engage and perpetuate these stories. The way I'm working in this thesis hopes to begin, in some small way, to see the region without these narratives--or to have, at leas, destabilized them. 


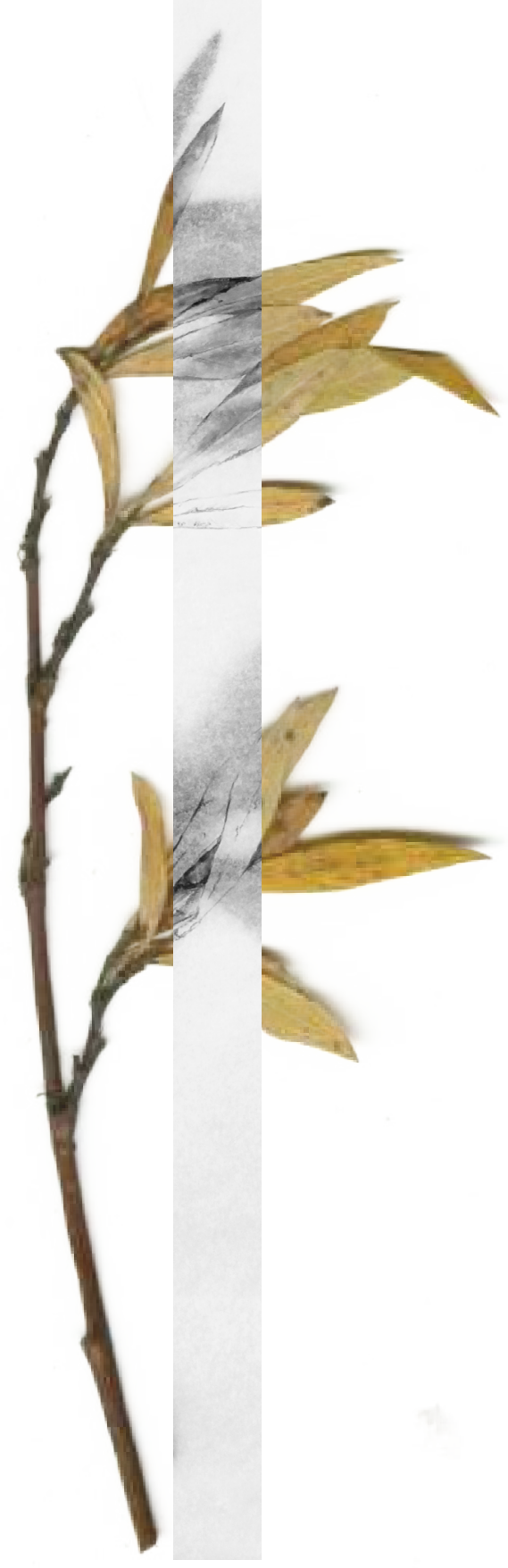

As a bridge between earth and animal, it is through plants that we take the earth into our bodies and it is also through them that a spatial awareness and attunement can be nurtured. During a visit to the site I had collected various plant samples. Some familiar and nostalgic, some new to me, but all of them as trace objects of an experience. I was simultaneously disappointed and unsurprised, when, during the act of "looking up" the plants, I realized that the first Euro-colonists had similarly collected them. I wanted the plants for more than taxonomies yet couldn't help but feel inclined toward them; recognizing the value of indexical approaches, of family groupings and the patterns and differences that this format of research can show But I was so reluctant to partake in the agency this organization might offer-as if taxonomy could confirm or suggest a level of expertise about the site-this was not a position I was willing to suggest of myself. And besides- a recitation of names and species and families wouldn't satisfy my still lingering sense that the plants have more information about the site than I know how to know. Plants are inherent spatial respondents. As the tip of this iceberg to this, they offer moments of legibility in that they can be intimately read as indicators of physical environmental condition that span multiple scales-outlining drainage basins or occupying the borders of soils disturbed by humans.

They are also a vehicle of narrative and carry projected storylines.

As receptacles of human-projections their Western documentation and definition holds a series of sociaospatial details: the Latin name and description, the person who collected and recorded it, where it was collected and recorded and in some case accounts that tie it to a story of colonial tales which displace both plant and self and conjures a perpetuated memory of an individual and his limited physical presence in space and agency in a social system.

Salix richardsonii is named after John Richardson who accompanied Franklin on early expeditions and was the initiator of the taxonomies which catalogued the exotic flora of the new world. These catalogues were compiled in what was for many years the official document of reference on Northern plants, known as the 


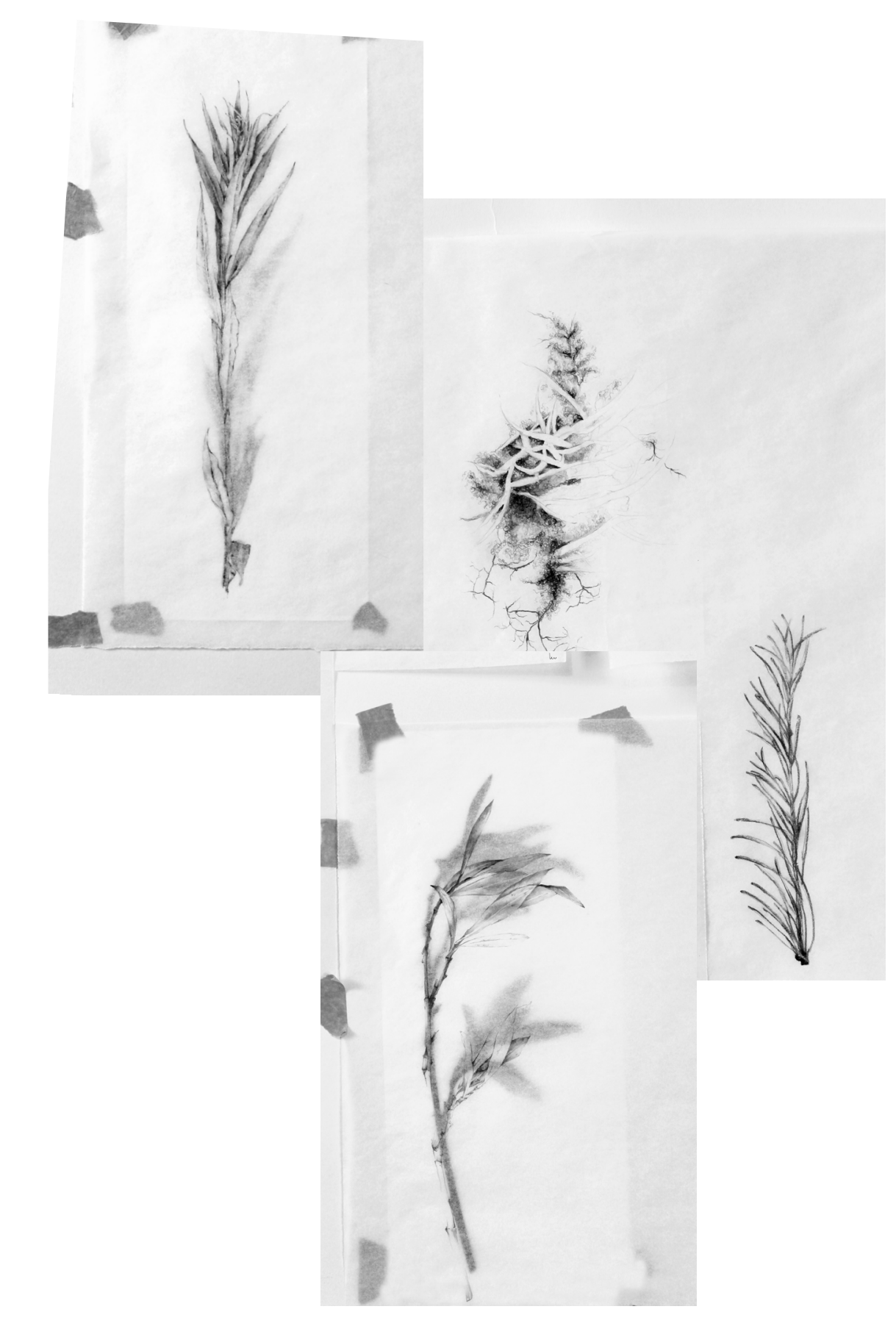

Flora Boreali-Americana. This book established stories that still hold ground today. In some of the descriptions, plants are documented with names of explorers and tales of their chronicles (senecio lugens, salix richardsonii). The plant becomes a vehicle for asserting jurisdiction (just as a taxonomy can indicate an authority). That which is called salix richardsonii is no longer itself, nor of the place in which it thrives: it is the ghosts of a moment of a brave colonial hero, initially brief, now lasting. Senecia Lugens ${ }^{43}$ mourns for the lives lost in a savage massacre as witnessed by the imagination of Samuel Hearne in his sensational fiction that caught public attention and forged his career with a British trading company of Adventurers. The rich potential of spatial knowledge legible in the plant is reduced to a few grand moments of an individual's career. Perhaps, some of the commencing acts of the Anthropocene were to lay human names upon the land to carry the stories of ourselves forward. Without anticipating the complexity of seemingly simple actions, the act of naming leaves a legibility of human operations that both reveal a past and are consequential bevond initial intentions; subtly erasing the authenticity of the subject in favor of human icons. It is the antithesis of ecological: the singular, heroic.

A more recent account of a sister species to the salix richardsonii reads:

Common in the Mackennie and Richardson Mountains, and ranging east across the barrens beyond Great Bear Lake at least to Coronation Gulf. A common species of inland and alpine tundra where it is characteristic of sheltered but well watered slopes and hollows and of the banks and lakes and streams in places where snow accumulates in winter... On the gently sloping tundra the reddishbrown bands formed by salix pulcbra thickets beautifully outline the drainage systems; seen from the air in early winter, when the willow thickets are not yet completely covered by snow drifts, the effect of the brown bands meandering across the wbite plains is most striking.

\section{METHOD}

This was not free drawing but rather, the tracing of a printed scan of the plant. It's remarkable the level of intimacy that tracing demands: it necessarily oscillates attention between scales of information and relieves the output from the anxiety of reproducing the iconic image attached to a subject's name. During this process there are lapses in conceptual understanding of what is being drawn outside the 
concentration of gradients-names of the object disappear in my awareness and urn to shades of light and dark that are pressing into each other. In this proces, a "leaf" is small textured shades and fine edges and linear marks might disappear but still imply the lenoth of a twig-a form that becomes rendered inarticulately as an edge defining contour. The lichens were especially difficult in their tangle of indecipherable patterning, unclear edges and unknown structures. Being between known categories of flora and fungi, they have no place in the document of exotic plants of the new world.

This method of drawing felt simultaneously more intentional and less genuine. It was much easier to transfer into two dimensional marks because it had already been flattened-physically and digitally; yet I knew I was seeing more detail because I was marking it before I could define it-following the shades of gray hrough the trace paper alleviated the need to understand by means of a category or name of a part of the plant.

During this exercise I became more aware than before of the agency of 'convincing' drawing (ie, well drawn). A portion could be drawn and the rest left blank-an editorial exclusion of my choosing. Without the presence of the source (the scan or plant) no-one would be the wiser I was building reality anew and it could be believed due to the realistic quality of the marks I was making. It could be both a spectacle and a trusted stand-in for the source, which would now be obsolete. But in the physical drawings, there was a greater thrill and curiosity in exposing the scan, which remained as an indicator of process, an origin of translation and a veiled substitute for what has been excluded in the graphite expression (the plan that is no longer). I am curious about combining technical abilities (here, control of graphite and realistic rendering) with layers that disrupt the power of it, exposing a selective authorship that questions the instinctual response of trust in marks that appear 'accurate'

\section{fis. 3.5 (right)
Dedication page in $\mathrm{F}$

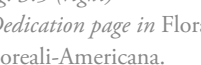



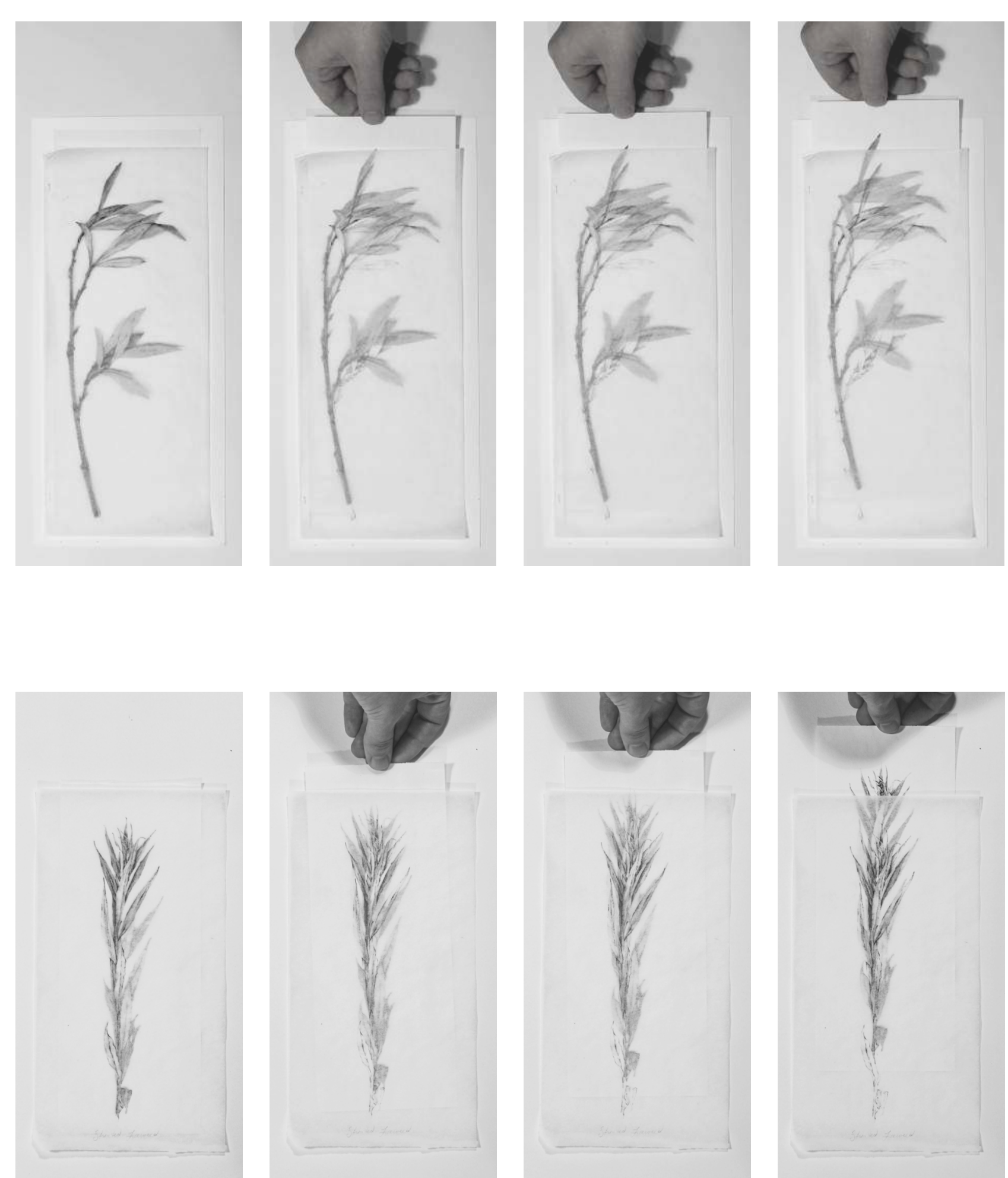
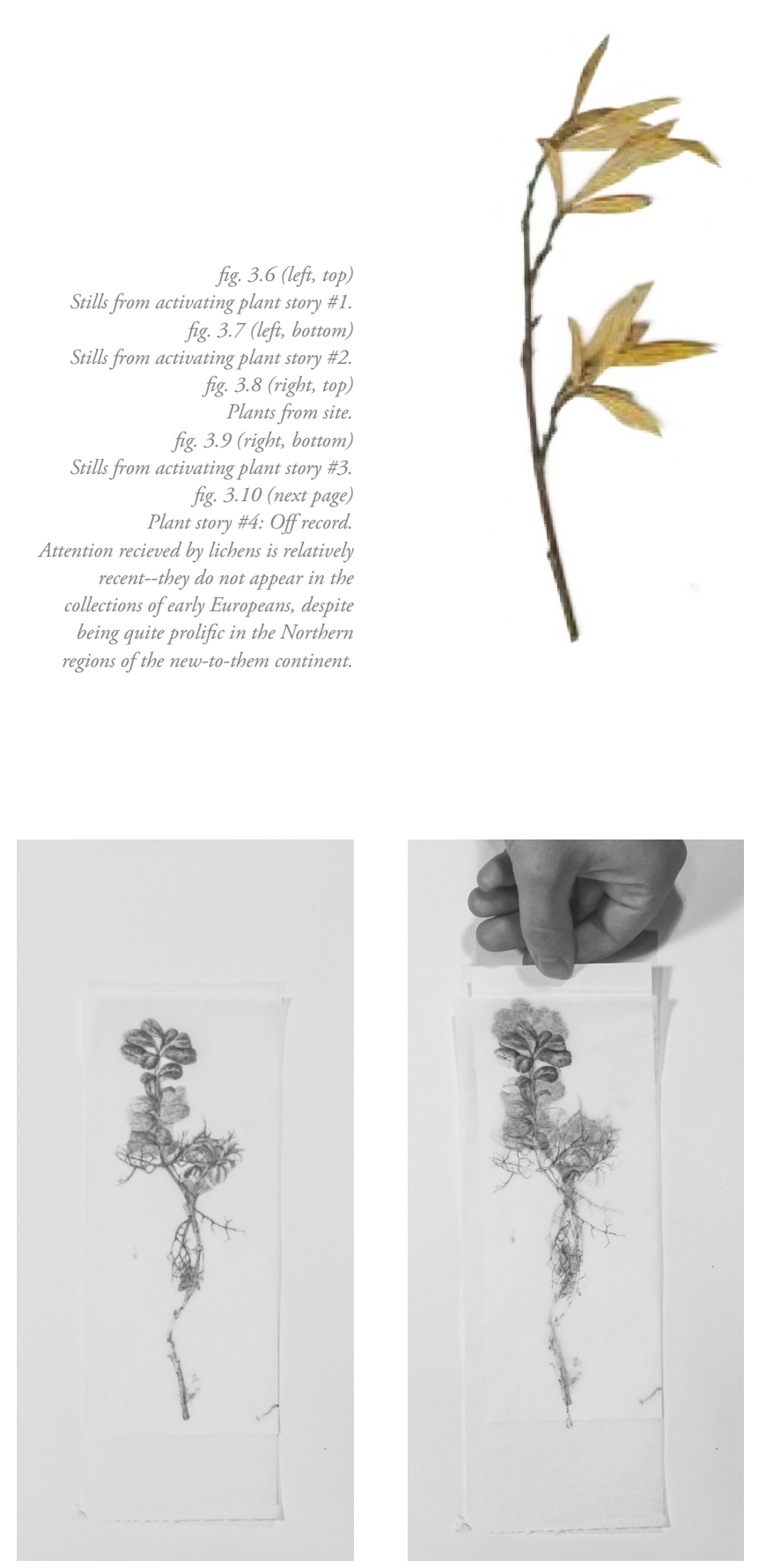
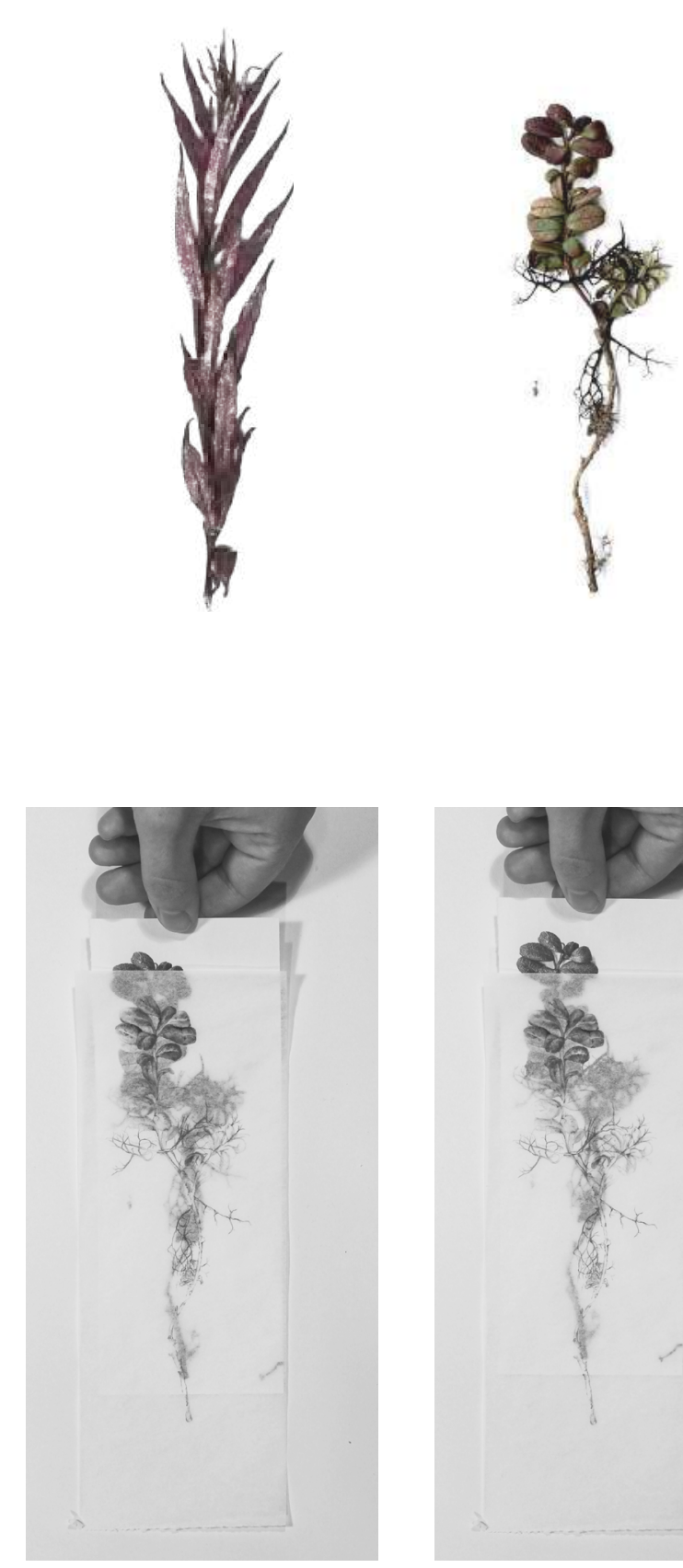

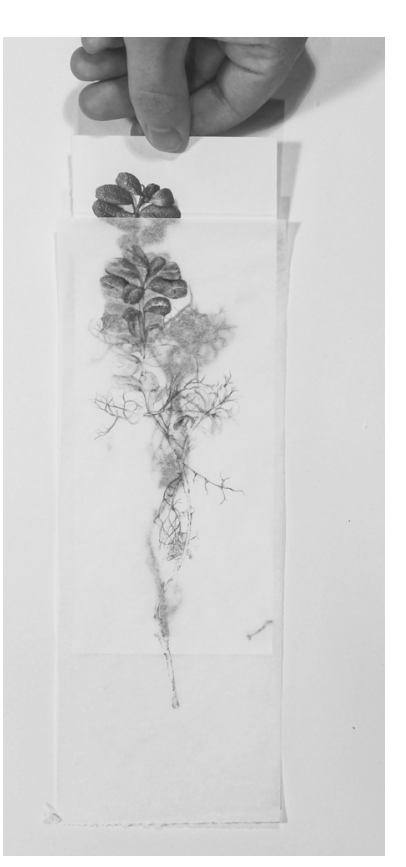


ENDNOTES

PART 3: CULTIVATING CHRONICLES, TRACING STORIES

pg $41-72$

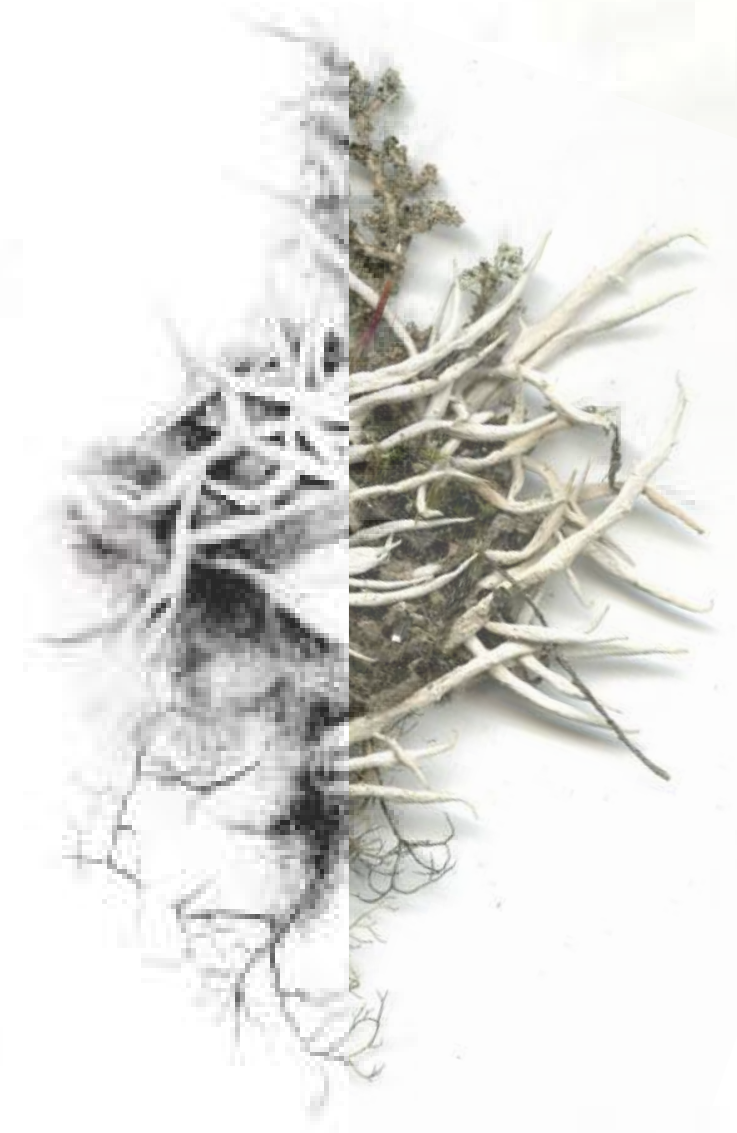

\section{For example, the "discovery" of the "New World"}

2. Crown lands (also crownlands) are land considered to be "public" and are legally controlled/monitored

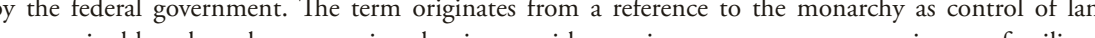

3. Both ontologies and epistemologies.

4. This is further enabled by histories of regulating humans within this space, from restrictions on movement, forced displacement and resettlement and the establishment of military and political presence. 3. Dilip da Cunha. The Invention of Rivers: Alexander's Eye and Gangas Descent. Philidelphia PA: University of Pennsylvania Press, 2019. pg 9. Includes borrowed notions from Donald Meinig

6. Timothy Morton, The Ecological Thought (Cambridge, Mass: Harvard University Press, 2010), 8.

7. Victoria Hermann, "Layered Landscapes, Layered Identities. Historic Narratives, Arctic Aesthetics, and Indigenous Agency in Canadas Anthropocene, in the Neeworked North: Borders and Borderlan. in the Cor

8. Hermann, "Layered Landscapes, Layered Identities. Historic Narratives, Arctic Aesthetics, and Indigenous Agency in Canadàs Anthropocene," 6.

. Ibid, 6.

10. Edward W. Said, "Orientalism," in The Edward Said Reader, ed. Moustafa Bayoumi and Andrew Rubin New York: Vintage Books, 2000), 68

11. A major critique of Said's work is that he conflates all cultural production into one homogenous category in which all producers and products have the same effect and intention. What is more importan than the academic or political qualifications of the producers is the fact that they are operating in a culture of consciousness which allows their work to be received, corroborated and respected. The accounts of

12. Said, "Orientalism," 92

13. Ibid 74

14. Ibid, 70

15. Ibid, 72

16. Ibid, 72-3.

17. Mustafa Bayoumi, Andrew Rubin, "Orientalism" in The Edward Said Reader, ed. Moustafa Bayoum 
18. He uses as an example a report on the Sabra Shatila massacre which clearly indicated the responsibilitities 42. Ibid, 26 作

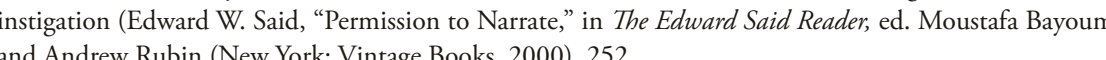

19. Ibid, 255 .

20. https://www.etymonline.com/word/orien

21. https://www.northernstrategy.gc.ca/index-eng.asp

22. Summarize Cameron's definition of Qablunaat: non-Indigenous, European descent individuals

23. Hermann, "Layered Landscapes, Layered Identities. Historic Narratives, Arctic Aestherics, and Indigenous Agency in Canada's Anthropocene," 9

24. Ibid, 10 .

25. Emilie Cameron, Far Off Metal River: Inuit Lands, Settler Stories, and the Making of the Contemporary Arctic (Vancouver: UBC Press, 2015), 22

26. Katherine Barton, "Why Canadians should brush up on their geography of the 3 territories," Canadian Broadcasting Corporation. July 7, 2019, https://Www.cbc.ca/ news c canada/ north/three-territitories-canadd

27. Ibid.

28. NB Expanded footnote describing story

29. A series of non homogenous regions conflated into one: Multiple indegenous regions or nation multiple eco-regions, multiple climatic regions are conflated into one

30. Hermann, "Layered Landscapes, Layered Identities. Historic Narratives, Arctic Aesthetics, and Indigenous Agency in Canadás Anthropocene," 8.

31. Ibid, 2,11.

32. Hermann, "Layered Landscapes, Layered Identities. Historic Narratives, Arctic Aesthetics, and Indigenous Agency in Canadás Anthropocene," 10.

33. The location of the ship was known by locals, a means of knowledge that had not been accessed by the

34. A characterization that is taken on by some residents, as well (just as Robert Service did)

35. Hermann, "Layered Landscapes, Layered Identities. Historic Narratives, Arctic Aesthetics, and Indigenous Agency in Canadás Anthropocene,"

36. (Cameron on Said, 23)

37. Inim.
38. Ibid, 21

39. Re-bring this into conclusion in relation to the practices of making that I am pursuing 


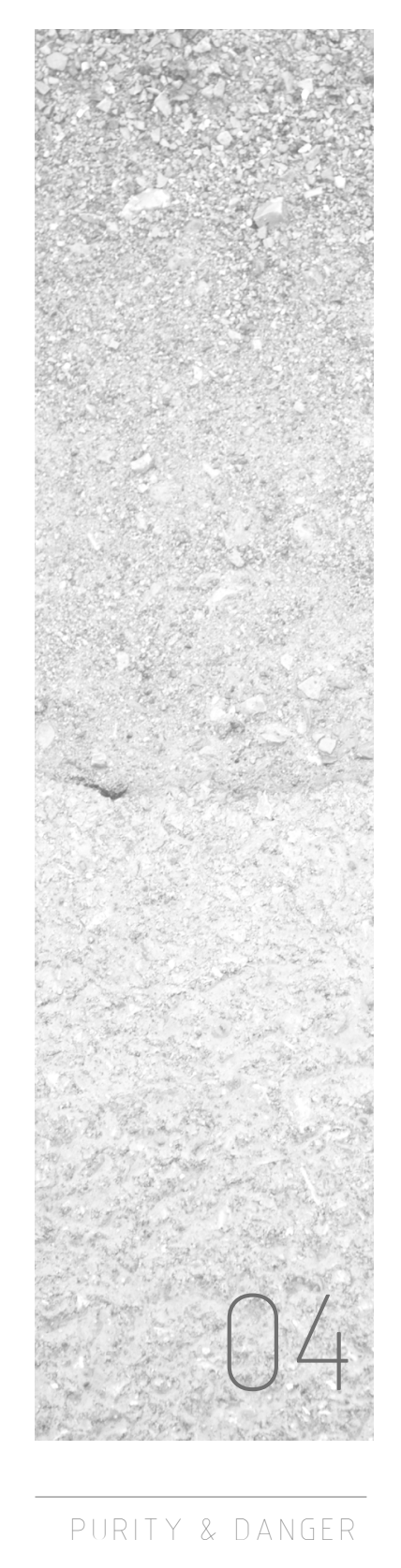




$$
\| 1
$$


In the article "Ungridable Ecologies" ethnographer and artist Natasha Meyers observes that "other [non-Western] forms of knowing, most especially local and Indigenous knowledges, are forced to make themselves legible to this rationalism," and further states that this method of clear categorization is a knowledge form that "facilitates the management of lands and bodies." Further commenting on her ethnographic work with people who partake in (Western) scientific research she states that individuals are aware of, but often tied to "the mundane ways that colonial and economizing logics still have a tenacious grip on our imaginations."

This rationalism which pervades outside the realms of laboratories maintains an undercurrent in general Western consciousness and drives the values behind information selection and presentation. I would argue that it even produces an aesthetic in the visual culture of architectural design (as well as others). It privileges "cleanliness," clean edges, clean lines, clean separations; all of which suggest control and rigor. More importantly, these visual inclinations maintain an agency. It is a bias and folly of our visual literacy and I would further argue, of our thinking, in that it sometimes eliminates or disregards information and ideas that fall outside the grids and guidelines (in process, presentation and critique). And thus it affects the development and reach of spatial literacy, which, thinking through practices of visual making. ${ }^{5}$

The ability to abstract something as a line in a design drawing often depend upon it being clearly definable in concept. At the clear edge of a category, a line is made, line becomes "road", and the road tries to be "line.". . In the case of the road, the gravel and earth built up to make it is constantly slipping out from under itself back into the surrounding landscape. The "road" is always falling out of its own category and away from the "line" that brought it into being, which attests to the ever-present translation between drawing and that which is drawn. This intimate and constant translation begs the question: to what extent do drawings reflect or construct our understandings of our environments? To what extent does the cleanliness of drawing or the clarity of lines within it perpetuate and condone the propensity for thinking within pre-existing categories, within inherited frameworks?

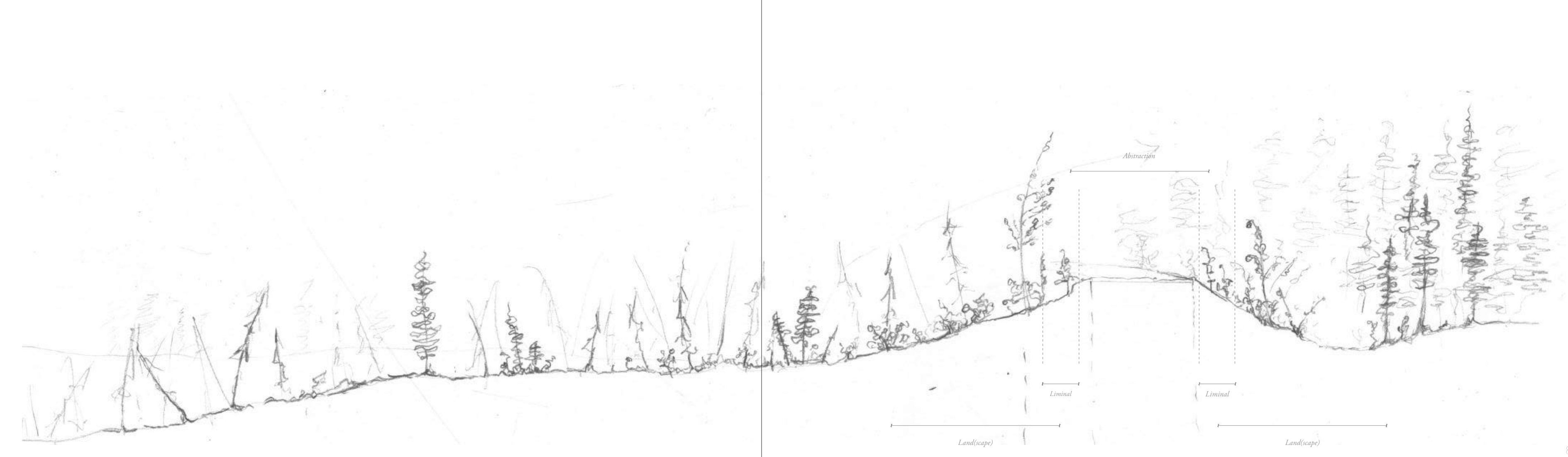




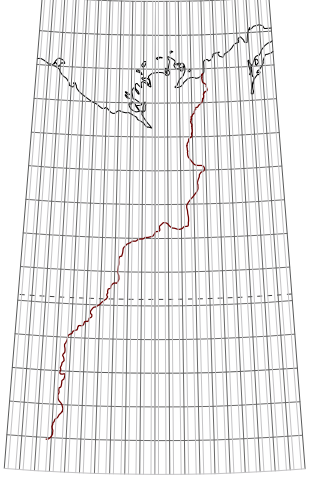

A response to these notions is a drawing that straightens the road (which itself offers an abstracted version of the landscape). Bringing order to the un-ordered the dirt surfaces of the road are documented and neatly organized. Lines that intersect the road are also collected organizing the dirt-road to hyperbolize this type of thinking as a venue of collecting lines and clear understandings of information such as ecoregions, territories, mining claims, intersecting access roads for communication towers and extraction sites.

A line reduces a form to an abstract concept of contour: the base of all mapping and architectural drawing conventions. The efficiency and empirical utility of this clarity is undeniable-but what about the information that can't be put into discreet lines, that has no pattern that can be transliterated in the marks of notations? Does that information stop existing in our consciousness and imaginations? We maintain an aversion to entropy, which Douglas also points out, is not decay, but slipping out of category. The road itself, as the site of this thesis remains a constant project as it falls away from its intended borders, slipping into the earth and is constantly re-piled and re-shaped into "road." What I would like to pursue (in the following sections of this thesis) is a fluidity between this rationalism and the mess moments of broken certitudes. Both offer valuable insights and it is the ambiguous combination of the two that seems so pertinent to this thesis.

A series of blind contour drawings were also done, based on panoramic images taken during the site visit. This drawing type focuses on contours but has interesting elements of un-naming and un-editing....I became frustrated with the lack of movement captured when the pen and switched to willow charcoal- a more 

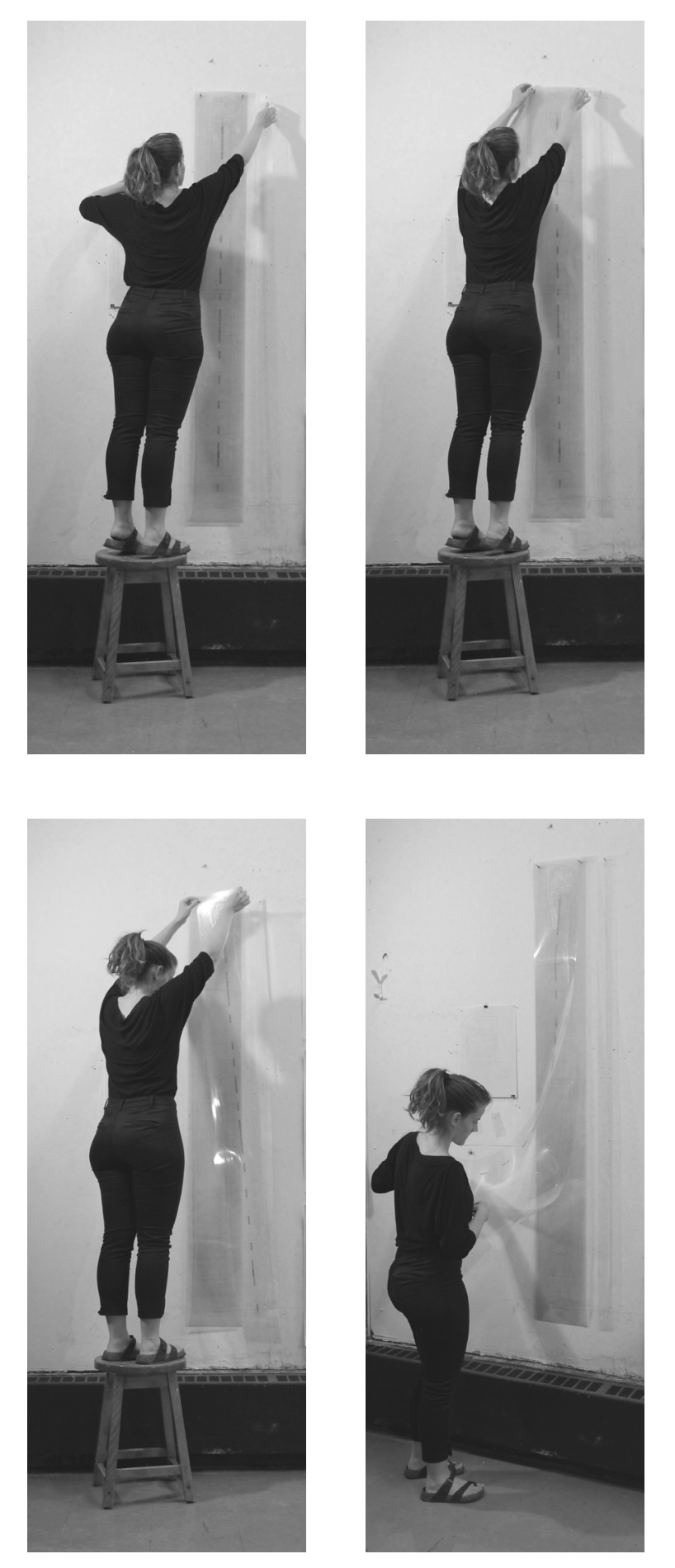

-EGEND

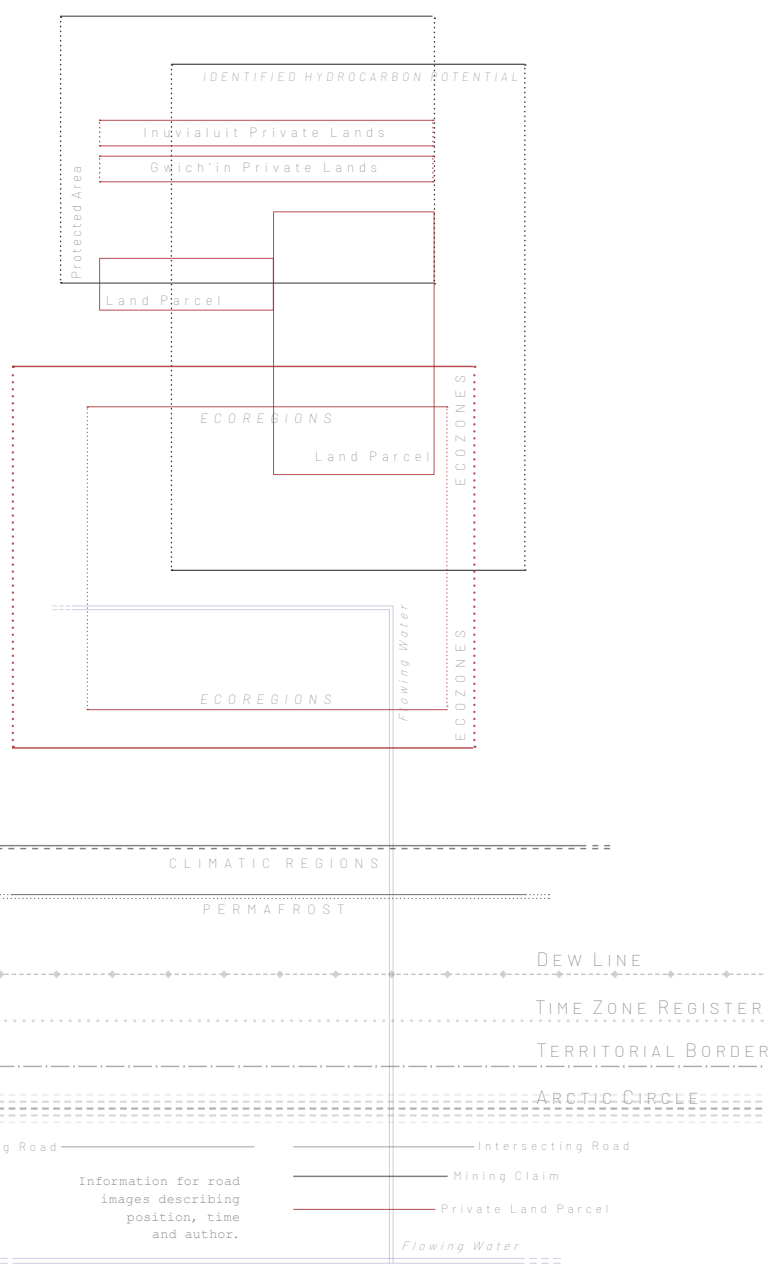




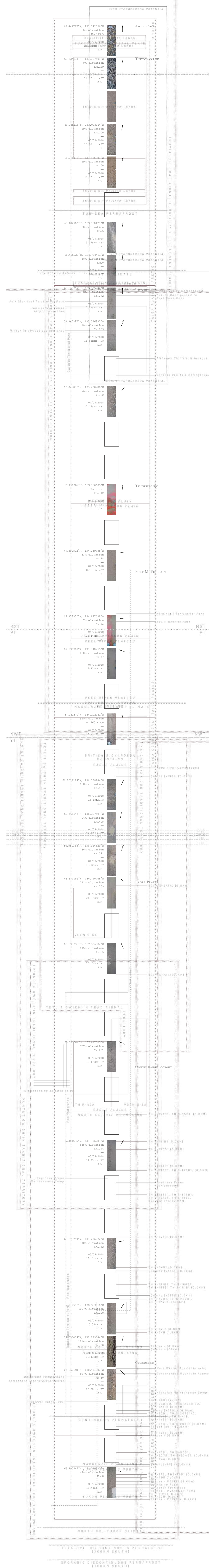



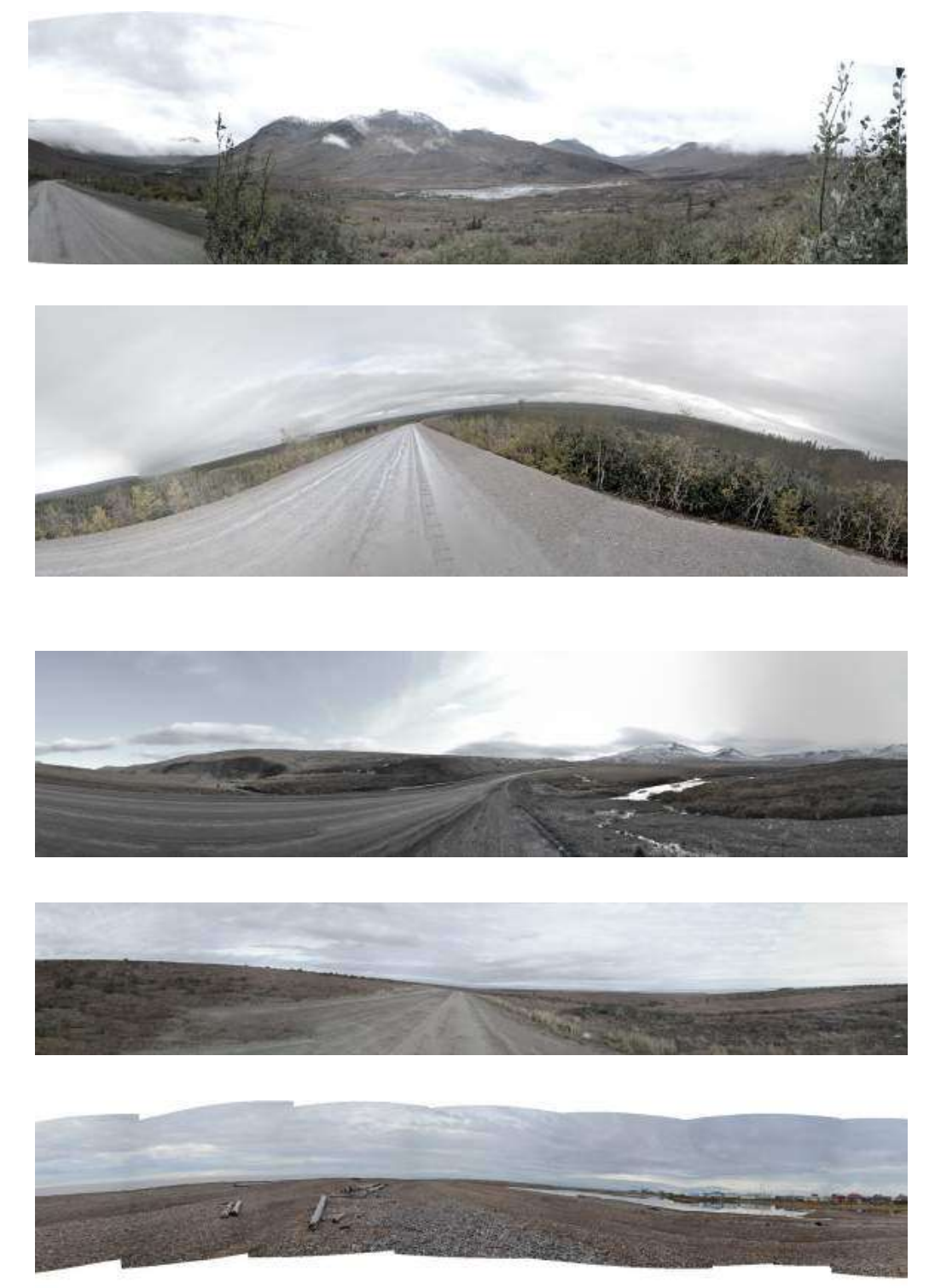

fig. 4.7
Panoramas from site which were used
for the following drawing.

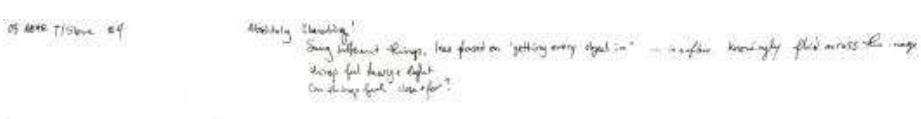

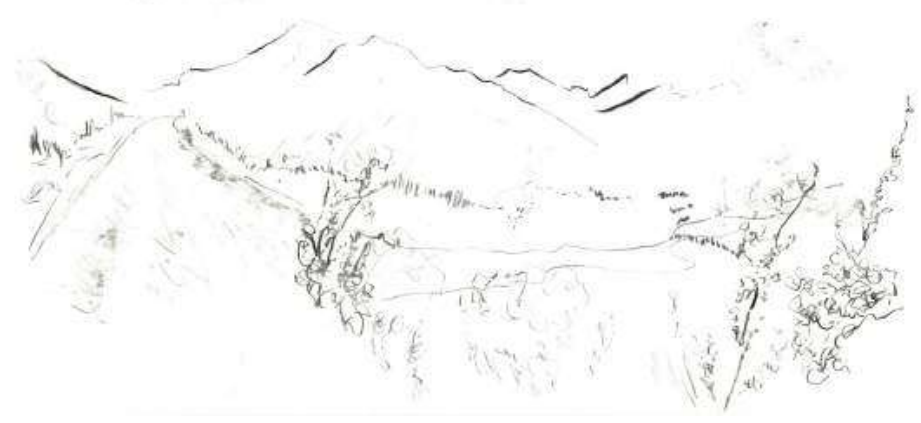

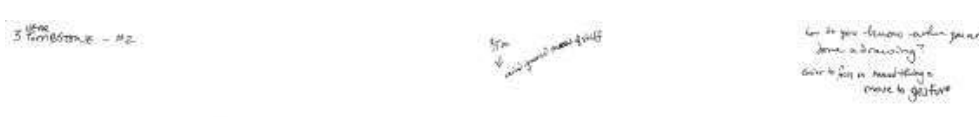

$\int_{1}^{2}$ 


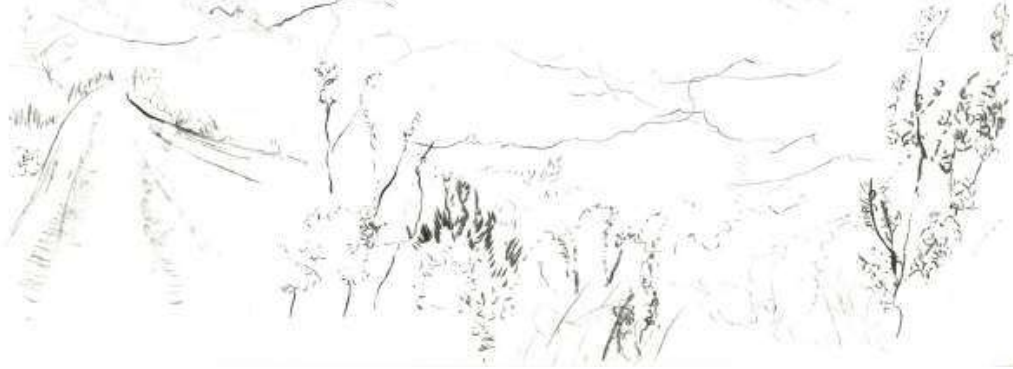

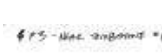

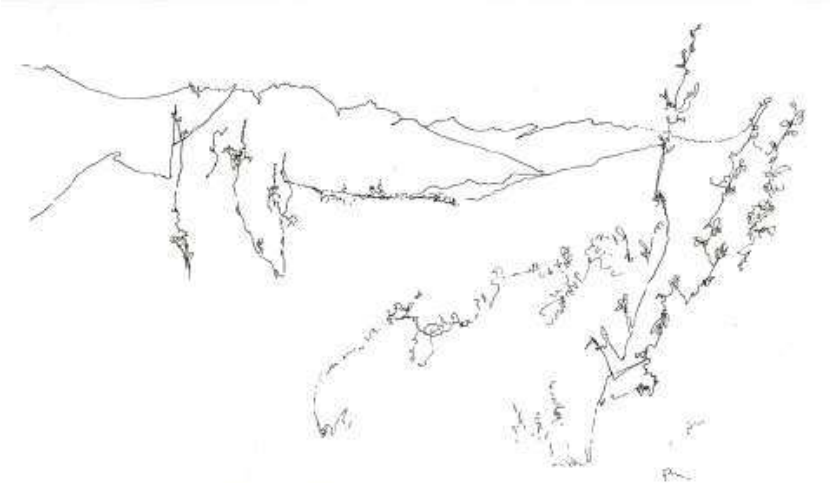

c...mos .
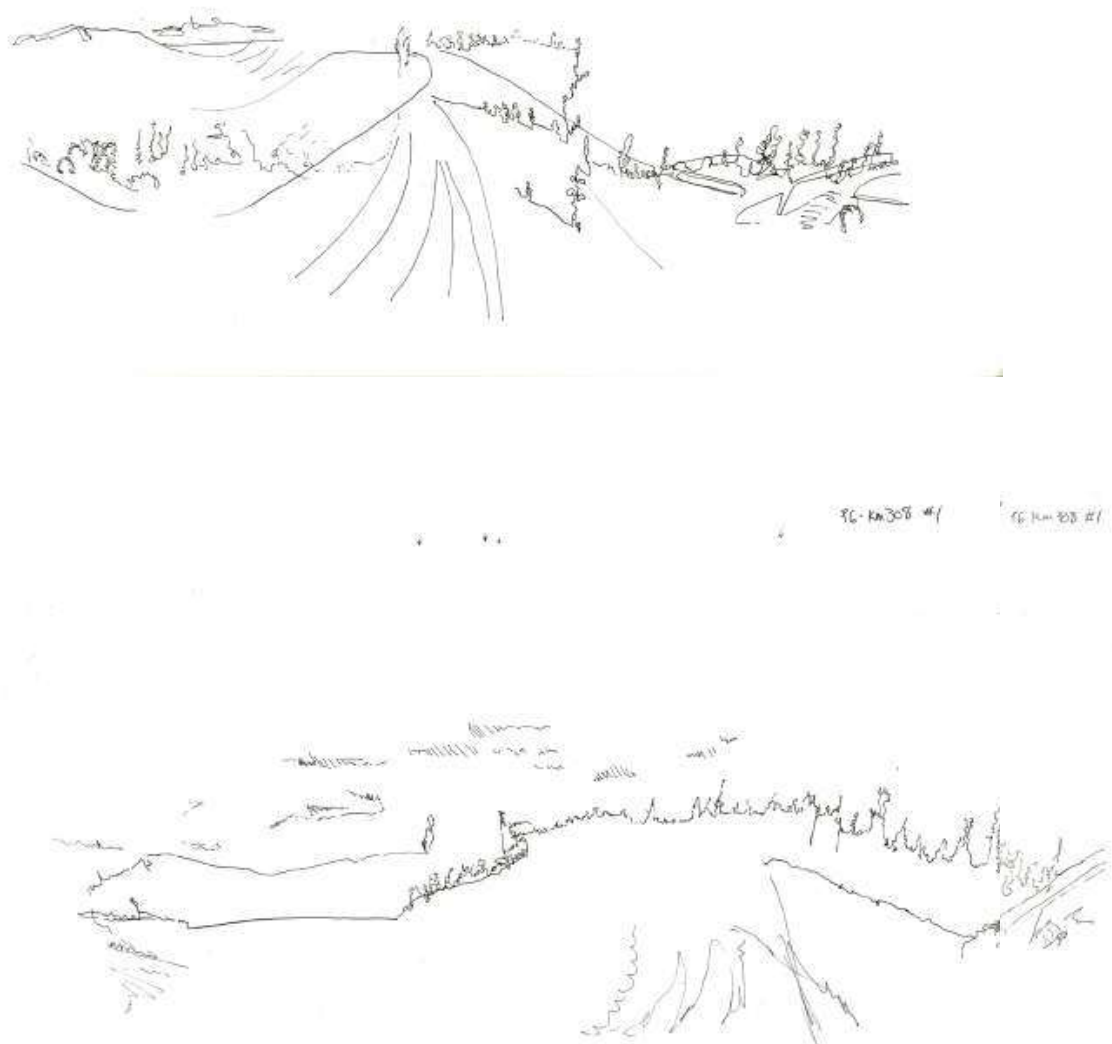

$$
\begin{aligned}
& \text { fig. } 4.10 \\
& \text { Blind contour drawings } \$ 5-6
\end{aligned}
$$




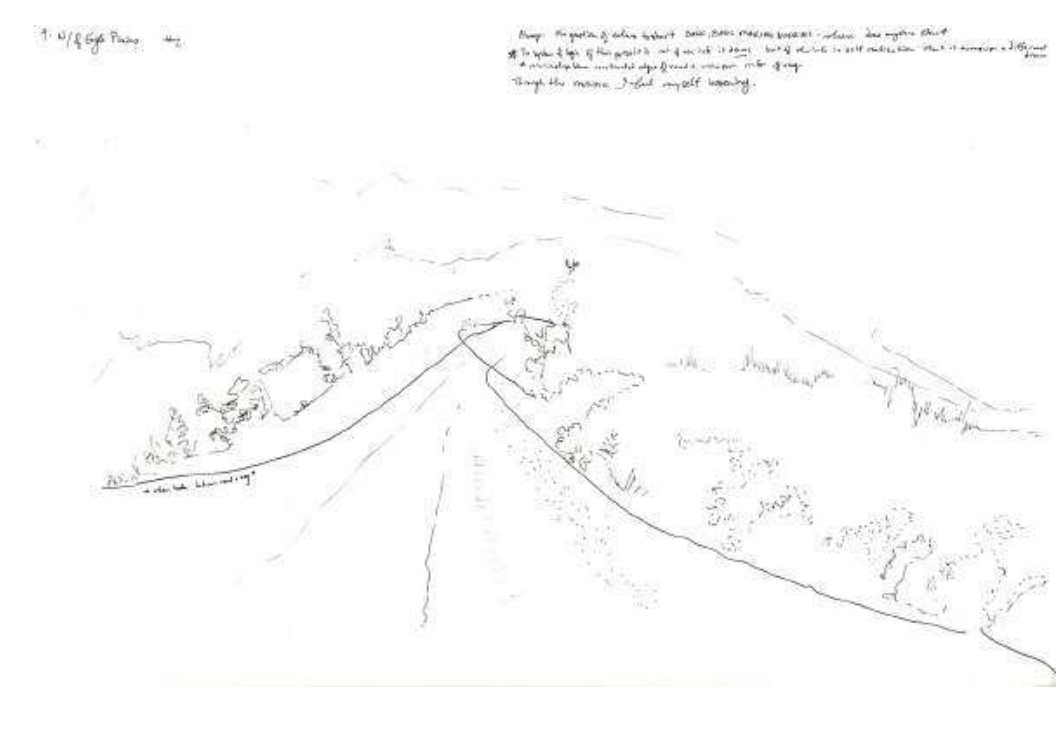

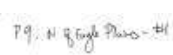

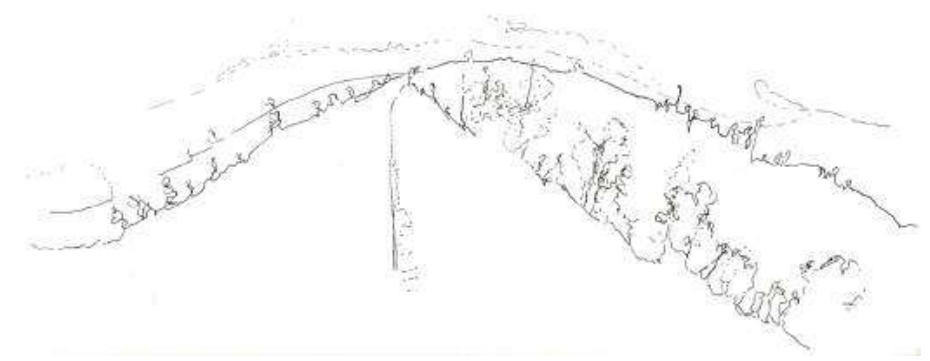

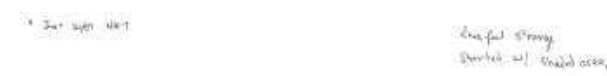

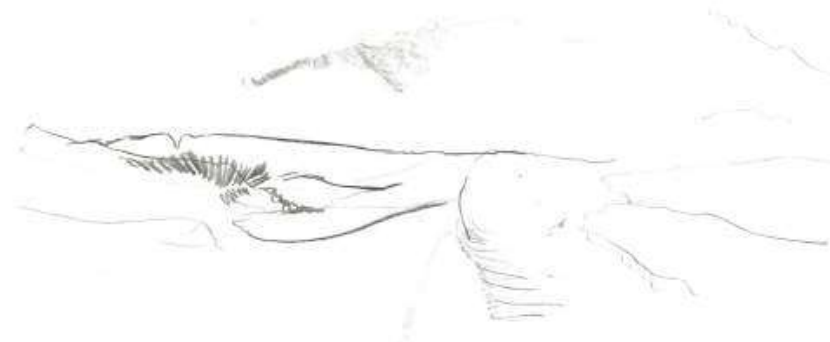

tintitherine

- 11

Blind contour drawings: $\$ 9-10$ 


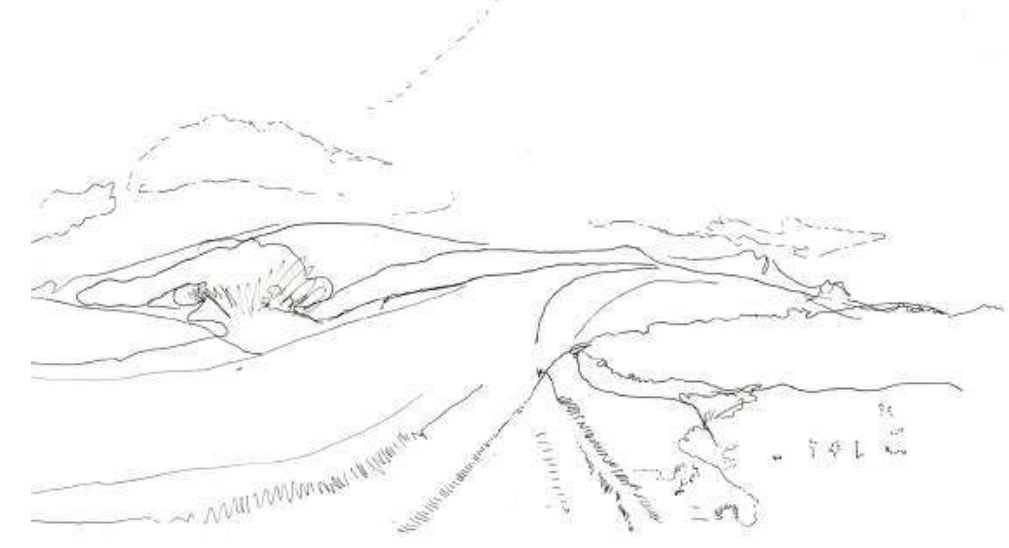

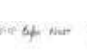
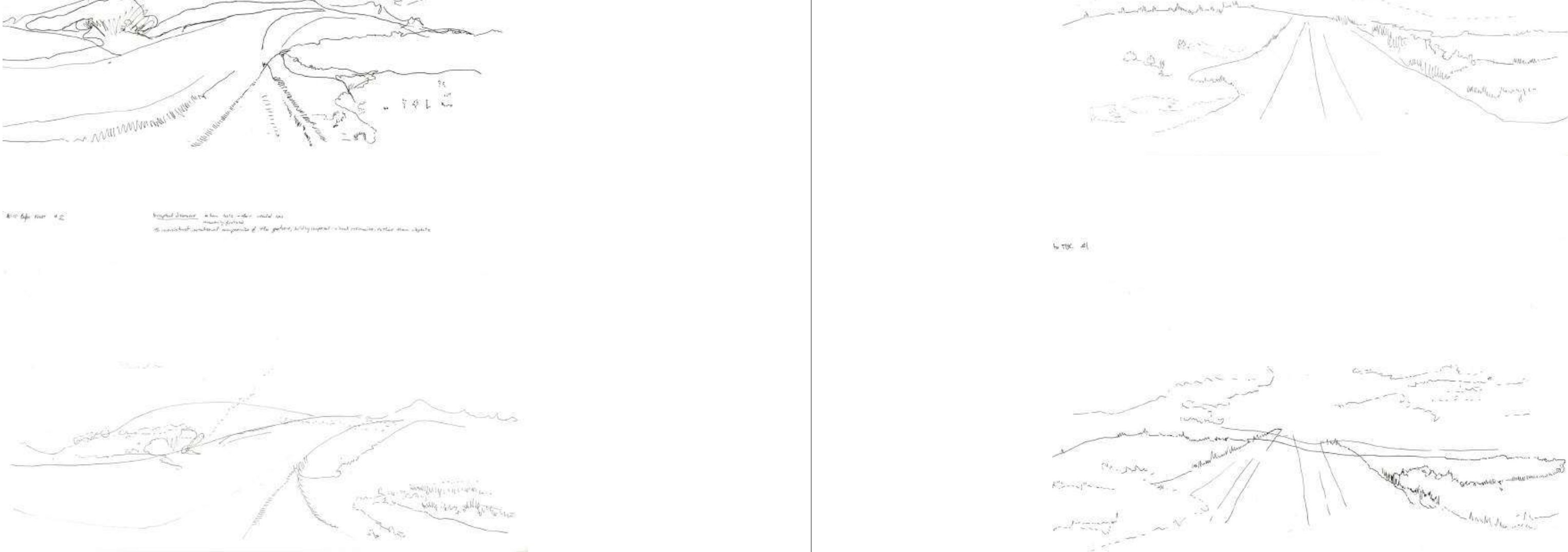
ENDNOTES

PART 3: TRACKS OF ABSTRACTION

pg $77-96$

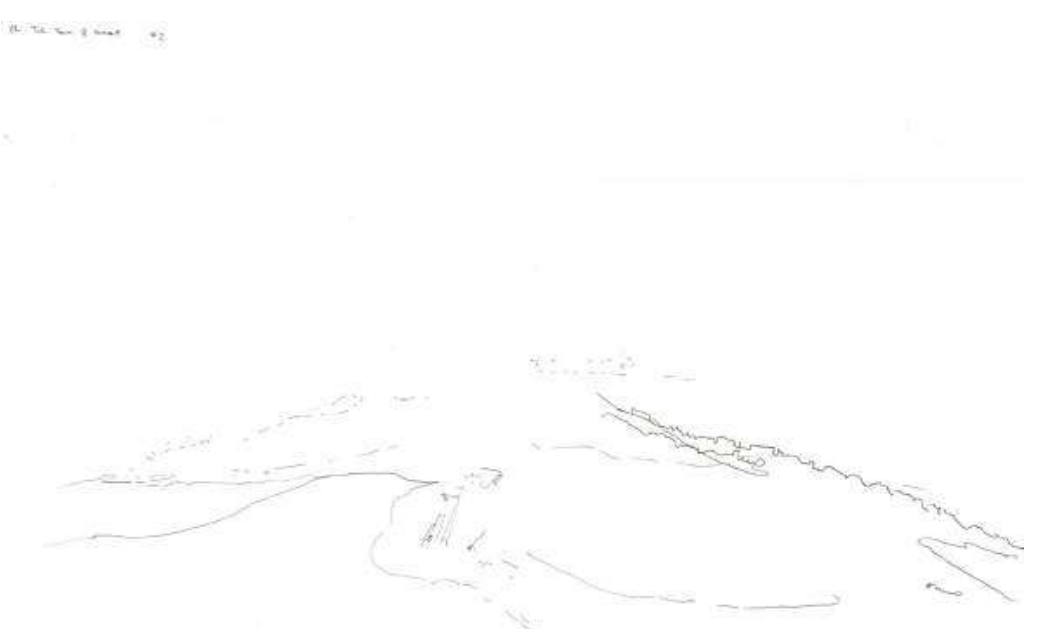

1. Mary Douglas. “Powers and Dangers." In Purity and Danger, 95-114. London: Routledge, 1966. pg95. 2. Roy Scranton. Learning to Die in the Anthropocene: Reflections on the End of a Civilization. Sa

3. Natasha Mvers. “Ungrid-Able Ecologies: Decolonizing the Ecological Sensorium in a 10,000 Year-Ord Catalyst 3, no. 2 (October 19, 2017): 2-24. https://dol.ofg/https://dold $\operatorname{org} / 10.28968 / \mathrm{cftt} . v 3 i 2.28848 . \mathrm{pg} 2$.

4. While not explicitly stated here by the author I would add a personal interpretation that "bodies" holds definition outside of buman bodies.

5. In which I include both two and three dimensional acts and objects.

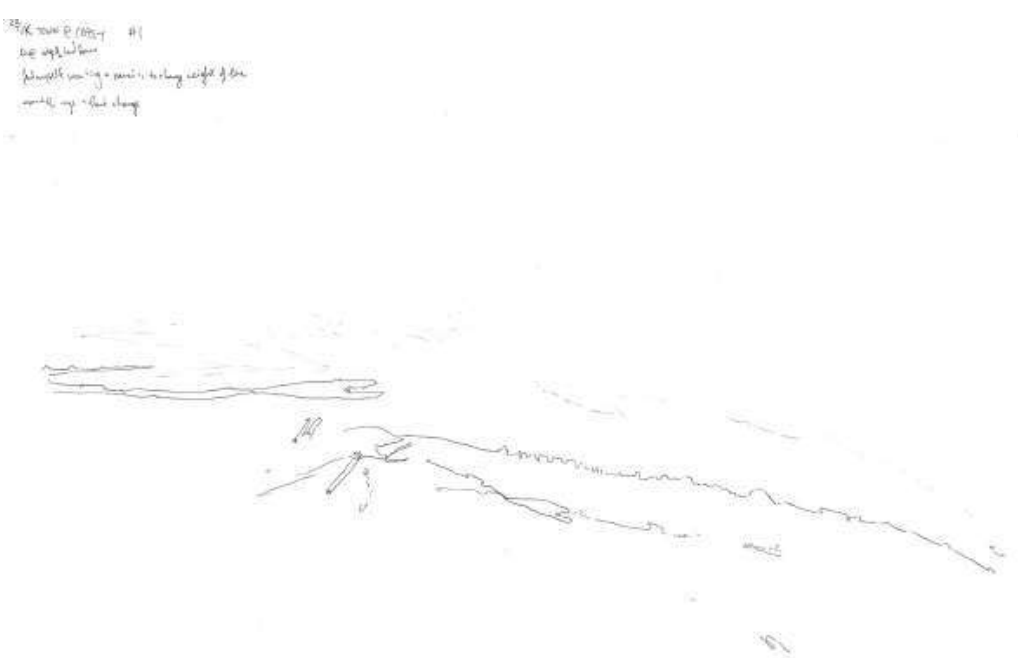




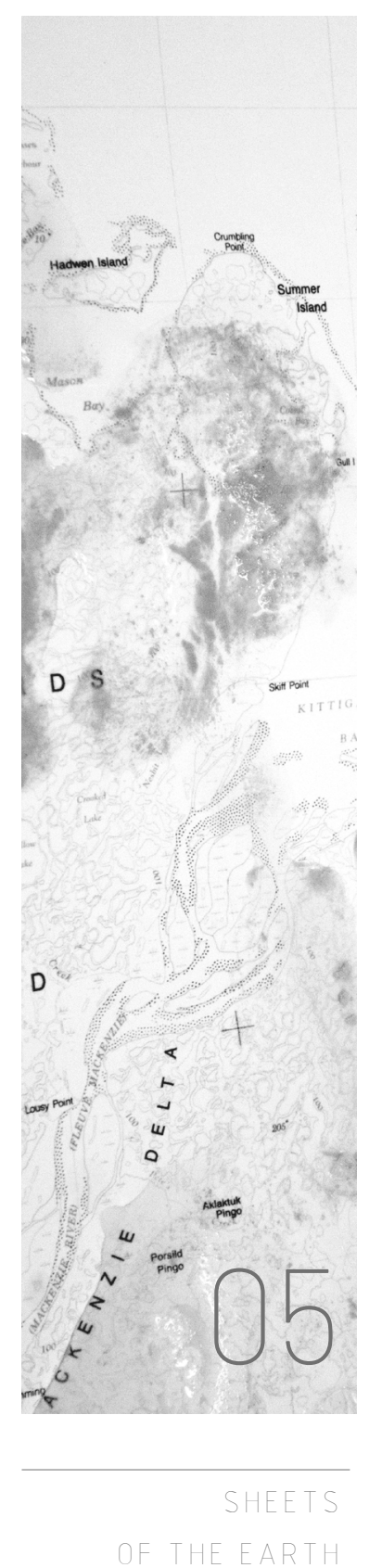


Geograbhy was teaching the native to see with an extraordinary eve, one the demanded an exceptional out of experience viewpoint and

an exceptional out of experience time.

Dilit da Cuhna Invention of River.

The word "map" derives from Latin mappa mundi, and translates, literally, as cloth o sheet of the earth. ${ }^{1}$ Maps are flat representations of three dimensional space. They impart spatial information without the necessity of physical presence, displacing both the subject (the physical space) and the sensory capacity of the human body; which, being distant, is void of sensory inputs. ${ }^{2}$ Maps position the body outside and abov the space of representation, allowing the view and associated point of authority to be held from a dislocated position. This becomes particularly consequential when maps are referenced as and assumed to be full truths while the partiality of the contained information is neglected or forgotten. Maps story spaces by privileging certain information andit is not the map itself but the agency it holds thet sobcr. or eliminates other information, perspectives and counter renditions.

Cartographic technologies are a remarkable feat of human creativity in their ability to communicate spatialities, but they are also inherently reductive and dependent on the literacies and intentions of their authors and viewers. They become edited stories of a visioned space and often form a base upon which to imagine new acts of human engagements in the imaged space. Due to their profound agency in Western hought, imagining a future different than the past necessarily requires a destabilization of the conventional acceptance of accepted authority and correctness. This destabilization is of particular importance when considering the possible futures of both decolonization and climate crisis realities.

Maps are a document of perception with an agency of assumed truthfulness. In the cartographic process, information is gathered, drawn, and can be easily corroborated by another author using the same or similar tools, rendering the outcome technically accurate only insofar as those instrument's capabilities within defined system of use. In his discussion on empiricism's under acknowledged self referential validation, Dalibor Vesely points out that scientific factualism merely 
reaffirms a process, but not the agency it claims in providing exclusive truths. He states "reality is interpreted (projected) in such a way that it can be described mathematically...[this] projection determines the facts of factual reality, and the facts in turn support the projection as a warranted conception of factual reality itself...' What in truth is merely a method and the results of that method is now taken for "real nature", nature is reduced to a mathematical manifold."

To exercise a line so measured and assured as in the act of drawing map is a convincing act of authority. It creates a product that is then able to be measured against its reference, reconfirmed with the same tools, but only ever within the system that created it. Thus it confirms the process of the system from which it comes, exhibiting a truthfulness defined only within the context of this same system. Over time, maps become official records and therefore official knowledge within settler methodologies, maintaining the jurisdiction of knowledge creation. Their maintenance acts as a venue for the perpetuation of dominant colonial epistemologies.

A map is not false, by any means, but selective, which is a detail that tends to fall away from attention. This renders cartographic productions simultaneously the accepted reality and a condoned vehicle of information exclusion, resulting in insufficient foundations upon which to imagine future possibilities of designed infrastructures and acts of habitation. This becomes particularly important in regard to mapping the North simply because the conventions of mapping were developed by individuals with ecological understandings that didn't include important local phenomena. Here lies a mismatch between the projection of space and the space itself. Whereas maps of the North often delineate land from water with a single line, what is lost are important features such as sea ice, lake ice, or solid rivers. Fluctuating water densities on the horizontal plane such as these are crucial phenomena to the habitation, navigation, spatial engagement and livelihood of locals.

The practice of mapping is an inherently non-liminal pursuit; it projects 2 static certainty omitting the reality of changing terrain, of seasonally fluxing physicalities, and of information between existing categorical possibilities. Treating land as a set of discrete values was instrumental for colonial acts because, as architect and author Leopold Lambert describes "blurry edges of territories...were not amenable to the control of resources and people." $\mathrm{Map}$ lines are drawn as indicators of vertical, material and conceptual change. They indicate edges and boundaries, and are abstractions understood within a system of communication which, in turn, inform spatial imaginaries, and later, the acts that follow

Maps, as drawn abstractions, inherently but perhaps not necessarily diminish a material understanding of space. In his discussions of the Western conceptual understandings of rivers, da Cunha suggests that 'river' is based on the map lines that have been chosen to delineate it. Annual fluctuations of this wate volume flood the river, where "flood" is the abnormal state, despite this volumatic flux being regular and therefore anticipatable. This suggests that we understand wate bodies not for the dynamic states or fluxing volumes that they are, but for their markability with lines on a sheet. A Western understanding of water bodies is based on our ability to draw them, as on a map, define them, as at an edge, creating a static delineation of a non static entity. In this way, linework constructs understandings of space, functioning in a manner outside of, but due to, "representation".

$\mathrm{Da}$ Cunha brings to light the functionality of map lines in their ability to create a hierarchical understanding of space. Specifically, this understanding is in regard to water densities, the imagined boundaries of water bodies, as well as thei separation from unsubmerged land. He illustrates this point through connecting descriptive traits of rivers with their cartographic demarcation. He states:

Rivers do not cease to exist when they are without water. It is accepted that they 'run dry,' some seasonally, some exceptionally. What remains is a space between lines which continues to be seen and enforced as a 'river' or a 'river bed,' suggesting that it is the line more than the water that is essential to rivers. 1 'flows' even when waters do not... There is then an art to seing and experiencing a river. It involves drawing a line between land and water on the earth surface. It also involves a choice of time when water is not precipitating, seeping, soaking air, soil and vegetation, collecting in interstices, pores, terraces, cisterns, and aquifers, evaporating, and transpiring in ways that defy delineation.

Further toward the conspicuousness of lines and rivers is that rivers are known to be fed by rain and melting snow and ice from across, through and over ground planes yet a river's 'source' is traced back, as far as possible, to the beginning of a line (the headwater). ${ }^{6}$ Having privileged one moment of the hydrologic cycle disfavors others As da Cunha states, water in the moments of dense liquidity have been "granted the status of residents" while vapour, rain, humidity, and snow, "are seen as visitors." I would add here that moments of dense solidity of water - ice - have also been disfavored in cartographic communications, eliminating entire ground planes as is the case in areas where rivers lakes and oceans freeze. Just as the surface of paper is a receptacle for lines marking out ideas, the imagined surface of the earth is receptacle in the cartographies of our imaginations. 
She imagined delicately dragging the instrument along river banks, looping around lake edges and spreading at the coast. She became dirzy with the thought of circling mountains, offsetting lines of elevation to describe the topography of the terrain. She wanted the perfect map of a place, wanted to do it justice with a grand and committed gesture. It was the idea of the place itself becoming its own canvas that enticed her, for the land to be the receptacle of the carefull lines that trived to capture it

As she made the map the lines began to disappear, it was a map that could never be whole. The rain softened road edges, rivers shiffed with the seasons and mountain faces fell in rockssides. And with this she was bappy, because the lines belonged to the moments that held them, and to the places that bestowed them.

And in a frenzy y of notational convullions she ses

the fragility and futility

of inscription 

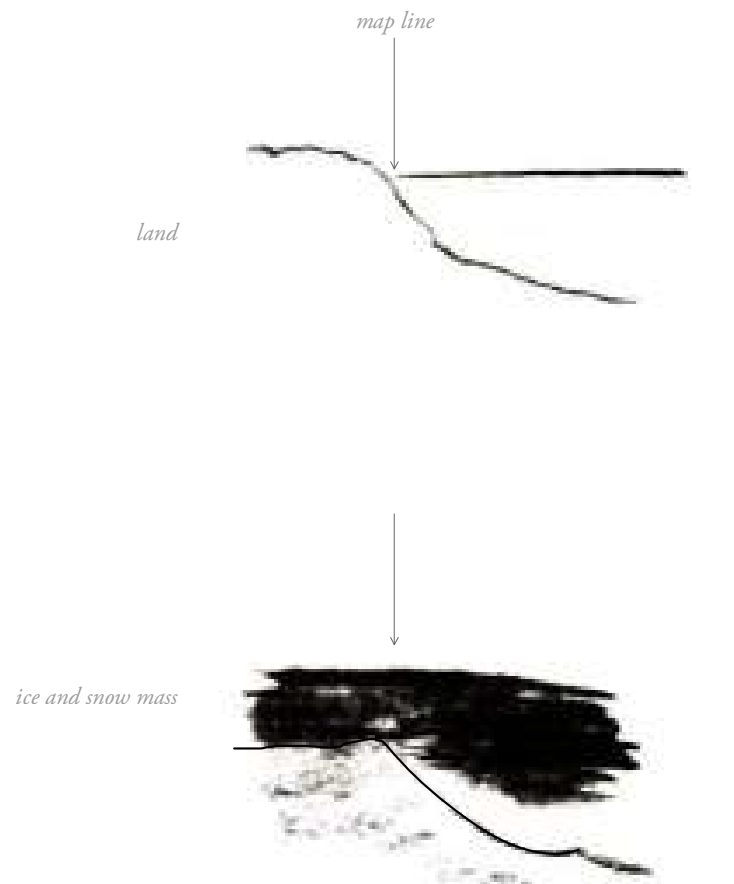

$+\infty$

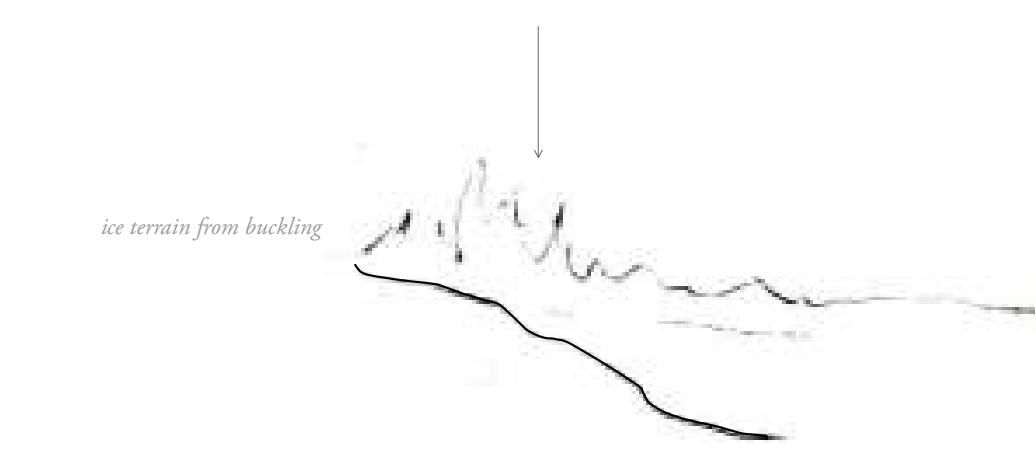

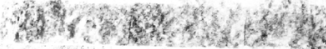

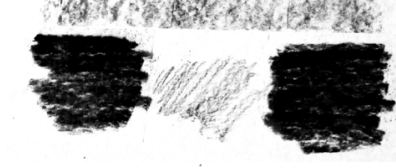

There was a point in time when the northern reaches of the continent remained uncertain in both the documents and cartographic consciousness of Europea settlers - leaving blank spaces on maps and inspiring cultural resolve to defeat the unknown. Emilie Cameron cites the mid to late eighteenth century as a period of time in which the polar reaches of the continent were being pursued with great interest in search of the Northwest Passage. At the time, there was a common belief that ocean water could not freeze, that all ice floating on salty waters had formed from fresh water and slipped away from its origin on land. ${ }^{8}$ This strengthened hope that a clear sailing passage north of the continent existed. Not only did this fuel the already highly motivated interests of pursuing such a passage, but could have also contributed to the conventional method of drawing icy places on maps, which is to exclude the fluxing frozen-ness (a frequent ground plane of solid ice over water) in favor of depicting unsubmerged land. This creates an image that, for this region, is one of a perpetually summer condition, or perhaps an unanticipated foreshadowing of its future melt.

The intelligence imbued in the map as an object disfavors fundamental realities necessary for understanding regional material conditions that affect spatial habitation and culture. These objects carry this preference, and a misrepresentatio remains present and dominant even in maps that loosely draw approximated seasonal ice extents, specifically because this information is secondary in its application on a conventional summer condition basemap. In this case, the changing ice edge becomes subordinate or alternate to the accepted norm of static delineation between "solid" land and liquid water and thus, an entire ground plane is omitted from primary representation. How is one to imagine, believe or conceive of icy habitations if their trusted reference, does not reference it?

Where da Cunha has argued that mapping conventions prioritize a moment of non-precipitation, I borrow and redirect his concept, in that it also prioritize the non-frozen. Through the act of mapping, a moving and changing body becomes known as a singular static possibility based on a chosen time frame, during a chosen

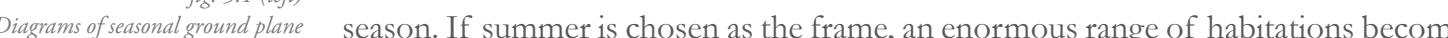
at which mapp lines are drawunn. invisible. For example, in the moment of frozen rivers, seas and lakes, the surface 
of land and water form a continuous solidity to extend a habitable ground plane. And even though this ground plane, which crosses the drawn boundaries between land and water (the majority of time in some areas), the solid land and liquid wate drawing typology was and is still the main conventional mapping articulation of frequently frozen spaces. If a "sheet of the earth" is meant to depict the surface of the globe (the ground planes), it is curious that one, or many, could be missing. It might even be that this understanding of water and habitable surface has its roots in the non-frozen regions of the globe and has been imposed, in a very colonia manner, onto frozen terrains. This results in a missing plane upon which to recognize or imagine human activities such as those of Indigenous peoples. And through the act of mark making, reality and possibility are created in parallel, as may or may not be welcomed. Maps, as objects that contribute to the telling, communicating and torying of a region, function outside their intended empirical utility because of the socially consequential material misunderstandings that relate to human habitation

Despite this, they maintain epistemological authority due to having been rendered in the form of map; enforcing perception and molding spatial awareness.

It is interesting to note the paradox between the same mapped region and other imaginaries that describe it as perpetually cold, icy and white and that a recognition for the planes of ice becomes recognized and mapped in relation to transportation visions of ice roads and are credited as feats of engineering and bravery, despite being a norm for centuries. The ice is tamed through calculations an the ground plane is altered to suit the needs of extraction operations, conveniently doubling as a gesture of social care for remote communities.
This is a story about a place where I used to live

Yet simullaneously bave never lived

Depending on the scale with which we reference it.

But it comes back to me in memories

In rusches and waves of silty snow melt harmonies

Watersheds

Rough delicate lichens

Caribou mothers

And purple mountains

And it comes back to me in temperate notions

In chilled and soggy soils, frosted summers, a frozen oceen

With solid water access

Expanding colder ground plane.

And earthy mounding beaves

Predicting summer travel domaines

And the water

Always

Changing 


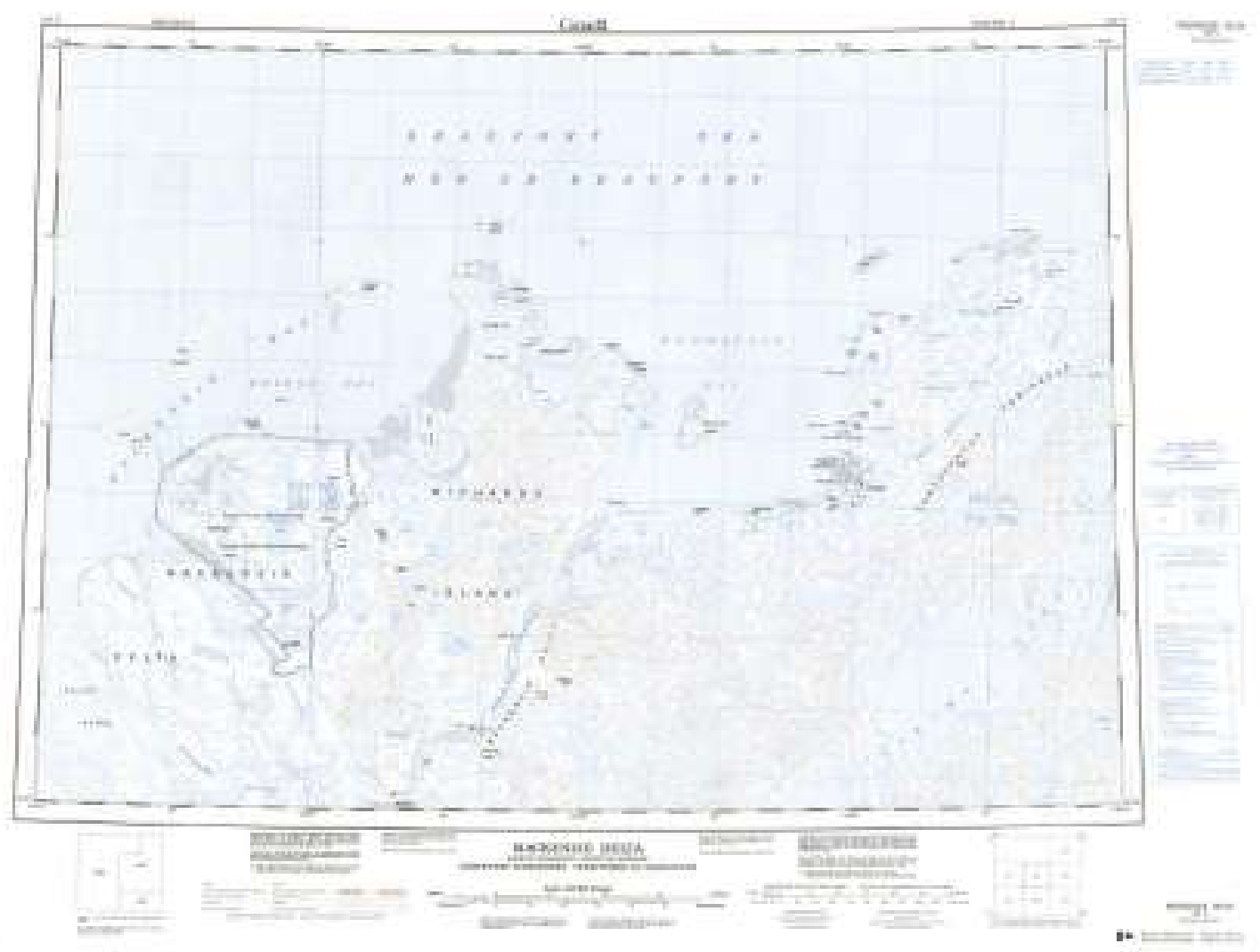

The following exercises are in response to the neglect of material conditions in cartographic base maps as well as aerial and satellite base imagery. It uses the notio that map and aerial or satellite information inform architectural vernaculars of understanding site, both two dimensional and three dimensional and investigates possibilities of destabilizing learned viewing as well as acts of authorship in making, giving more priority to frozen waters and their changing states, allowing them to collaborate in the making.I borrow again, from Natasha Meyers when she says "Art can alter how we sense, feel, and know; arts based inquiry can expose and subvert the colonial ecological sensorium, and in the process, open up perceptions of morethan-human worlds."

The first exercise uses official governmental maps of the site and informs them with a process of melting ice, as is present in the physical site. The act of melting ice shifts and morphs the clear lines of measure on the map and leave behind its own marks. In this way, scaled phenomena from the site (melting ice) disrupts the certitude, static quality of measured lines.

The second exercise continues with the notion of scaled phenomen in a more collaborative way, engaging non human elements of water in differen states to co-author a story of site. It explores a series of modeling materials a they respond to levels of wetness, at different temperatures, allowing moments of broken certitude to be rich informants where particles and liquids are recording the moments and processes of water changing states, whether its flakes of plaster lifting to meet melting ice or the ripples of cooling wax incrementally melting a frozen surface. Patterns of glycerin describe the moment of ice melt, flakes of dusty plaster particles respond to the changing states of water from solid to liquid to vapour and wax responds to the thresholds between loose and packed snow. The intention here is to build a vocabulary of model making that allows for scaled phenomena to be collaborative partners in acts that investigate site (ie. modelling). Instead of cleat lines of certitude, what might the less patterned marks of relevant phenomena be? How might we begin to visulize moments of fluctuation that are absent on maps, but present on site?

The marks become patterns and densities-the non-lines. 

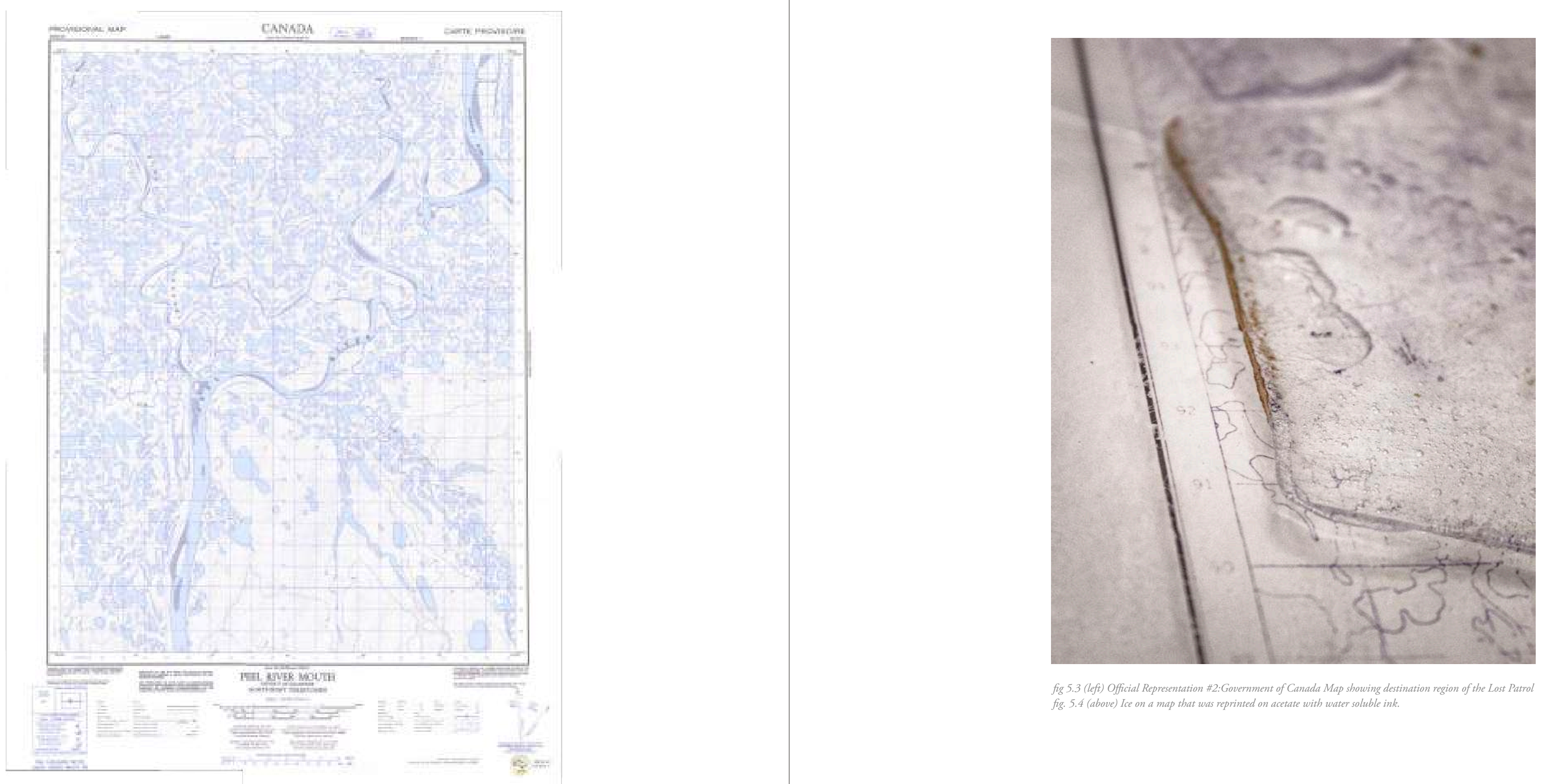

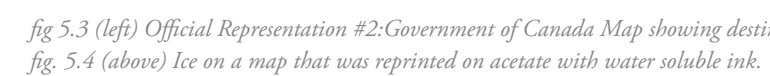



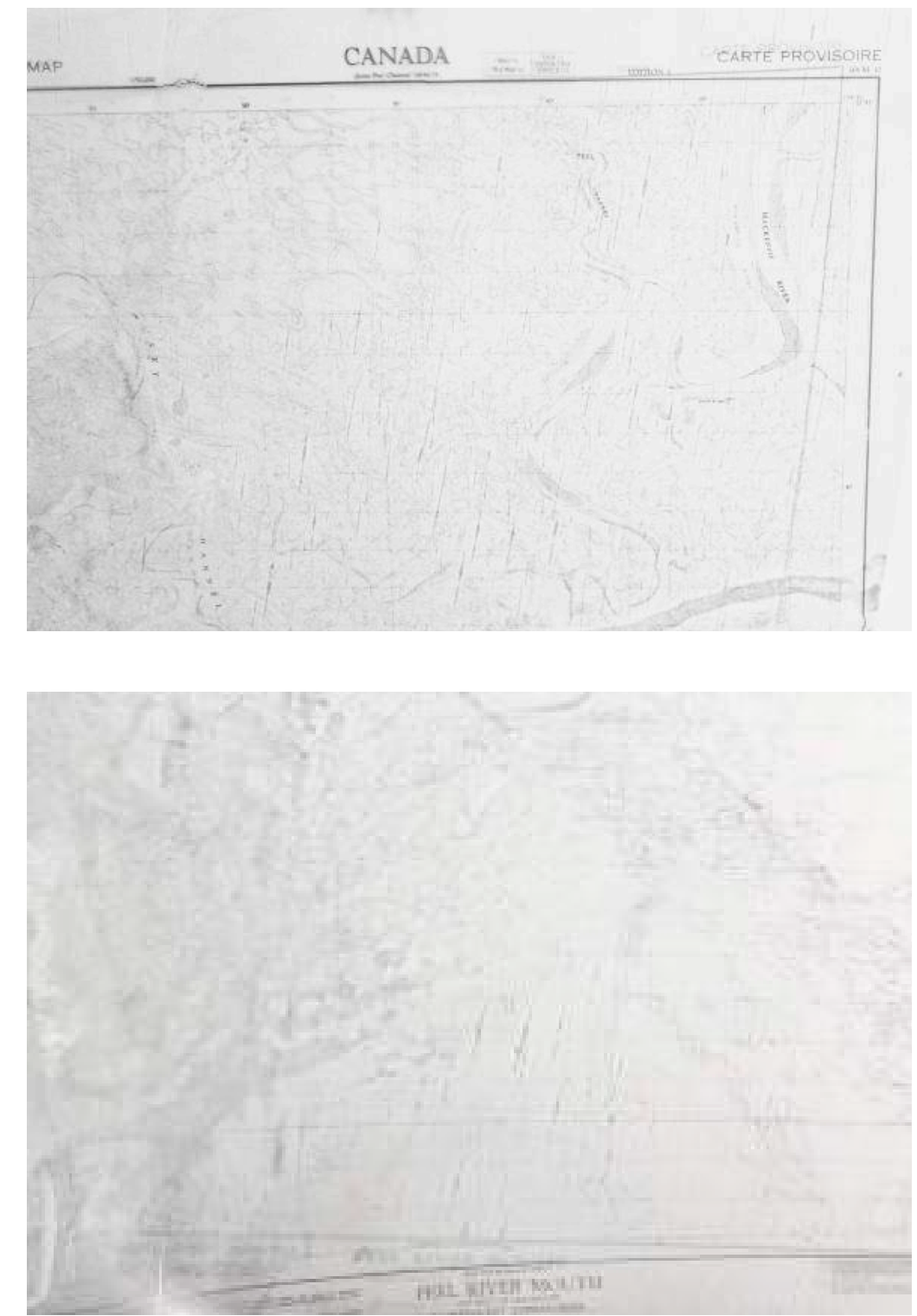

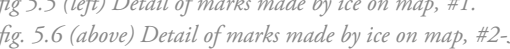




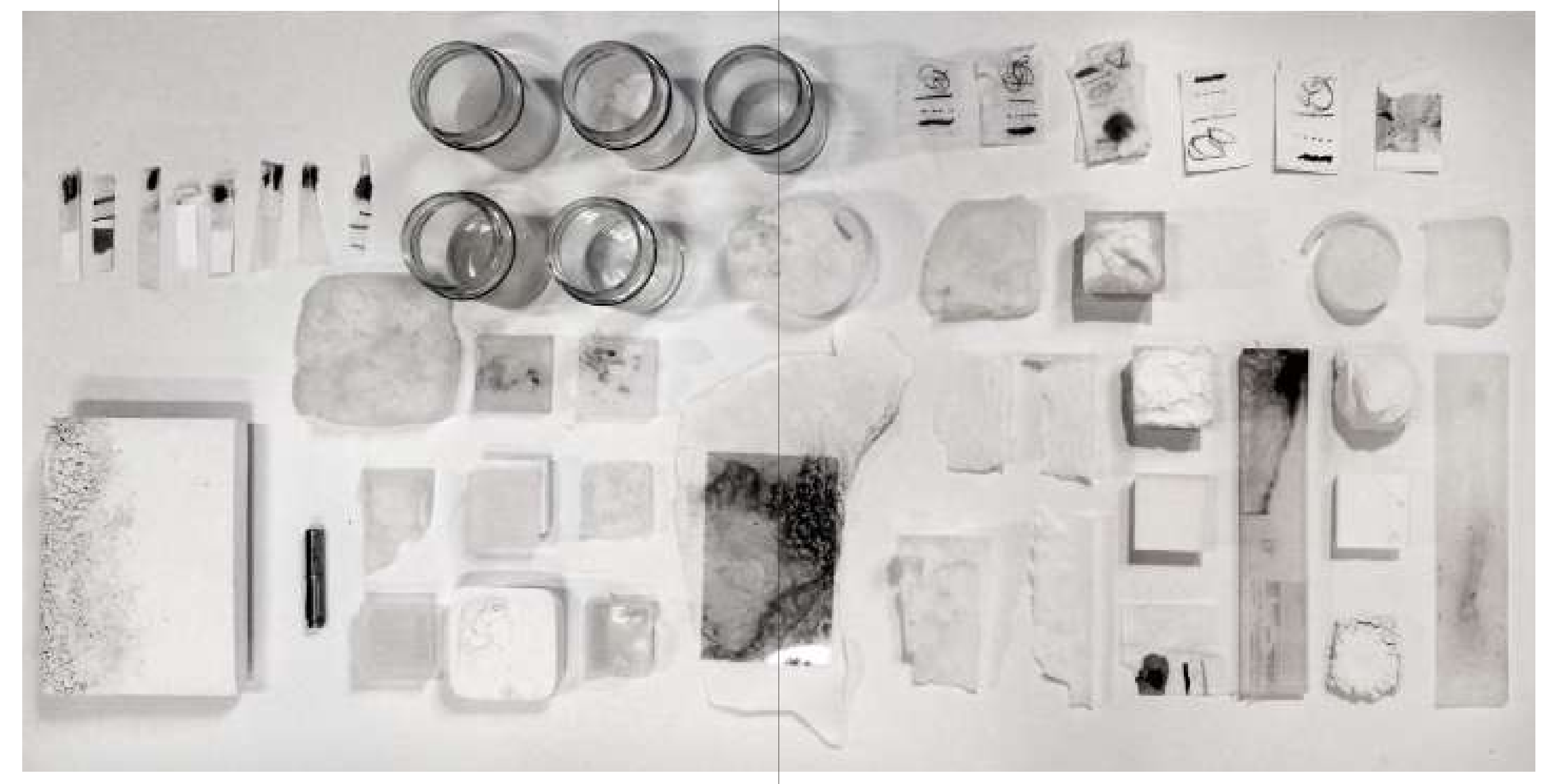

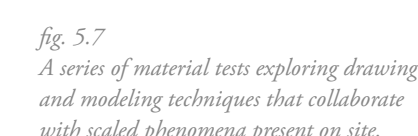



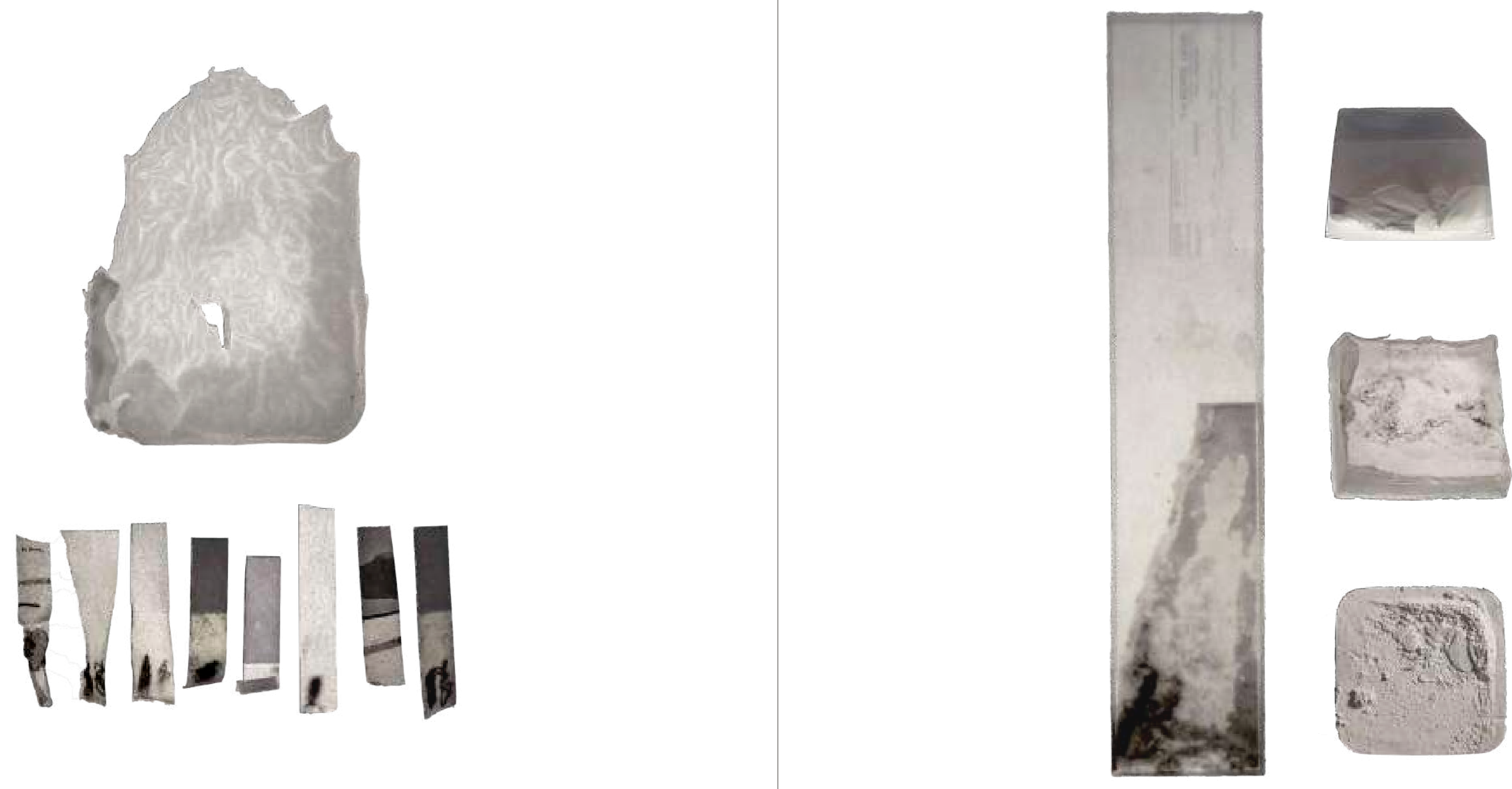

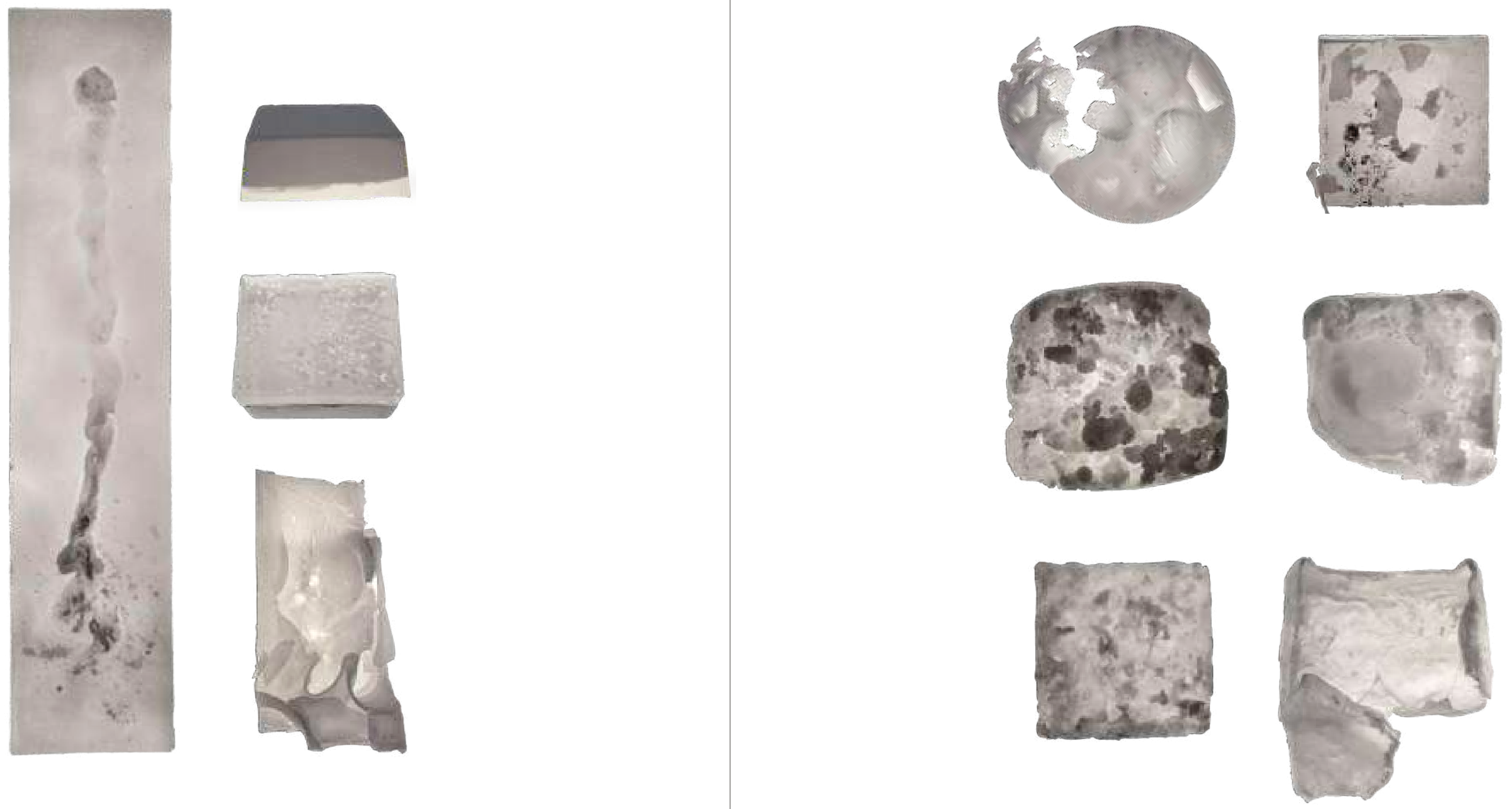

fig. 5.10: Material Tests \#3. hot wax in ice substitute (long), wax on liquid plaster (top), glycerine on setting plaser, perspiring with moisture (middle), hot wax on

fig. 5.11: Material Tests \#4: (from top left, reading left to right), hot wax in ice snow, hot wax in packed snow, wax and plaster powder mix, hot glycerine on ice 

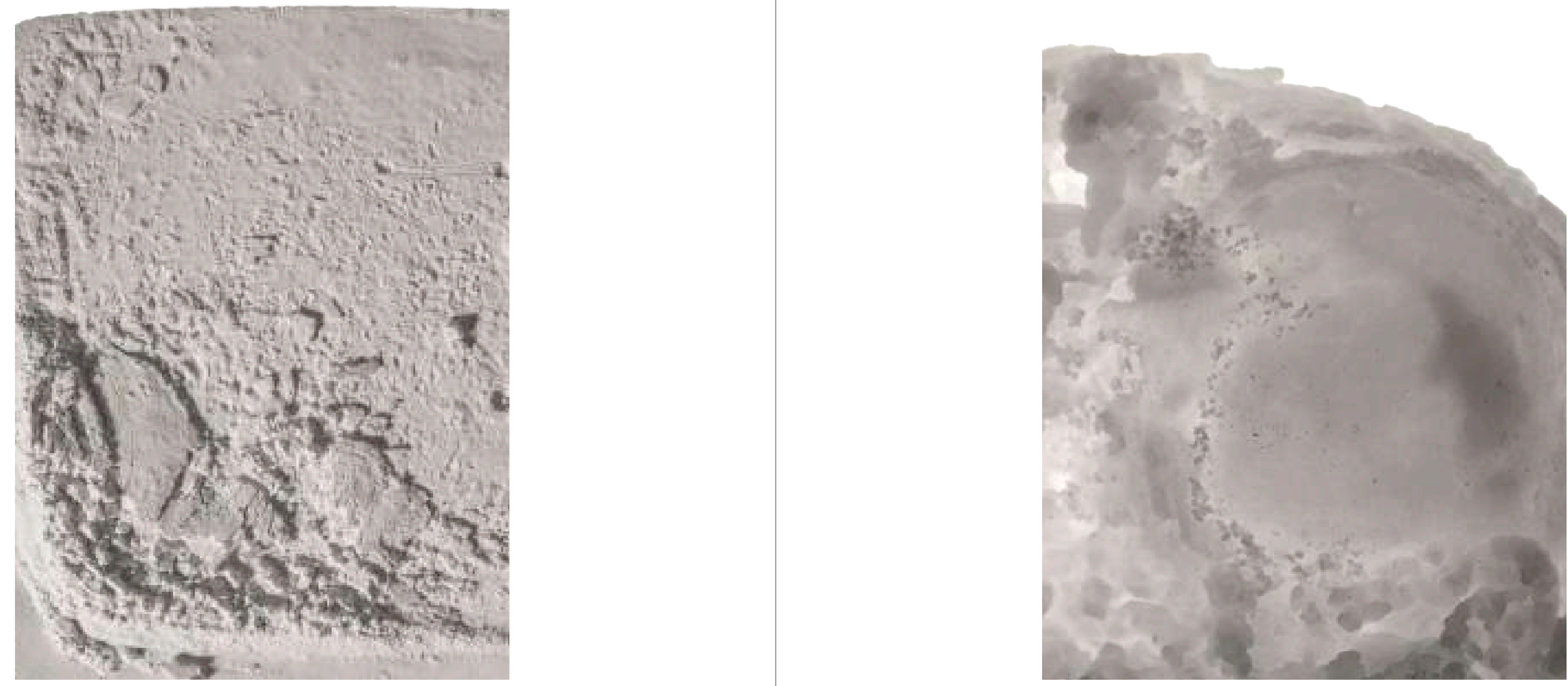

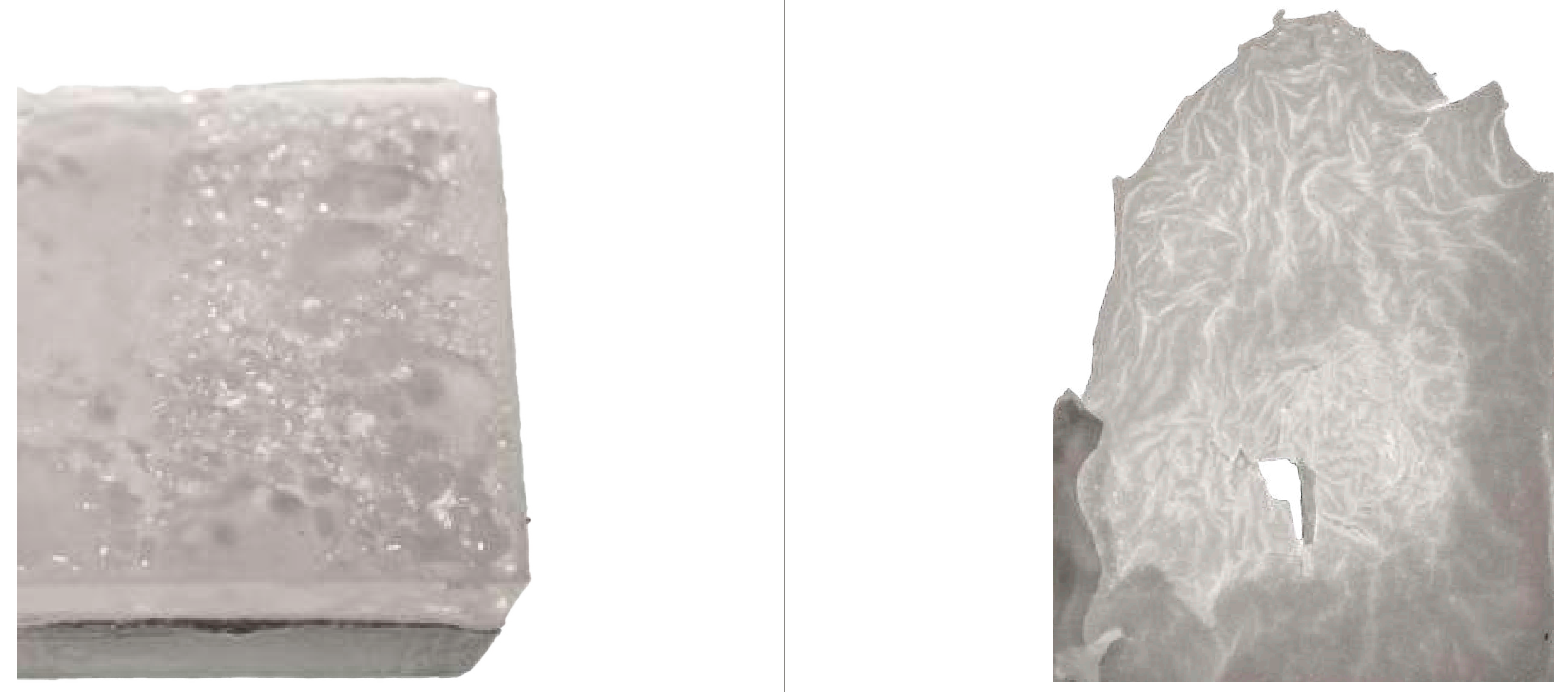
ENDNOTES

PART 5: SHEETS OF THE EARTH

pg $99-126$

1. Douglas Harper. “Map (n.).” etymonline, 2019. https:///www.etymonline.com/word/sense

2. Being distant, the body is void of sensory input from the site

3. Vesely, Dalibor. “Architecture and the Conflict of Representation.” AA Files, No.8, 1985, 21-38. pg 22

4. Lambert, Leopold. "Introduction: Cartography \& Power." Funambulist, no.18, 2018. Accessed December 2018. https://thefunambulist.net/articles/introduction-cartography-power

5. Dilip da Cunha. Invention of Rivers: Alexander's Eye and Gangas Descent. Philadelphia PA: University of Pennsylvania

6. Ibid, $4-5$

7. Ibid, 5 .

8. David I. Nicandri. Arctic Ambitions: Captatin Cooke and the Nortthwest Passagee. Washington: University of Washington Press. 2015. pg 120. To clarify, ocean water freezes at $-1.8 C$, due to the salt particles that

7. Natasha Myers. “"Ungrid-Able Ecologies: Decolonizing the Ecological Sensorium in a 10,000 Year-Old NaturalCultural Happening." pg 4 


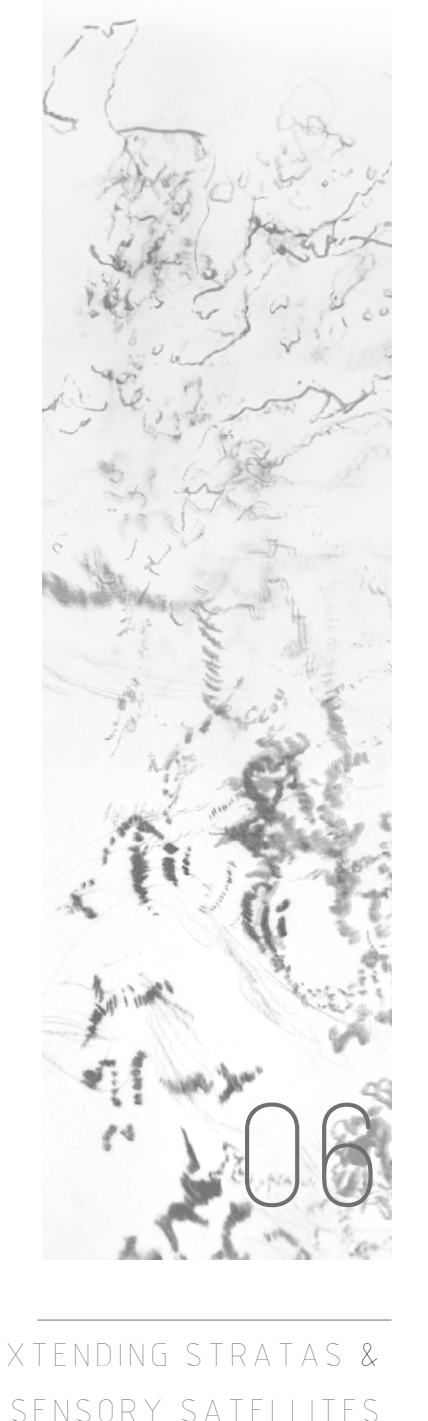




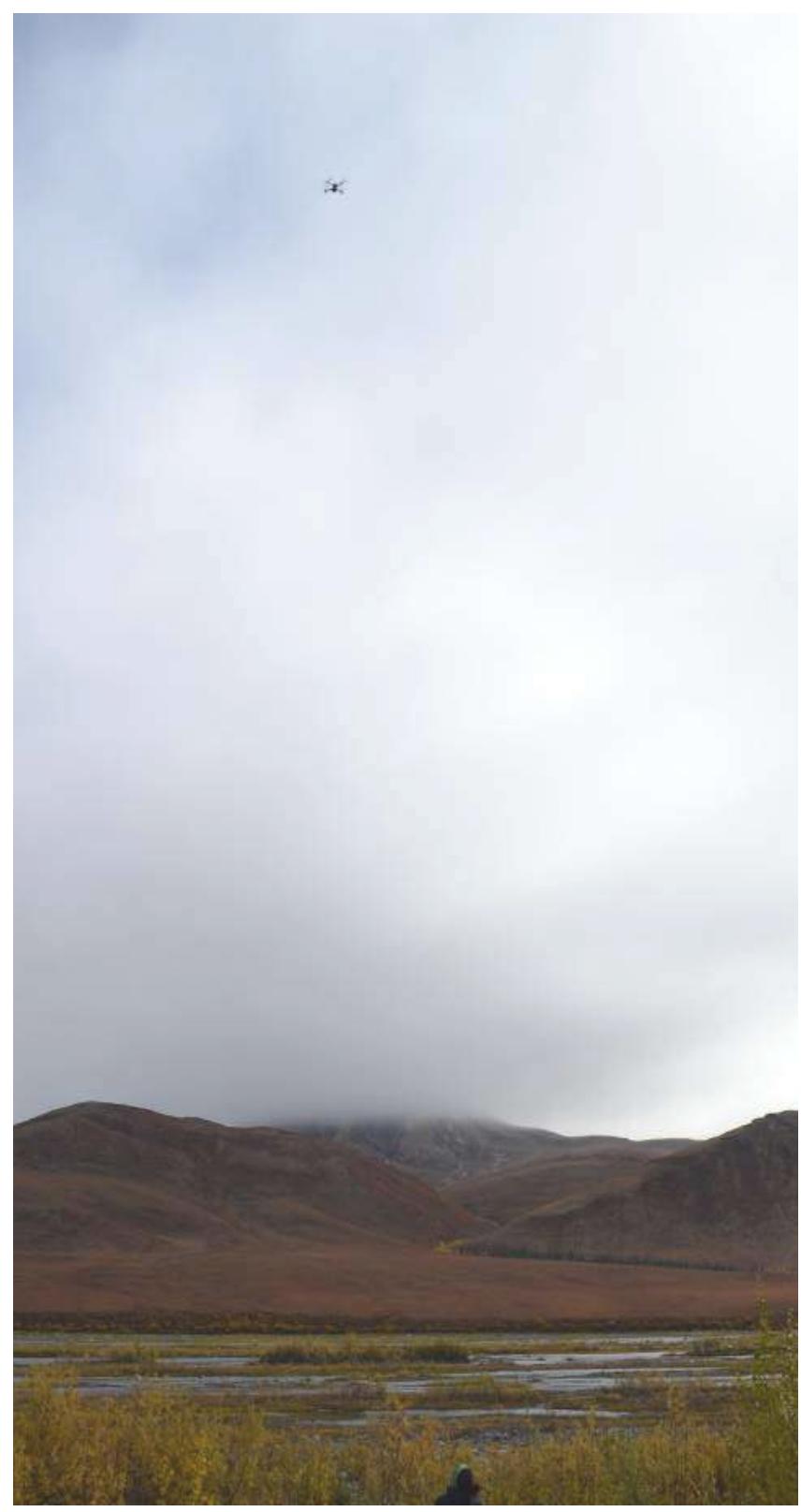

"These prosthetic devices show us that all eves, including our own organic ones, an active perceptual systems, building on translations and specific ways of seeing.. All these pictures of the world should not be allegories of infinite mobility and interchangeability but of elaborate specifficity and difference and the loving care people migbt take to learn how to see faitffully from another's point of vien, wen when the other is our own macbine." -Donna Haraway, Situated Knowledges

Sat-el-lite:

1. Someone or something attendant, subordinate, or dependent

2. An extension of a governing body

3. A manufactured body placed in orbi

4. A natural body existing in orbit

In March of 2019, the Government of Canada committed \$2.7M to the aerial surve of the northeastern Northwest Territories for the purpose of mapping the are one of the new access corridors intended to expand infrastructural networks in the North. This corridor (see fig 1.12 in Site Information) will provide access to existing diamond mines and new mineral exploration. The project will "serve as an importan transportation, hydro, and communications road that ultimately connects the region to a deep-water port in Nunavut."' This illustrates a contemporary land literacy that continues a view from nowhere/everywhere, originally held by maps, and the act of displacing bodies by casting an 'objective' vision, seemingly apart from ourselves. W take for granted that we position this view at a perpendicular angle above the earth's surface, constantly abstracting our own occupational experience to that distant view, then back to ourselves again; abstracting images between a detached position and ou own bodies in physical space.

While maps as constructed representatives had already displaced the physicality of spaces, the continued siteline from no-where/everywhere views earth from the free visions of orbiting sentinels and suspended aircraft. These satellites 
that extend our bodies take our vision "above and beyond" and here the spatiality of this catch phrase is perhaps telling of how entrenched we are in the value of the displacement of our own bodies from the land that holds us.... so perhaps, it makes sense that we would be willing to displace other bodies, other physicalities in the settlement of a nation or within the land engagements of the context of global extraction economies.

In the records of its own organizational history and the rise of satellite technology the United States Geologic Survey (one of the most prolific earth maging organizations) states:

$$
\begin{aligned}
& \text { The authoritative information gathered by multiple Earth observation satellites, } \\
& \text { such as Landsat, now serves as a common, reliable record... Indeed, in the } \\
& \text { last half century, the record of Earth observation from space has become the } \\
& \text { indispensable foundation of almost all deliberations about the state of the Earth. } \\
& \text { Secretary Udall's vision Ito "bsserve the Earth for the benefit of all" }]^{3} \text { has } \\
& \text { fundamentally remade how we see and understand our planet.4 }
\end{aligned}
$$

In the digital age in which we have begun retooling our representation (through hyper mathematical accuracy producing high resolution 2D and 3D information), perhaps what we need to be retooling is our relationship to these technologies. Impressive in their scale of reach and mathematical accuracy, the veneration of these advancements leaves the development of social technologies in the margins (perhaps because the latter occurs at longer time scales, immediacy, as it turns out is a long standing human vice). The consequences of this acute utilitarian focus might be the neglect of non empirical consequence in its network of effect.

In her article TITLE Donna Harraway asserts that the reason the view from nowhere is a conquering one is due to two reasons. First, it is assumed to be objective, but it's not given that the machines and their use are the result of a series of decisions, biasing the information it produces via its mechanical capabilities. And secondly because it's body is forgotten-it's physical position and actuality are forgotten, rendering it unaccountable for its actions. A non-body cannot be called upon to answer for its doings. In this position, the view engages the "forgetting and disappearing acts-ways of being nowhere while claiming to see comprehensively"s
Haraway critiques the conventional practices of "disembodied scientific objectivity" which is not the reality of practice but a professed ideology in which the physicality and the inherent biases associated with physical entities are presumed to be non existent and therefore, unbiased. Haraway argues that this type of erasure is impossible and problematic in that it leaves the source untouchable and unaccountable, therefore, being non-partial is impossible and thus, objectivity is false. A satellite image of the earth surface, for example, is from a physical position and the image is obtained through physical mechanics and components that do or don't do specific acts. This makes the satellite the result of intentionally or unintentionally curated decisions and therefore non-objective; it is situated in its position and history.

Images from this perspective produced by these mechanical bodies do offer unanticipatable information (such as material changes and atmosphere) and in some ways, paradoxically provide an interesting partial-counter to maps, which are drawn from a similar perspective (as is the case with maps drawn from aerial photographs, the triangulation of GPS stations bouncing information to satellites or the imagined position from which earlier maps were based). The satellite image shows the unmeasured seasonal fluctuations of snow, vapour and ice that are absen in conventional maps; they show the atmosphere and allow for imagined possibilitie of how the fluxing air volumes and shifting water particles might affect a spatial experience.

How might we act responsively in recognizing the physical positions of this view destabilizing what Donna Haraway calls the "God trick," in the grips of its impressive reach and agency? One response might be to denounce them (perhaps toward a romantic nostalgia, perhaps toward an alternate), one response might be to re-know them-to test a rearticulation of our relationship in which we are the mutua satellites of one another and in so doing acknowledge their capacity for assuming jurisdiction and authority over spaces. Haraway proposes that we try to reckon with, rather than disavow, the tricky nature of our always already cyborg sensoria of which these machines are part. Good cyborgs learn how to hack into and jam hegemonic systems. ${ }^{8}$ The following exercises might not be a 'hack' but they are an attempt re-seeing the physical position of the view from nowhere. The following exercise include drawings of atmosphere as a way of situating the cyborg view, a satellite of ourselves, extending our perceptual parameters. 

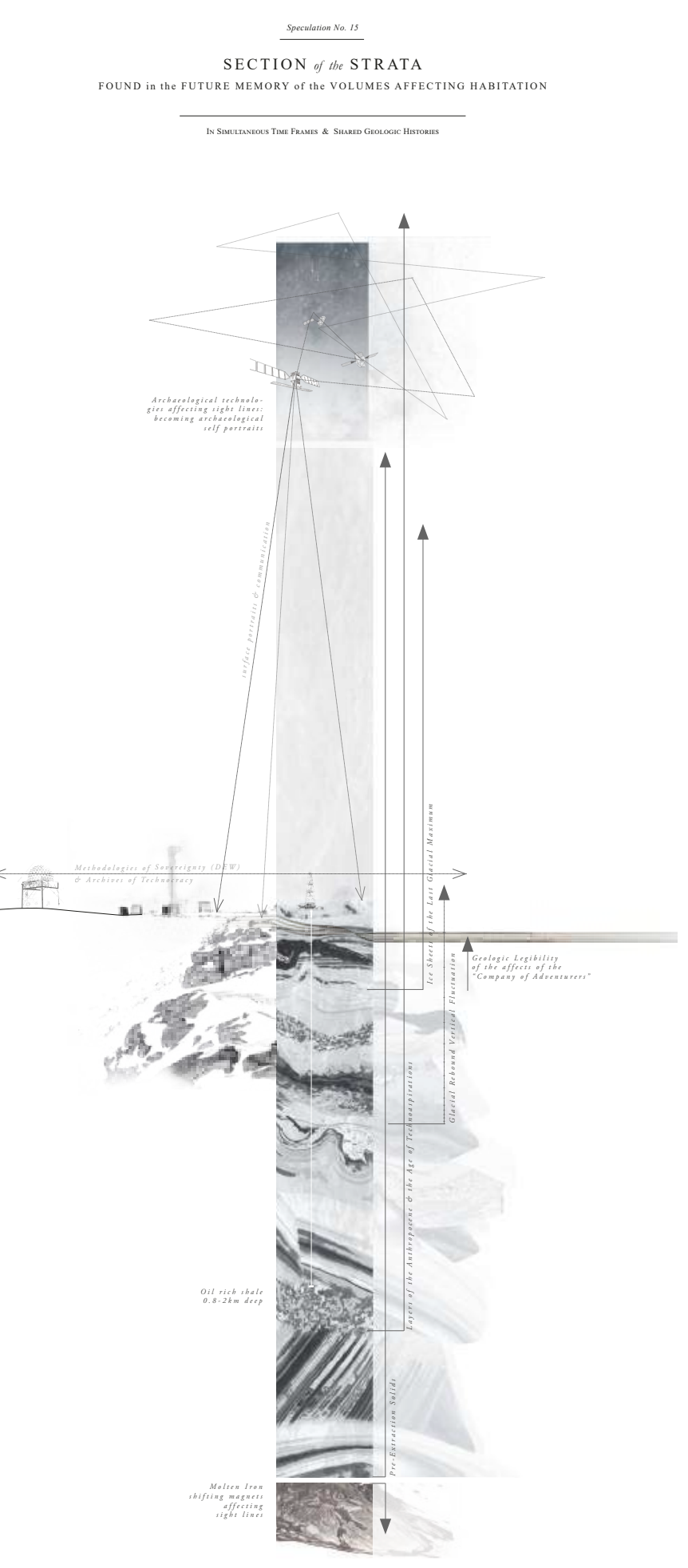

It is a future in which bumans began to realize a timelessness to volumes. In the "Antbropoocenen" we had become geologic and so our geologic conssiousness arose. Our scale, which initially impressed us, became the terror and awe of our ruilty conssiences. Our stories surpassed the conceivable eenerations into a future. For so long we were obsessed with the histories we wanted, that we began to forget the histories that might be remembered. The earth recorded us, but not by individual name or status-as we had done for ourseleves. It recorded our acts and showed them back to us in carbon levels wittin the soils of a continent and particles caught in ice that read the atmosphere; and then it caught us too, in devastating winds that skipped off imbalanced oceans.

We had found patterns, we were proud, they were pervasint

Measurements, statistics, perrentiles, algorithms and equations made us confident. It made some of us:

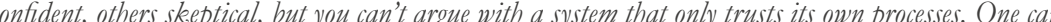
simply make evidence for others out of a different belief system, out of different lannugeges, different literacies, different intimacies.

With a mission to observe the Earth for the benefit of all, a sight line manifestffrom our long existing disembodied eve. We sent our trechnoastirations to be our vision, we called thems satellites, we called them sentinels. It showed us different information than was drawn, it showed us scales we couldn't see with our own bodies. And so we forgot our bodies

And in this challenging time we found ourselves confronted with physicalities we hadn't allowed ourselves to know. having lived without our bodies in the knowledges we claimed, sending satellites of our senser to see for us, to bear and feel for us. we curated our information intake and pursued our spaces from a distance and distrusted intimacy, we distrusted disorder, and we venerated discernible, repeatable patterns, forgetting that we only saw what we were willing to see. And we only felt what we were willing to feel. We only existed where we were willing to be. 

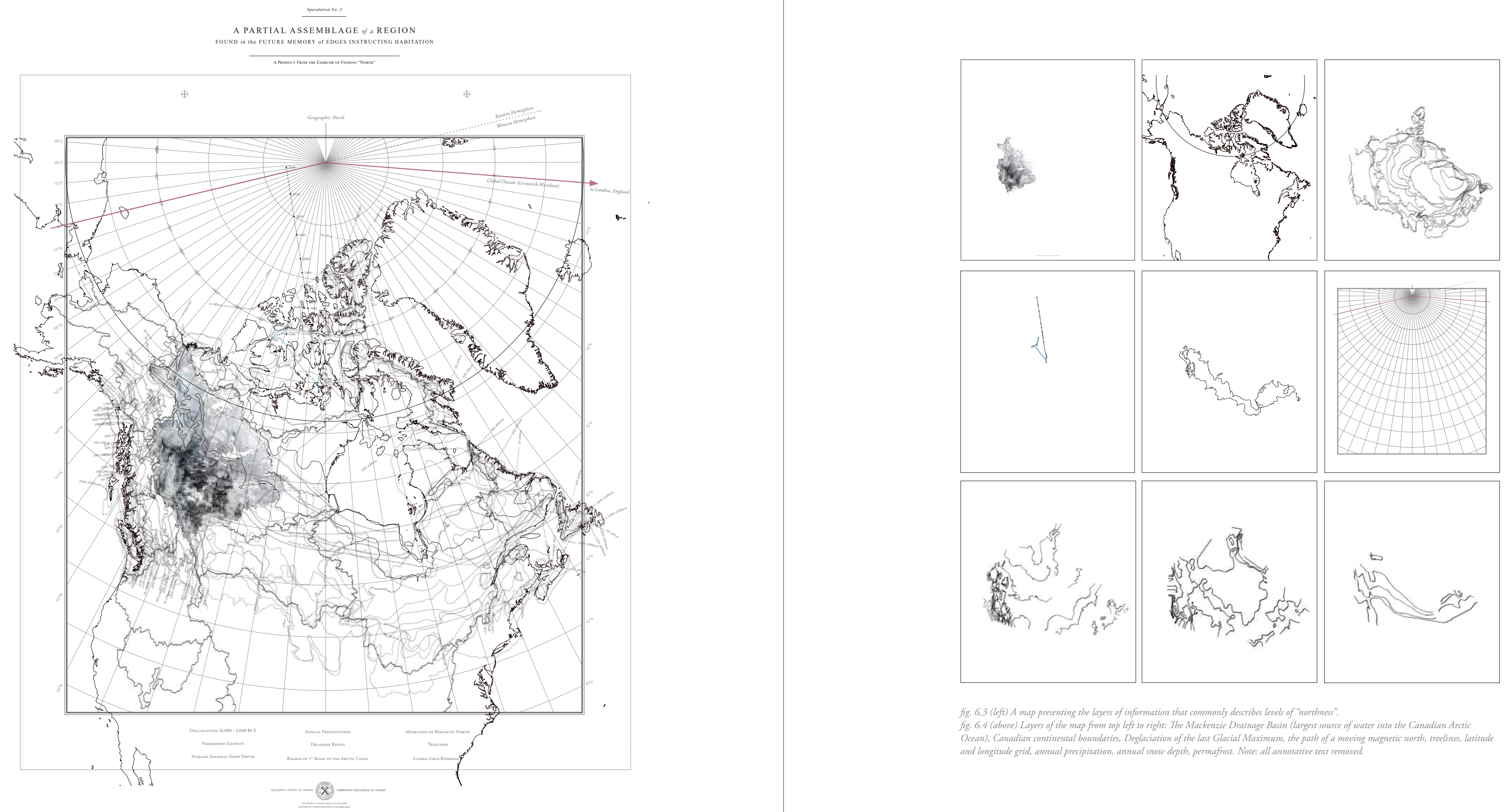

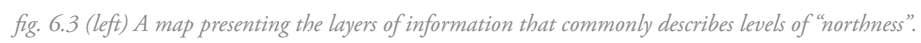

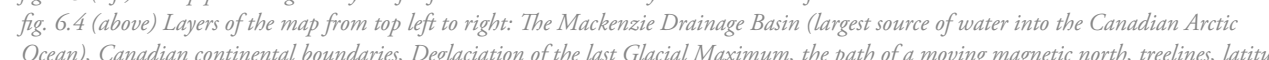

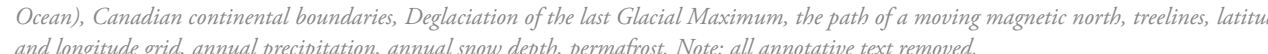



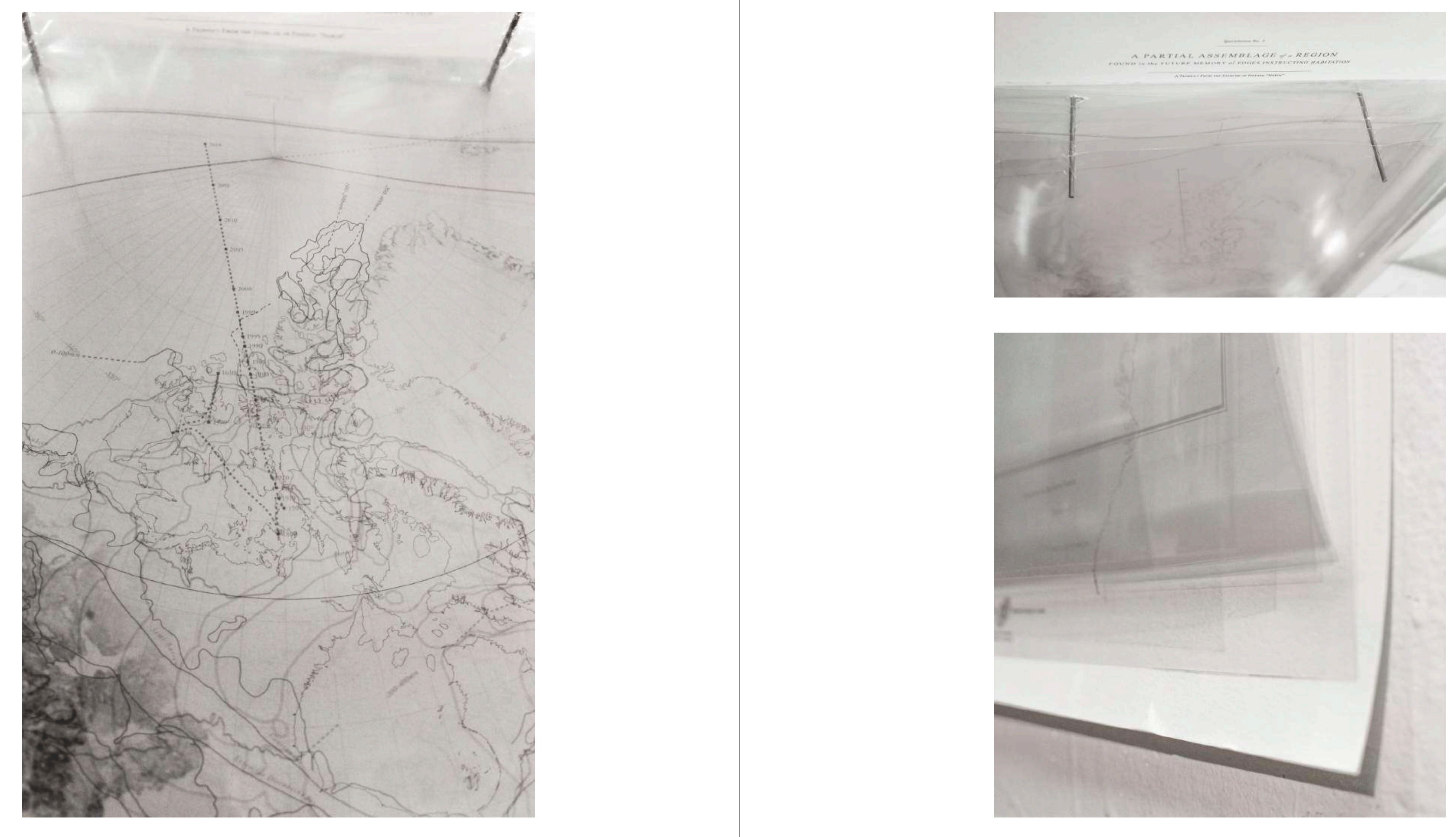

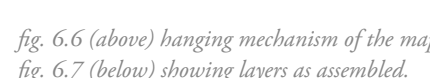



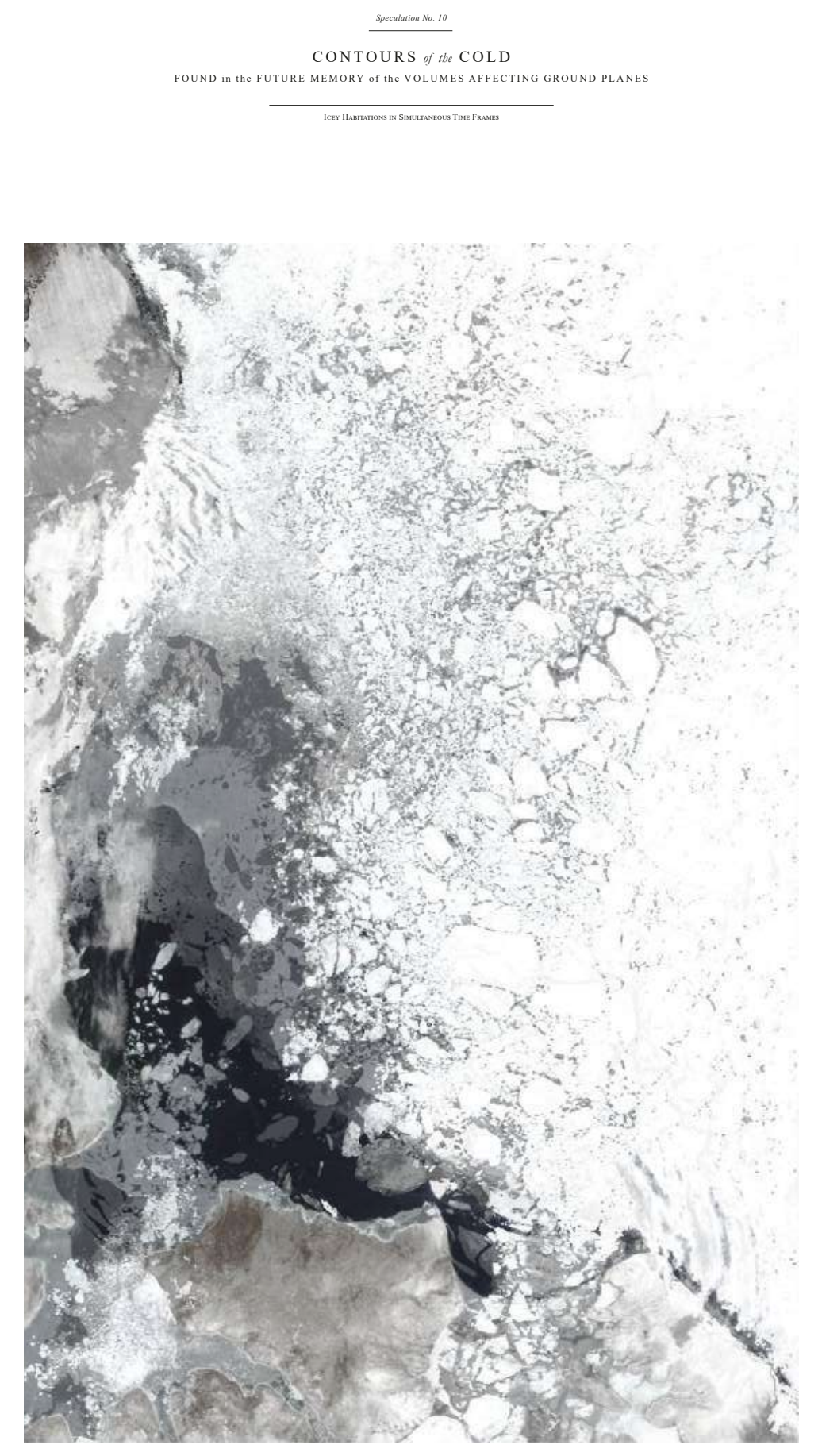

\section{SPECULATIVE FUTURES}

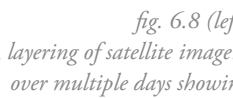

The documents of a hindsight that recalls curious logics and formative acts of the pastto-be that is the present. It counters the common post apocalyptic narrative with a pre-apocalyptic narrative in which a culture reflects and acts. In this exercise, noticed the stratified sensorium: our corporeal displacement where our sensing capacity extended in both vertical directions, so the disembodied site and self. Thes drawings intend to archive notions and tendancies that I speculate will become known as peculiar or astonishing oversights of previous (current) practices. 

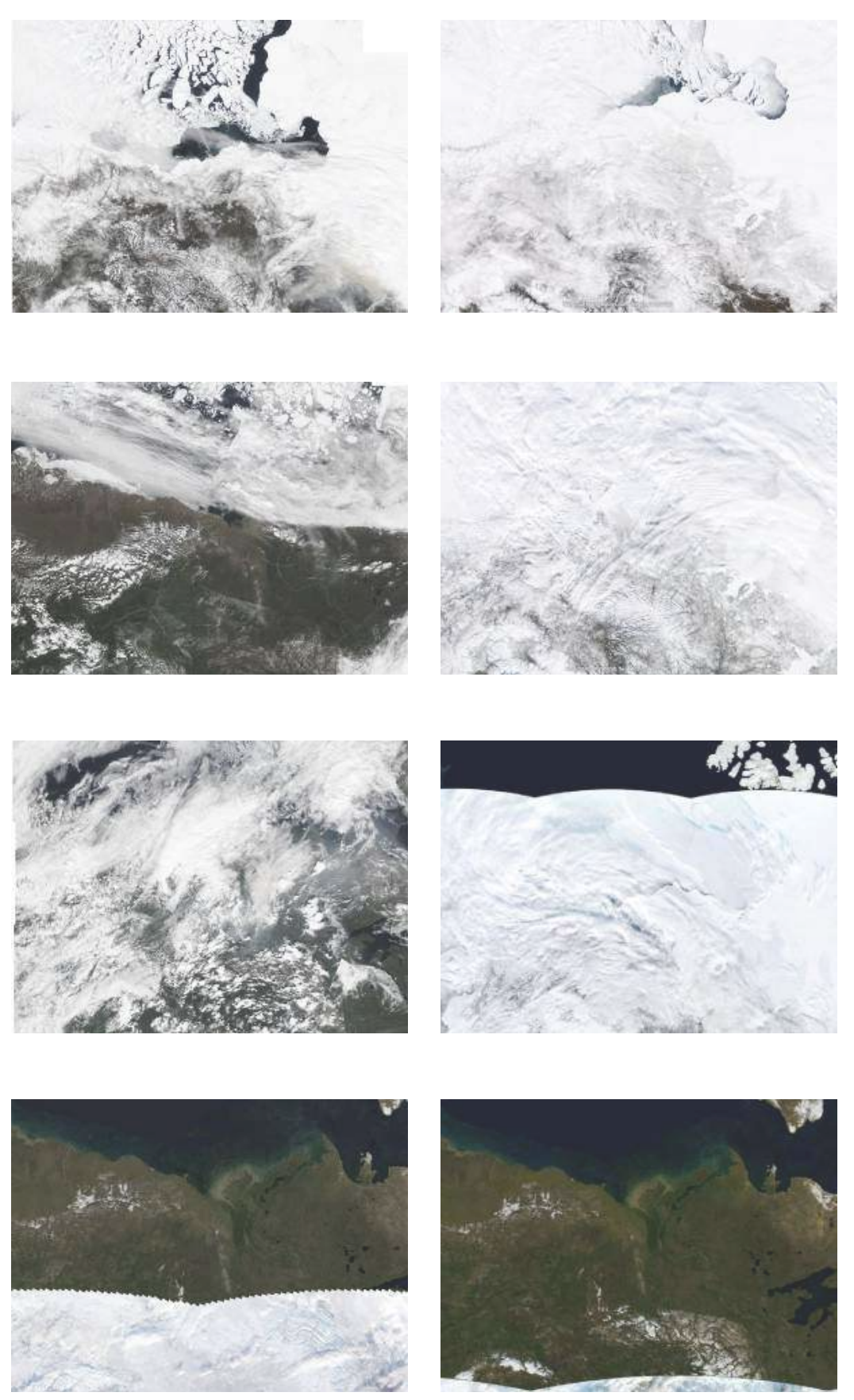

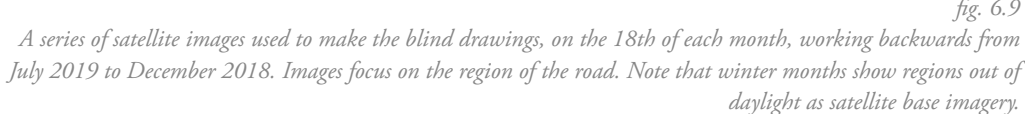

BLIND DRAWINGS

Drawings give insight into our thought processes, giving insight into what we privilege and value, in both the object and the act. A drawing can reflect a physica position but it can also reflect a political and philosophical position. These drawings were done in a way that focuses on un-naming and has no intention for the end object to be anything other than a document of acts. There is no planning of marks or legibility and marks follow in response to satellite imagery (day per month, show atmosphere, flux, the matter between the ground and the view from nowhere). Following drawings were re-layered with collaged portions of the satellite image that put drawn portions in place to where the marks are (showing the vibrational quality of multiple moments of seeing). In this way, the process of drawing becomes meditation that bears witness to the candid self.

The drawings were challenging and initially frustrating given the visual uncertaint of their reference. The images used, being specific to a day, had not been edited to eliminate the clouds and vapour, as is common with satellite imagery. Though the lack of clarity was confronting it did become an exercise of recalling the volumes of atmosphere that layer onto the solid surface of the earth. In this way I like to think that these drawing became an exercise in acknowledging the physical situation of the view that collected the image, remembering to situate satellite views and the bodies that hold them. 

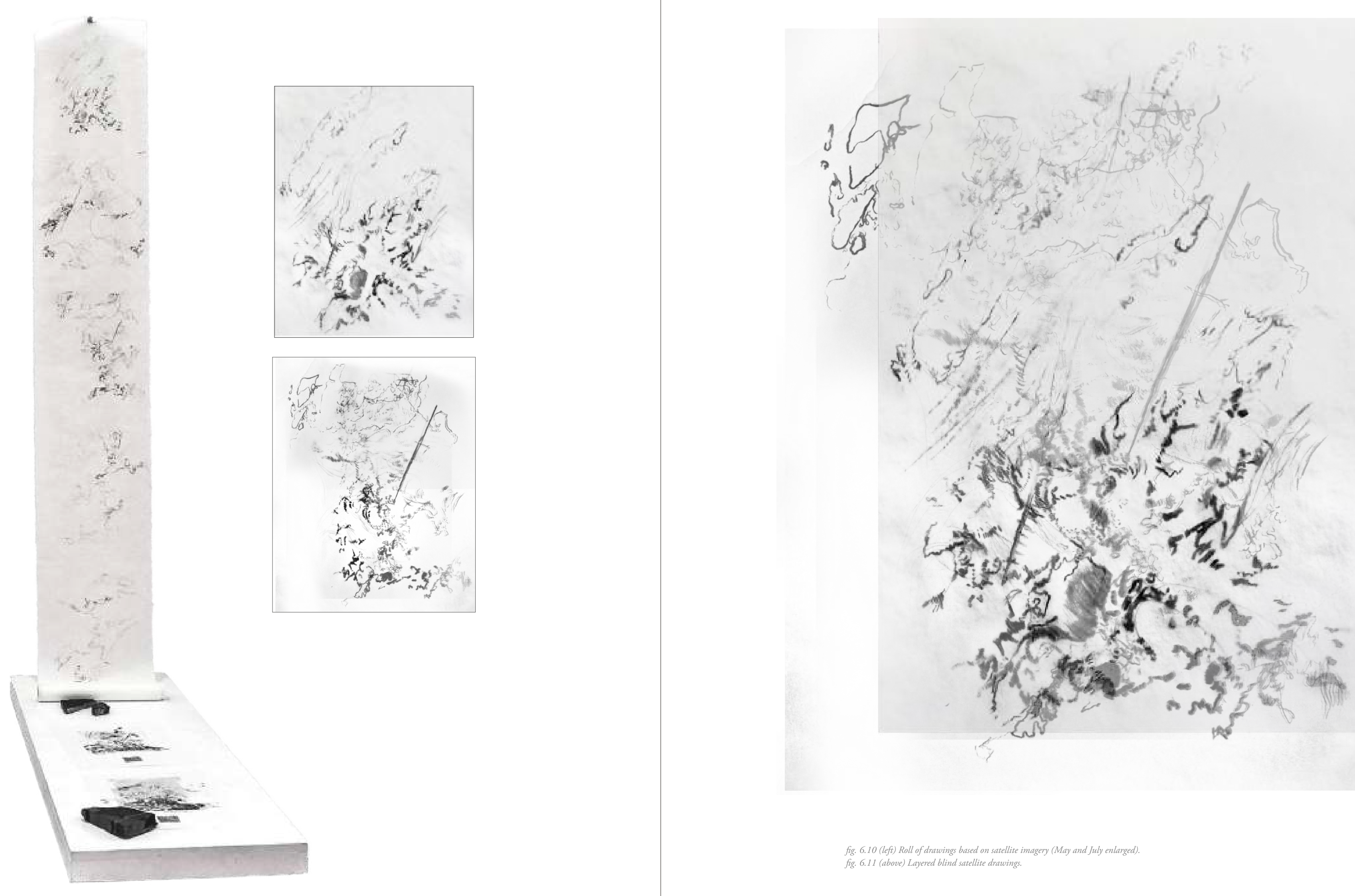

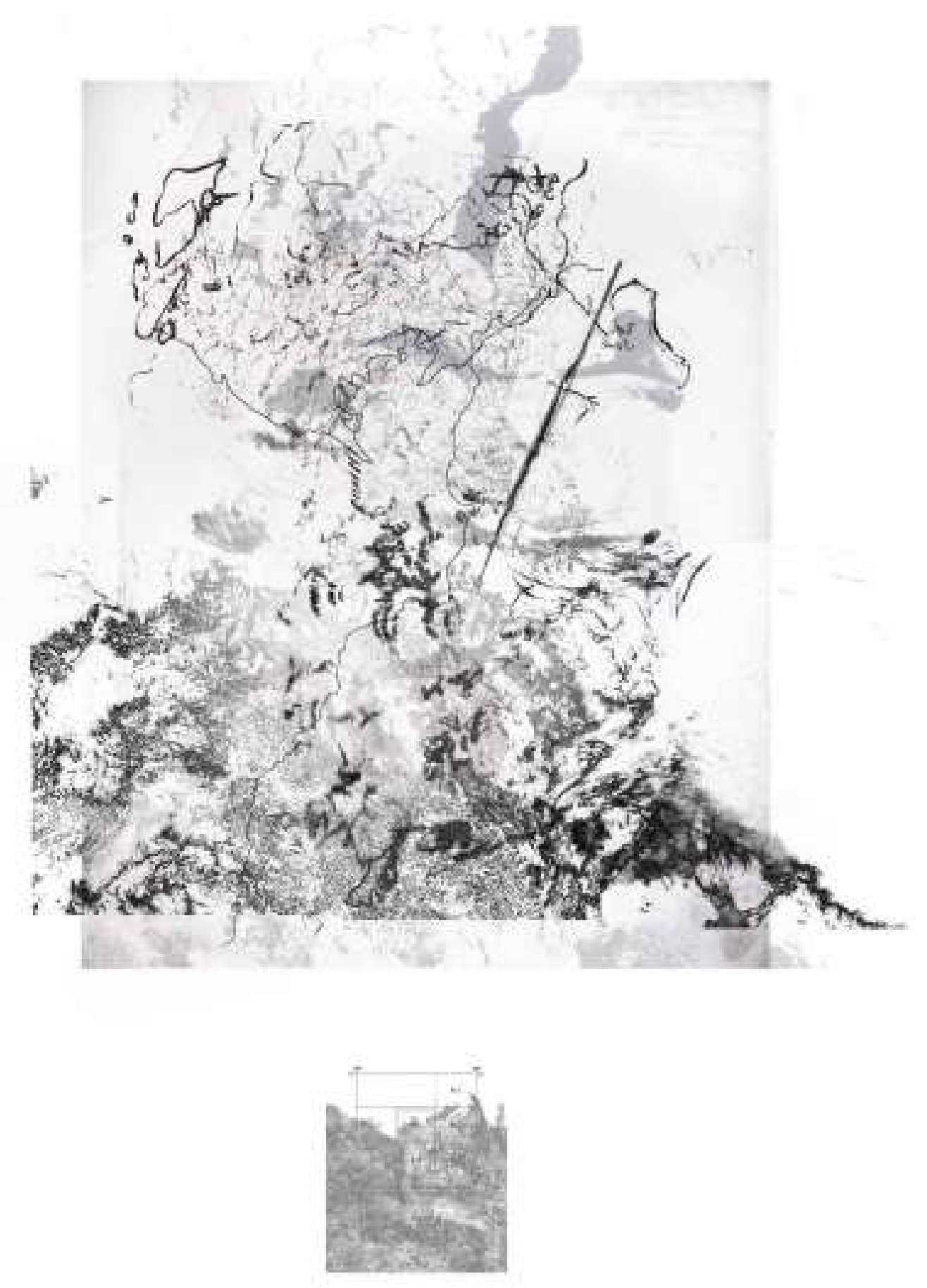
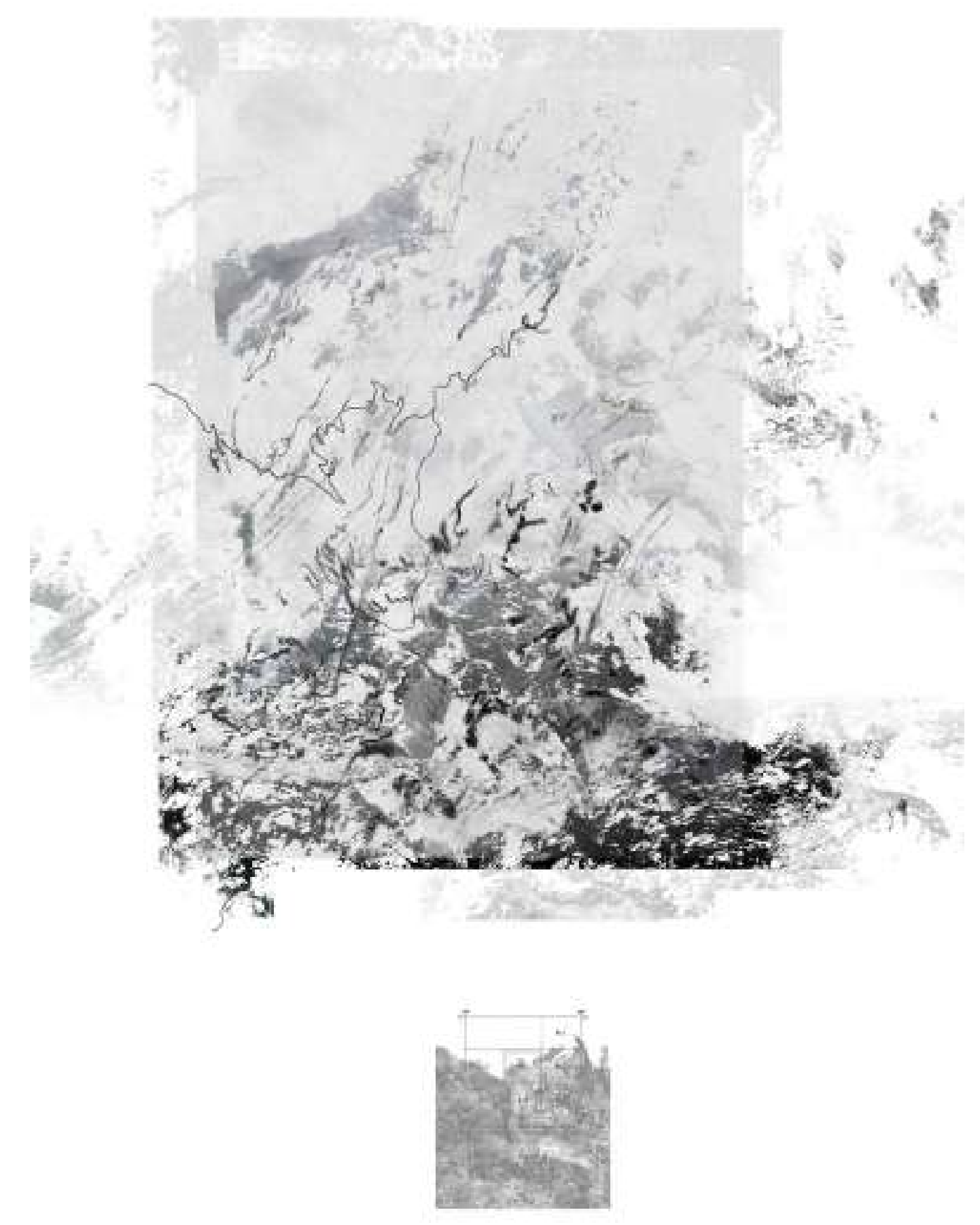
ENDNOTES

PART 5: EXTENDING STRATAS \& SENSORY SATELLITES

pg $129-148$

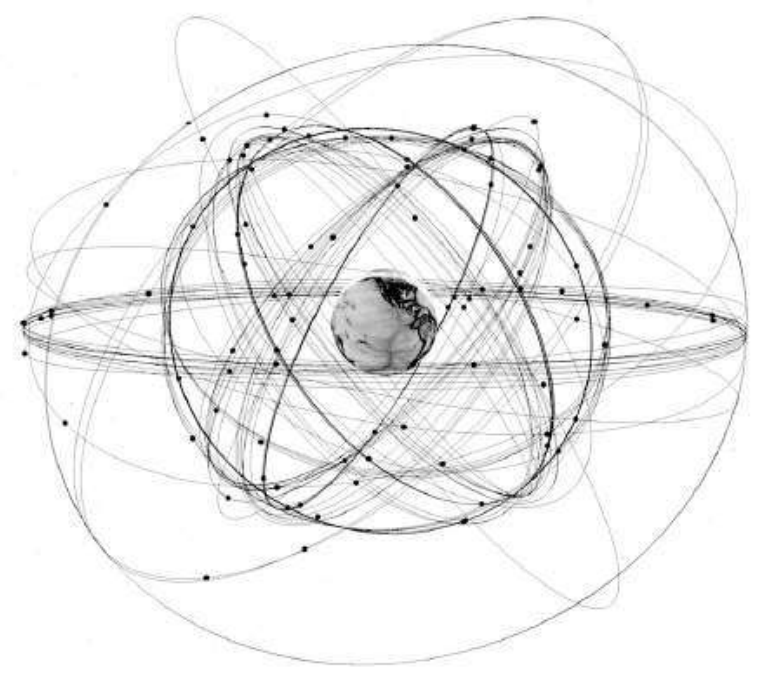

1. Kevin Dow "\$27 Million Invested by Feds on NIVT Mine Access Road toward Nunavut" My eds-on-nwt-mine-access-road-toward-nunavut/. which allows

3.United States Geological Survey (USGS). "Landsat Satellite Missions." US Department of the Interior

4. United States Geological Survey (USGS). "A Mission to Observe Earth." US Department of the Interior. Accessed April 4, 2019. https://www.usgg.gov

5. Donna Haraway. "Situated Knowledges: The Science Question in Feminism and the Privilege of Partias

6. Ibid, 575 .

7. Ibid, 581

8. Natasha Myers. "Ungrid-Able Ecologies: Decolonizing the Ecological Sensorium in a 10,000 Year-Old NaturalCultural Happening." prot.

9. (in fig. 6.2 caption) Heather Davis and Zoe Todd. "On the Importance of a Date, or, Decolonizizing the Anthropocene." ACME: An International Journal of Chical Geographics, wh.16, no.4, 20 Dec 

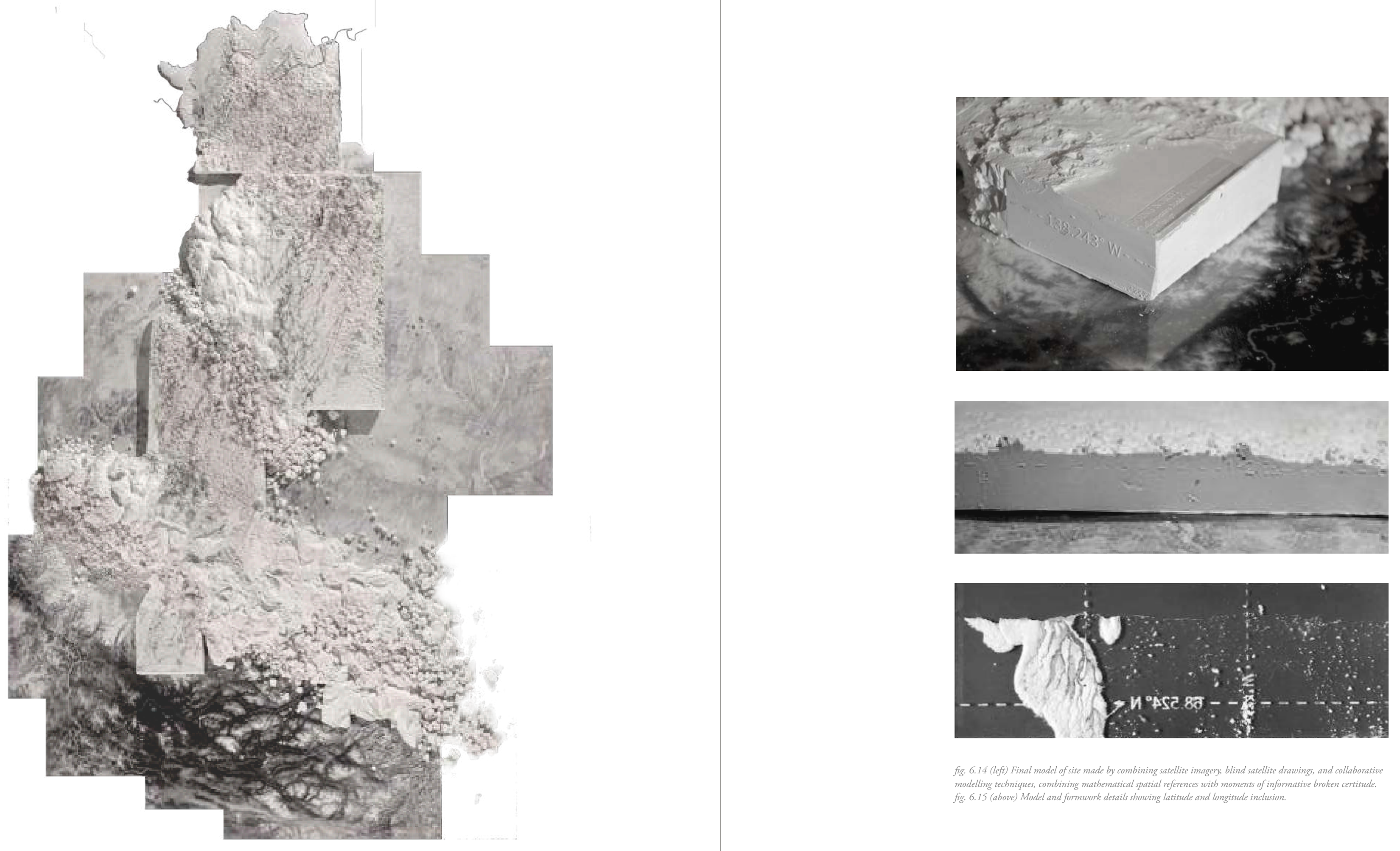

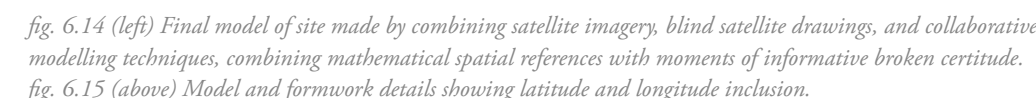



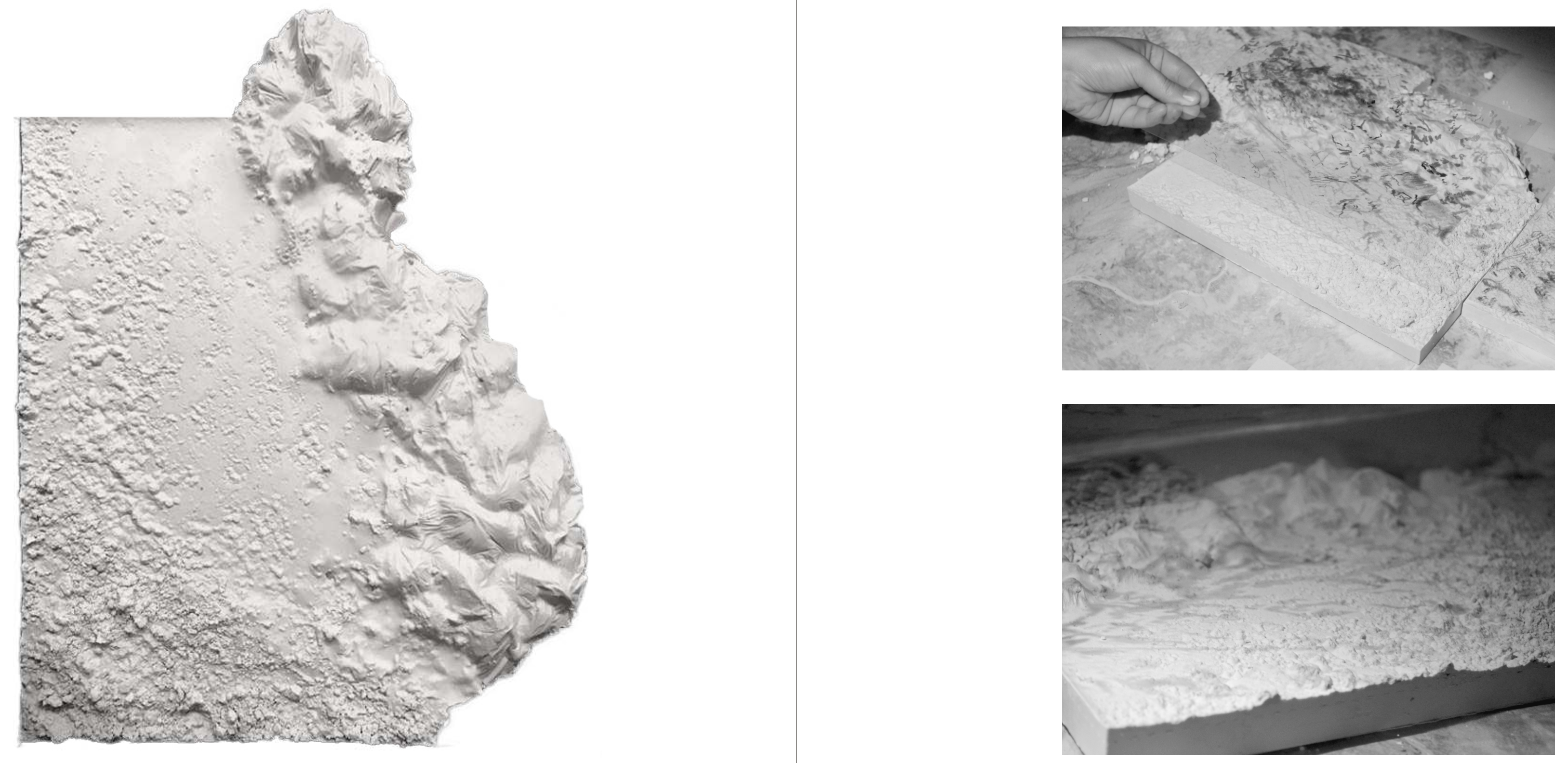

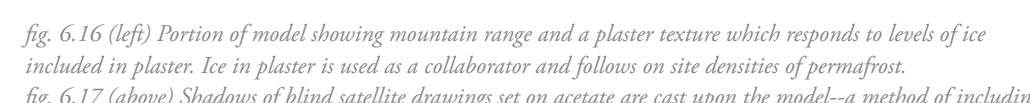
impressions of to nulume of the atmosishere 



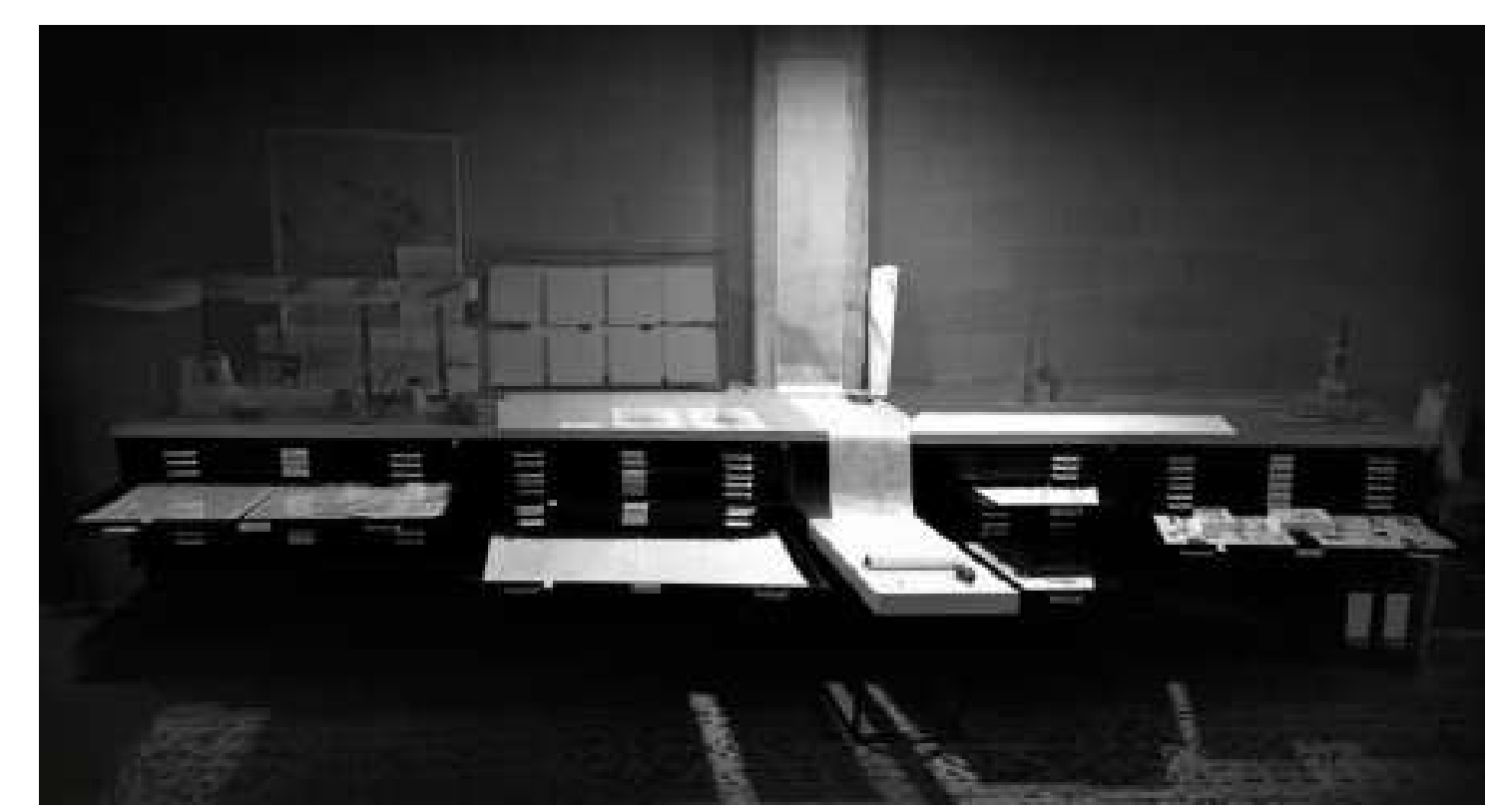

This thesis isn't finished yet.

Architecture is both a cultural participant and respondent; but the field is manifold and fluid and as such, the bounds of practice cannot remain static or singula

It would be reprehensible to promote the work and intentions of this thesi as anything close to a solution to settler issues; but it is, perhaps, a facet of the complex and morphing solution that (I hope) we are on track toward. No partial efforts should provide moral licensure on this pursuit, nor should 'good intentions' exonerate effects of actions or the physical situated-ness of their accountability. This thesis did not touch on topics of the very immediate human rights issues faced by some Indigenous and Northern communities such as youth suicide rates, access to health care or food and water security; especially urgent in light of the increased volatility of sustenance sources in the midst of climate change. These issues certainly demand a more immediate resolve than what the exercises undertaken within this thesis are conducive to. The studio research of this thesis plays a longer game and speaks toward the development of a criticality toward the measurable utility of the small particles of our practices that make up the whole of our work, and more importantly the cultural priorities on which they are built I say 'our' because I have inherited these skills from people before me and we are collectively responsible for them

Ialso chose to use the platform of this thesis (however wide reaching it may or may not be). to focus on the notion of the existence of valid alternates beforc they are clear and present, and even before their justification is clearly articulated. This approach is an exercise that hopes to destabilize the authority and agency of asymmetrically privileged conventions and epistemologies regardless of the over presentation of an 'alternate.' The pursuit of acknowledging our 'truths' as socially ccepted storying practices, I hope, allows an openness to alternates as they arise, and before they arise.

There are many values developed during this thesis that I intend to carry forward. One in particular is art as a method of research; which calls back from 


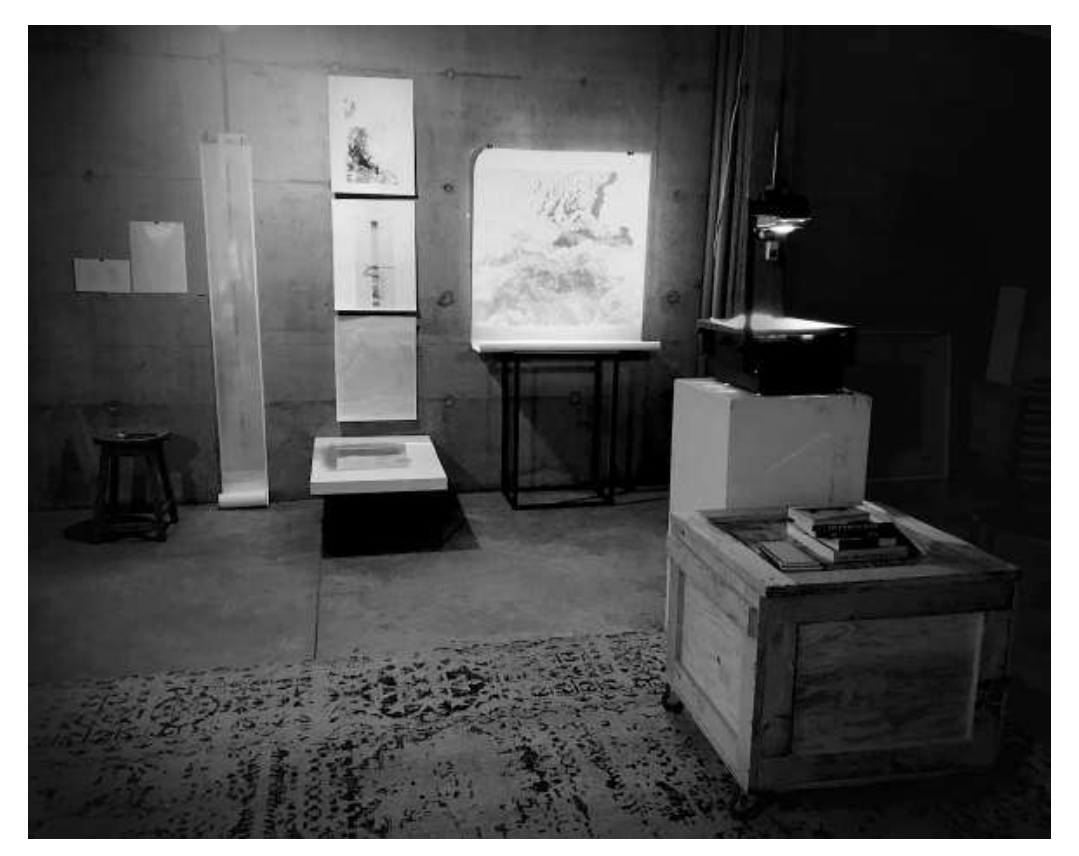

These words were confidently stated by the first practicing architect I worked for during my time in Whitehorse (Mary Ellen Read at Northern Front Studio). I never asked her what she meant by it but in the final moments of the official time frame of this thesis I am going to offer my own understanding of how I anticipate it can serve a practice of architecture. Art is a way of thinking through things, drawing ideas out of our heads so that we can test them, see them, evaluate them, and witness them Honest studio research offers not just 'results' but rich and unanticipatable insights.

Another item to carry forward is to be wary of the ruses of our own 'sophistication,' seemingly evidenced by our accomplishments. I mean this specifically in reference to ways of knowing, or what counts as valid knowledge and how these appear in the simple rudiments of our ways of engaging, documenting and thinking through ideas about the spaces we encounter.

I intend to continue developing a criticality toward drawing practices, namel for their direct relevance to self reflection, at any scale of personal identity (ie. an individual, student, researcher, Canadian, settler). Many of the exercises within this thesis use the framework of drawing to see, rather than to show as well as unseeing the lines of definition that we tend to put around things. In times of necessar change, what might the exercises of un-naming and unseeing be able to offer we Ultimately I believe that we need to be willing to slow down and see ourselves, to allow ourselves the time to understand the effects of our actions; and to allow ourselves to be in uncertainty, to see moments of broken certitude as moments of opportunity for new knowledge.

also intend to carry forward the notion that explorations of site can be understood through collaborative terms-with the non-human. And recognize that simple acts $\mathrm{Cn}$ begin to medinte some of the causalities of our current ent of colonial tendencies and the anthropocene.

The biggest takeaway, however, is recognizing that a line doesn't necessarily manifest as "the dot that went for a wall", but often as an inclination, a thought pattern, habit of spatial engagement, an assumption, expectation, or a physical act. The lines we draw and imagine, order our spatial and social practices and write the stories of our understandings.

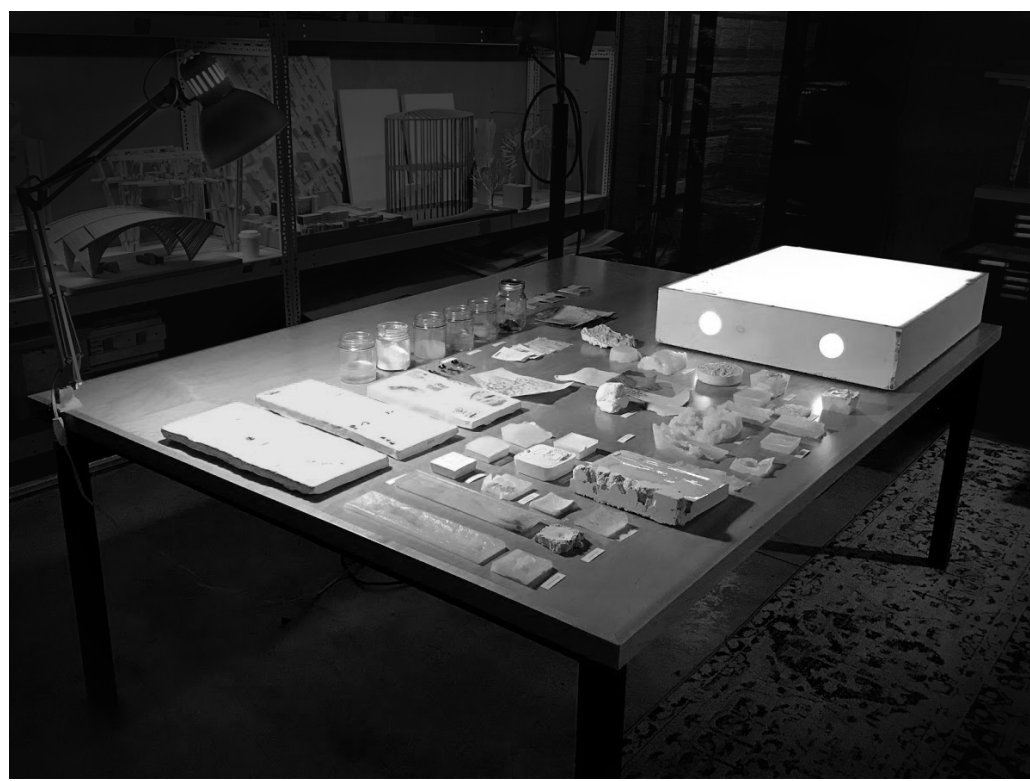


Allen, Dennis. “Crazywater.” National Film Board of Canada. 2013. Accessed September 16, 2018.https://www.nfb.ca/film/crazywater/.

Aporta, Claudio. “Inuit Orienting: Traveling Along Familiar Horizons.” Sensory Studies. Accessed March 2018. http://www.sensorystudies.org/inuit orienting-traveling-along-familiarhorizons/\#_ftn1.

Basso, Keith H. Wisdom Sits in Places, Albuquerque: University of New Mexico Press. 1996

Corner, James. "The Agency of Mapping: Speculation, Critique and Invention.” In Mappings, edited by Denis Cosgrove. 213-52. London: Reaktion, 1999.

Cowen, Deborah. "The Jurisdiction of Infrastructure: Circulation and Canadian Settler Colonialism” Funambulist, no. 17. Accessed August 2018. https:// thefunambulist.net/articles/jurisdiction-infrastructure-circulationcanadian-settler-colonialism-deborah-cowen.

Cunha, Dilip. Invention of Rivere. Alexander's Eye and Gangas Descent. Philadelphia PA. University of Pennsylvania Press, 2019.

Davis, Heather and Zoe Todd. "On the Importance of a Date, or Decolonizing the Anthropocene." ACME: An International Journal of Critical Geographies, vol.16, no.4, 20 Dec. 2017, pp 761-780

Douglas, Mary. “Powers and Dangers.” In Purity and Danger, 95-114. London: Routledge, 1966.

Hampton, Rosalind and Ashley DeMartini, "We Cannot Call Back Colonial Stories: Storytelling and Critical Land Literacy." Canadian Journal of Education. rol.40, no.3. 2017, pp245-271
Haraway, Donna. "Situated Knowledges: The Science Question in Feminism and the Privilege of Partial Perspective." Feminist Studies 14, no. 3 (1988): $575-99$.

Hermann, Victoria. "Layered Landscapes, Layered Identities, Historic Narratives, Arctic Aesthetics, and Indigenous Agency in Canada's Anthropocene" in The Networked Nortb: Borders and Borderlands in the Canadian Arctic Region, ed. Heather Nicol and P. Whitney Lackenbauer. Waterloo: Borders in Globalization/Centre on Foreign Policy and Federalism, 2017.

Hooker, W J. Flora Boreali-Americana; or the Botany of the Northern Parts of Britis America. Vol. 1. London: Henry G. Bohn, 1840

Lambert, Leopold. "Introduction: Cartography \& Power." Funambulist, no.18, 2018. Accessed December 2018. https://thefunambulist.net/ articles/introduction-cartography-power

Lilburn, Tim. Thinking and Singing: Poetry \& the Practice of Philosophy. Cormorant Books Inc, Toronto Ontario, 2002.

Lyons, Natasha. Where the Wind Blows Us: Practicing Critical Communit Archaeology in the Canadian North. Tucson, AZ: The University of Arizona Press, 2013

MacBride Museum “The Force in the North." Virtual Museum of Canada. 2006. Accessed January 30, 2019. http://www.virtualmuseum.ca/sgccms/expositions-exhibitions/gendarmes-mounties/en/adventures adventures/lostpatrol/.

Macfarlane, Robert. The Old Ways: a Journey on Foot. New York: Penguin Books. 2012. 
Macfarlane, Daniel. Neonatiating a River: Carada, the U.S., and the Creation of the

St. Lawrence Seawray. Vancouver: UBC Press. 2014.

Mathur, Anuradha with Dilip da Cunha. SOAK: Mumbai in an Estuary. Daryaganj, New Delhi: Rupa \& Co. 2009

-- with Dilip da Cunha, Rebekah Meeks and Mathew Wiener. Design in the Terraan of Water. Philadelphia PA: University of Pennsylvania Press, 2014.

Morton, Timothy. The Ecological Thought. Cambridge, Mass:: Harvard University Press, 2010.

Myers, Natasha. "Ungrid-Able Ecologies: Decolonizing the Ecological Sensorium in a 10,000 Year-Old NaturalCultural Happening." Catalyst 3, no. 2 (October 9, 2017): 2-24. https://doi.org/https://doi.org/10.28968/cft.v3i2.28848.

Morris, William R. “W.J.D. Dempster (1876-1964).” Arctic Institute of North America 39, no. 2 (1986): 190-91.Accessed January 30, 2019. https:/ /arctic ournalhosting.ucalgary.ca/arctic/index.php/arctic/article view/2073/2050

Nicandri, David I. Arttic Ambitions: Captain Cook and the Nortthwest Passage. Washington: University of Washington Press. 2015.

Phillips, Rashedah. "Placing Time, Timing Space: Dismantling the Master's Map and Clock.” Funambulist, No.18. Accessed December 2018. https:/

hefunambulist.net/articles/placing-time-timing-space-dismantling masters-map-clock-rasheedah-phillips.

Regan, Paulette. Unsettling the Settler Wittin: Indian Residential Schools Truth Telling, and Reconciliation in Canada. (Vancouver: University of British Columbia Press, 2010)

Said, Edward W. "Orientalism," in The Edward Said Reader, ed. Moustafa Bayoum and Andrew Rubin (New York: Vintage Books, 2000).
"Permission to Narrate" in The Edvard Said Reader, ed Moustafa Bayoun and Andrew Rubin (New York: Vintage Books, 2000).

Scranton, Roy. Learning to Die in the Anthroopocene: Reffections on the End of Civilivation. San Francisco, CA: City Lights, 2015.

Soderstrom, Mary. Road Through Time: the Story of Humanity on the Move. Regina, SK: University of Regina Press, 2017.

Vesely, Dalibor. "Architecture and the Conflict of Representation." AA Files, No.8, 985, 21-38.

WEB SOURCES

Coyle, Jim. "Inuvik to Tuktoyaktuk Road Finally Connects Canada from Sea to Sea to Sea" The Star November 18, 2017. Accessed January 31,2019. https://www.thestar.com/news/insight/2017/11/18/inuvik-totuktoyaktuk-road-finally-connects-canada-from-sea-to-sea-to-sea.html.

DigitalGlobe. “About DigitalGlobe.” Maxar, 2019. Accessed July 20, 2019. https://www.digitalglobe.com company/about-us.

Dow, Kevin. “\$2.7 Million Invested by Feds on NWT Mine Access Road toward Nunavut." My Yellowknife Now, March 4, 2019. https://wwwmyyellowknifenow.com/37175/2-7-million-invested-byfeds-on-nwt-mine-access-road-toward-nunavut/.

Foster, Peter “Does Stephen Harper’s \$300M Northern Highway to Tuktoyaktuk Make Economic Sense?” Financial Post. January 10, 2014. Accessed January 30, 2019.

https://business.financialpost.com/opinion/peter-foster-does stephen- harpers-300m-northern-highway-to-tuktoyaktuk-make economic-sense. 
Gates, Michael. "Building the Dempster Highway: An Engineering Challenge." March 4, 2015. Accessed January 30, 2019

https://www.yukon-news.com/life/building-the-dempster-highway-an engineering-challenge/.

Harper, Douglas. "Map (n.)." etymonline, 2019 https://www.etymonline.com/word/sense.

-. "Sense (n.)." etymonline, 2019.

https://www.etymonline.com/word/sense

Karpenchuk, Dan. “John Diefenbaker Dies at 83.” CBC Digital Archives. 2018. Accessed January 30, 2019

https:/ /www.cbc.ca/archives/entry/john-diefenbaker-dies-at-83.

Kujawinski, Peter. "The Road to the Top of the World." The New York Times. February 11, 2016. Accessed January 30, 2019. https://www.nytimes.com/2016/02/14/travel/canada-tuk-northwest territory.html?_r $=0$

Scott, Shannon. "Stephen Harper Hails Start of Inuvik's Road to Resources." CBC North. January 8, 2014. Accessed January 31, 2019.

https://www.cbc.ca/news/canada/north/stephen-harper-hails-start-of urik-s-rod to-resources-1.2488439.

“Tuktoyaktuk”. Northwest Territories Tourism. 2019. Accessed August, 2018. https://spectacularnwt.com/destinations/western-arctic/communities ktovaktuk.

United States Geological Survey (USGS) “Landsat Satellite Miscions” US Department of the Interior. Accessed April 4, 2019 https://www.usgs.gov/.

-- "A Mission to Observe Earth." US Department of the Interior Accessed April 4, 2019 https://www.usgs.gov/
IMAGE \& MAPPING SOURCES

fig 1.12

Roads and Highways." Open Government Portal. Accessed November 16, 2018 https://open.canada.ca/data/en/dataset?organization=pc\&res

format $=\mathrm{SH}$

fg. 1.13

"The R.N.W.M.P Expedition Leaving Dawson." Library and Archives Canad Image Search. Government of Canada. Accessed August 13, 2018. http://www.collectionscanada.gc.ca/lac-bac/search/images.

MacKenzie, James. "Inuvik to Tuktoyaktuk Highway Construction to Resume in January." CBC News, December 10, 2015 .

https://www.cbc.ca/news/canada/north/inuvik-tuktoyaktuk-highway 2016-season-1.3358210

fig. 1.15

Lynds, Corinne. "Final Winter Construction Season Begins on the Inuvik Tuktoyaktuk Highway.” On-Site: Canada's Construction Magazine, November 22, 2016. https://www.on-sitemag.com/construction/final-winter-construction season-begins-inuvik-tuktovaktuk-highway/1003955450/.

fig. 3.5

Hooker, W J. Flora Boreali-Americana; or the Botany of the Northern Parts of British Americe Vol 1. London: Henty G. Bohn, 1840.

fig. 4.6

"Dempster Highway Travelogue.” Environment Yukon, 2014.

"Dempster Highway, Inuvik to Tuktoyaktuk Highway." Google Earth. Accessed November 29, 2018

https://www.google.com/earth/. 
fig. 4.6 cont'd

"The Inuvialuit Settlement Region." Inuvialuit Final Agreement Annual Report of the Implementation Coordinating Committee, 2010.

https://www.rcaanc-cirnac.gc.ca/eng/1427987089269/1543249556315.

"Yukon Lands Viewer." Yukon Energy Mines and Resources. Accessed November 29, 2018.

https://mapservices.gov.yk.ca/Lands/Load.htm.

"Yukon Languages and Communities." Council of Yukon First Nations, 2007. https:/ /www.sgsyukon.ca/language-initiatives/yukon-first-nations languages/.

fig. 6.3-6.4

“Annual Precipitation.” Natural Resources Canada. Accessed March 21, 2019. https://open.canada.ca/data/en/dataset/50d4dad2-6c8a-5b29-9e27 8baa3ee19a48.

“Annual Snowfall.” Natural Resources Canada. Accessed March 21, 2019. https://open.canada.ca/data/en/dataset/50d4dad2-6c8a-5b29-9e27 8baa3ee19a48.

"Deglaciation of North America." GEOSCAN. Government of Canada, 2003. https://geoscan.nrcan.gc.ca/starweb/geoscan/servlet starweb?path=geoscan/fulle.web\&rsearch1 $=\mathrm{R}=214399$

"Forest Regions of Canada." Research Gate. Natural Resources Canada, 2007. https:/ /www.researchgate.net/figure/Forest-regions-of-Canada-Natural Resources-Canada-2007_fig2_267199012.

Newitt et al., "Location of the North Magnetic Pole in April 2007", Earth Planets Space, 61, 703-710, 2009. Accessed March 21, 2019.

ttps://en.wikipedia.org/wiki/North_Magnetic_Pole\#/media

File:Magnetic_North_Pole_Positions_2015.svg fig. 6.3-6.4 cont'd

"Permafrost." Environment and Natural Resources. Government of Northwest Territories, 2014. https://www.enr.gov.nt.ca/en/state-environment/13 permafrost.

fig. 6.9

"Site Region Images." Zoom Earth. NASA/NOAA/GSFC/EOSDIS, Suomi-NPP VIIRS. Accessed July 18, 2019.

https://zoom.earth.

fig. 6.13

Reid, Tyler. "Orbital Diversity for Global Navigation Satellite Systems." Stanford University Department of Aeronautics and Astronautics, 2017. 


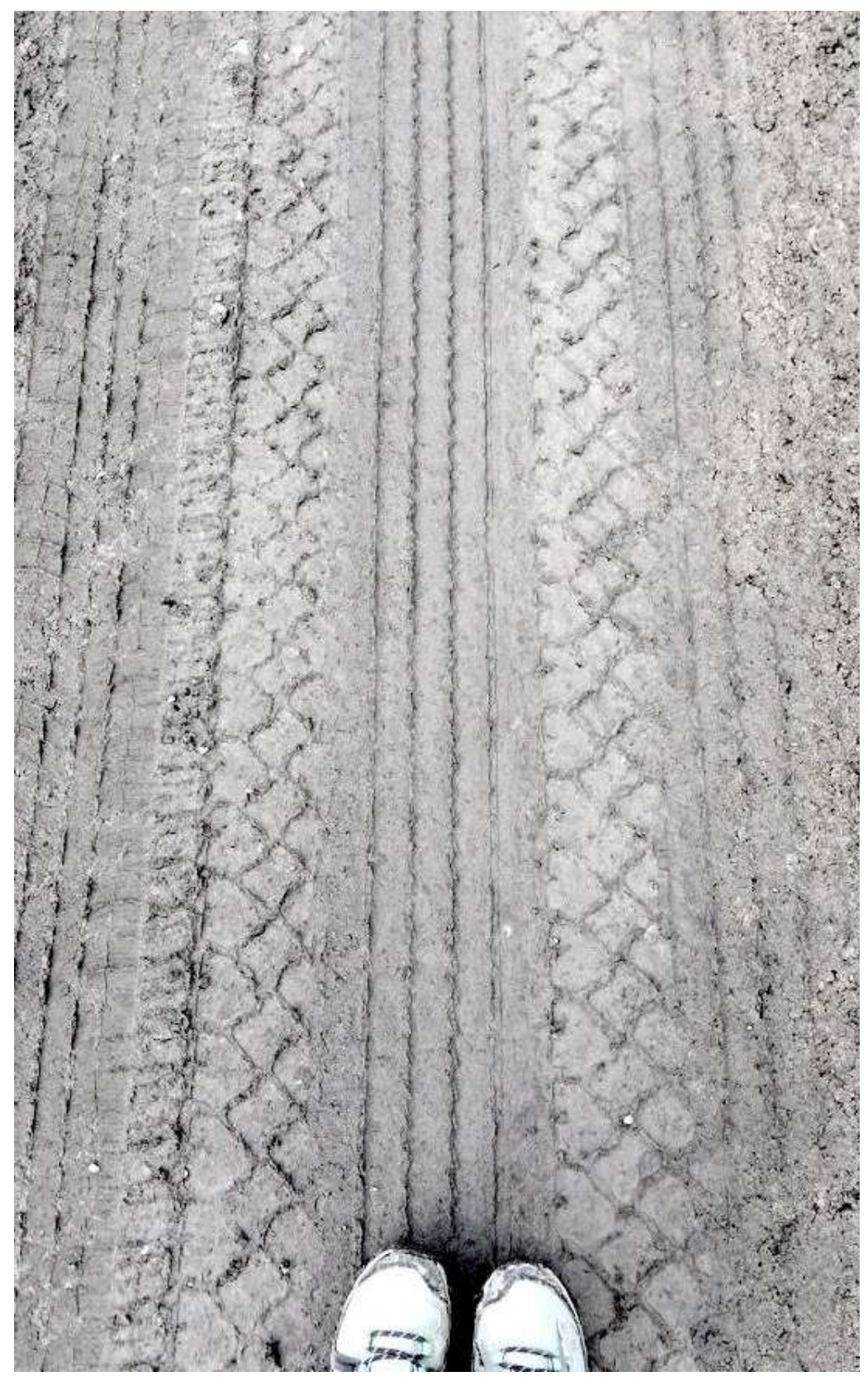

